\title{
Potential Application of Exosomes in Vaccine Development and Delivery
}

\author{
Md Nurul Huda1,2,3,4 • Md Nurunnabi 1,2,3,4 (iD
}

Received: 29 September 2021 / Accepted: 15 November 2021 / Published online: 13 January 2022

(C) The Author(s), under exclusive licence to Springer Science+Business Media, LLC, part of Springer Nature 2021

\begin{abstract}
Exosomes are cell-derived components composed of proteins, lipid, genetic information, cytokines, and growth factors. They play a vital role in immune modulation, cell-cell communication, and response to inflammation. Immune modulation has downstream effects on the regeneration of damaged tissue, promoting survival and repair of damaged resident cells, and promoting the tumor microenvironment via growth factors, antigens, and signaling molecules. On top of carrying biological messengers like mRNAs, miRNAs, fragmented DNA, disease antigens, and proteins, exosomes modulate internal cell environments that promote downstream cell signaling pathways to facilitate different disease progression and induce anti-tumoral effects. In this review, we have summarized how vaccines modulate our immune response in the context of cancer and infectious diseases and the potential of exosomes as vaccine delivery vehicles. Both pre-clinical and clinical studies show that exosomes play a decisive role in processes like angiogenesis, prognosis, tumor growth metastasis, stromal cell activation,
\end{abstract}

Responsible Editor: Vivek Gupta

Md Nurunnabi

mnurunnabi@utep.edu

1 Department of Pharmaceutical Sciences, University of Texas at El Paso School of Pharmacy, 1101

N. Campbell St, El Paso, TX 79902, USA

2 Enviromental Science and Engineering, University of Texas at El Paso, El Paso, TX 79968, USA

3 Biomedical Engineering, University of Texas at El Paso, El Paso, TX 79968, USA

4 Border Biomedical Research Center, University of Texas at El Paso, El Paso, TX 79968, USA

intercellular communication, maintaining cellular and systematic homeostasis, and antigen-specific T- and B cell responses. This critical review summarizes the advancement of exosome based vaccine development and delivery, and this comprehensive review can be used as a valuable reference for the broader delivery science community.

KEY WORDS cancer immunotherapy - exosomes · vaccine development $\cdot$ infectious disease $\cdot$ immune system

\section{ABBREVIATIONS}

APP

AKT

ARDS

APCs

BACE

BCG

CAF

CARs-

CE

CD

circRNA

COPD

CTL

DCs

DAMPs

EMT

EPI

EGFR

ESCRT

ESAT-6

FGF
Amyloid precursor protein

Protein kinase B

Acute respiratory distress syndrome

Antigen-presenting cells

$\beta$-site APP cleaving enzyme

Bacillus Calmette-Guérin

Cancer-associated fibroblast

Chimeric antigen receptors

Cholesterol

Cluster of Differentiation

Circulating RNA

Chronic obstructive pulmonary disease

Cytotoxic T Lymphocyte

Dendritic cells

Damage-associated Molecular Patterns

Epithelial-mesenchymal transition

Expanded Program on Immunization

Epidermal growth factor receptor

Endosomal sorting complexes required

for transport

Early secretory an tigenic target- 6

Fibroblast growth factor 


\begin{tabular}{|c|c|}
\hline GP & Glycoprotein \\
\hline HCG & Hepatocellular carcinoma \\
\hline $\mathrm{HCV}$ & Hepatitis $\mathrm{C}$ virus \\
\hline hACER2 & Human Angiotensin-Converting \\
\hline & Enzyme Receptor II \\
\hline HSP & Heat shock proteins \\
\hline ICTV & $\begin{array}{l}\text { International Committee on Taxonomy } \\
\text { of Viruses }\end{array}$ \\
\hline $\operatorname{IgD}$ & Immunoglobulin D \\
\hline IL-7 & Interleukin-7 \\
\hline ILV & Intraluminal vesicles \\
\hline INF- $\square$ & Induce natural interferon- $\square$ \\
\hline LCMV & Lymphocytic choriomeningitis \\
\hline LMP1 & Latent membrane protein 1 \\
\hline IPF & Idiopathic pulmonary fibrosis \\
\hline MCH I & Major histocompatibility complex class I \\
\hline MDSC & Myeloid-derived suppressor cell \\
\hline MERS & Middle East Respiratory Syndrome \\
\hline miRNAs & Micro ribonucleic acids \\
\hline MMP & Matrix metalloproteinase \\
\hline MVB & Microvesicles \\
\hline mTORC & $\begin{array}{l}\text { Mammalian target of rapamycin } \\
\text { complex }\end{array}$ \\
\hline NPs & Nano particles \\
\hline nSMase & Neutral sphingomyelinase \\
\hline NK cells & Natural Killer cells \\
\hline NSCLC & Non small cell lung cancer \\
\hline PAMPs & Pathogen-Associated Molecular Patterns \\
\hline PLGA & Poly(lactic-co-glycolic acid) \\
\hline PS & Phosphatidylinositol \\
\hline qRT-PCR & $\begin{array}{l}\text { Quantitative reverse transcription poly- } \\
\text { merase chain reaction }\end{array}$ \\
\hline RBD & Receptor-binding domain \\
\hline $\operatorname{RdRp}$ & $\begin{array}{l}\text { RNA-dependent RNA polymerase } \\
\text { enzyme }\end{array}$ \\
\hline ROS & Reactive oxygen species \\
\hline SARS-CoV2 & $\begin{array}{l}\text { Severe Acute Respiratory Syndrome } \\
\text { Coronavirus } 2\end{array}$ \\
\hline siRNAs & Small interference RNAs \\
\hline SM & Sphingomyelin \\
\hline STAT3 & $\begin{array}{l}\text { Signal transducer and activator of tran- } \\
\text { scription } 3\end{array}$ \\
\hline TAG & Triacylglycerol \\
\hline TCR & T-cells receptor \\
\hline TEX & Tumor exosome \\
\hline TGF- $\beta$ & Transforming growth factor beta \\
\hline TLR & Toll like receptor \\
\hline TNF-Y & Tumor necrosis factor- $\Upsilon$ \\
\hline VEGF & Vascular endothelial growth factor \\
\hline WHO & World Health Organization \\
\hline
\end{tabular}

\section{INTRODUCTION}

Vaccination, also known as immunization, traditionally delivers a weakened or inactive form of a pathogen into the human body to induce antibodies and $\mathrm{T}$ cell response that protects the individual against infectious disease (1). A vaccine can also be used after infection as a therapeutic agent. Traditionally, there are two types of vaccine- one that contains live attenuated, and the other has inactivated pathogens. A live attenuated vaccine is produce by modifying a diseaseproducing bacterium or virus in the laboratory (2). These vaccines can replicate and induce immunity but usually do not cause illness (3). An inactivated vaccine is based on either whole viruses or bacteria or fractions of these pathogens. Fractional vaccines are either polysaccharide-based or protein-based. Most polysaccharide-based vaccines are composed of pure polysaccharides cell wall that are derived from bacteria (4). Conjugated polysaccharide vaccines contain a polysaccharide that is chemically linked to a protein, making the polysaccharide a more potent vaccine (5). The protein-based vaccines include subunit or subvirion products and toxoids (inactivated bacterial toxin) (6).

mRNA-based vaccines have been studied for Zika, flu, HIV, cytomegalovirus (CMV), and recently the FDA authorized COVID-19 vaccines from Pfizer-BioNTech and Moderna for emergency use. The surge of diseases like severe acute respiratory syndrome coronavirus (SARS), Middle East respiratory syndrome (MERS), severe acute respiratory syndrome coronavirus 2 (SARSCoV-2), Ebola, Zika, HIV, all types of cancers, hepatitis, and tuberculosis, to name a few, have driven the growth of the vaccine market over the past 40 years (7). The North American vaccine market is projected to generate 24 billion USD by 2024 (8).

The ongoing vaccine program's efforts have successfully eradicated infectious diseases like polio in the USA and smallpox worldwide (9). This success led the World Health Organization (WHO) to introduce the Expanded Program on Immunization (EPI) in 1974 (10). EPI led to the foundation of promising public health interventions and comprehensive vaccine programs (11). Although progress is impressive, in 2014, nearly 19 million children had not yet received the three doses of the diphtheria-tetanus-pertussis (DTP) vaccine that are required for adequate protection (12). There is room for improvement in global vaccination coverage rates in most developing countries (13). .In contrast, most developed countries have a high child vaccination rate, indicating vaccination remains a widely accepted public health measure in the modern 
world (14). However, vaccine hesitancy remains a barrier to maximizing our vaccination rates.

Given that COVID-19 has triggered severe economic loss and enormous human casualties, we urgently need to develop new vaccine strategies and understand how vaccines contain the virus's spread (15). New vaccine technologies have emerged recently, including DNA, mRNA (16), and live vectors (17). In addition, we have gained insight into the epidemiological profiles of many vaccine-preventive diseases. Together, these have significantly changed the objectives and the target of today's immunization strategies (18).

Cell-derived exosomes have emerged as a novel platform for vaccine delivery with high demand in the vaccine research field (19). Exosomes contribute to cellcell communication and contain active molecules such as lipids, proteins, carbohydrates, and nucleic acids $(16,17)$. Recent studies confirmed crucial roles for exosomes in both physiological and pathophysiological processes, including antigenic presentation (20), pathogen immune surveillance (21), intercellular signaling (22), alternative secretion of protein and RNA (23), and infectious agent shuttling $(22,24)$. However, further investigation is required to elucidate the exact biological functions of exosomes. A recent study confirms that exosomes act as key players in viral pathogenesis (25, 26). Exosomes can transfer active molecules between cells and modify target cells (27). Li et al. (28) demonstrated that exosomes derived from nonpermissive liver nonparenchymal cells (LNPCs) could induce antiviral activity via releasing interferon- $\alpha$ (IFN- $\alpha)$ against hepatitis $B$ virus (HBV). Exosome proteomic and lipidomic analysis also demonstrated that exosomes carry various biomacromolecules, including proteins, lipids, full-length viral RNAs, and regulatory RNAs (e.g., miRNAs and small interfering RNAs) (16, 29). Cheng et al. (30) found that exosomes derived from macrophages treated with mycobacterium tuberculosis induce antigen-specific IFN- $\gamma$ and interleukin 2 (IL-2)-expressing $\mathrm{CD} 4^{+}$and $\mathrm{CD} 8^{+} \mathrm{T}$ cells. This exosome vaccine application can cause a similar $\mathrm{T}$ helper cell type 1 (Th1) immune response but a more limited Th2 response than the Bacillus Calmette-Guérin (BCG)-vaccine, providing better protective immunity.

Exosomes have also been shown to modulate cancer progression. In the case of tumor-derived exosomes (TEX), exosome cargo carries a pro-EMT (epithelialmesenchymal transition) program, including hypoxiainducible factor 1 alpha (HIF1 $\alpha$ ), $\beta$-catenin, caveolin-1, and transforming growth factor-beta (TGF- $\beta$ ) that enhance migratory capability and invasion of recipient cells (31). Thus, TDEs contribute to premetastatic niche formation and stromal remodeling. TDEs also carry endogenous tumor antigens and induce antitumor immunity via transferring tumor antigens to antigenpresenting cells (APCs) like dendritic cells (DCs) (32, 33). Therefore, TDEs could potentially be applied as a cancer vaccine to induce tumor antigen-specific immune responses without purification of tumor antigens (34). Additional evidence by Koyama et al. indicates that exosomes derived from tumor cells that are genetically modified to express early secretory antigenic target-6 (ESAT-6) from Mycobacterium tuberculosis act as a potential cancer vaccine (35).

In chronic infectious lymphocytic choriomeningitis (LCMV) disease, $\mathrm{CD} 8^{+}$cytotoxic T lymphocyte (CTL) exhaustion is a critical factor that limits the removal of virus-infected cells (36). Previous studies found that exosome-mediated $\mathrm{T}$ cell-based vaccines counteract $\mathrm{T}$ cell anergy and convert $\mathrm{CD} 8^{+} \mathrm{CTL}$ exhaustion in chronic infection via CD40L signaling through the mammalian target of rapamycin (mTOR) complex 1 pathway (37). This strategy could significantly improve host defense by restoring the CTL response and facilitating virus elimination to resolve chronic infectious diseases.

In this review, we discussed the potential of exosomes as a vaccine development and delivery method. We also discuss current vaccine development challenges and how exosomes are suitable for mitigating or advancing the vaccine research field. We also discuss the role of exosomes in cancer, infectious and respiratory diseases, and how DC and mesenchymal stem cell exosomes modulate the immune response and tumor metastasis.

\section{MECHANISMS OF THE HUMAN IMMUNE SYSTEM}

A pathogen can spread through water supply contamination, air inhalation, physical contact, or the exchange of body fluids like sexual intercourse or blood transfusion (38). The mechanism of pattern recognition of these pathogens (toxic, microbial, virus, and bacteria) can be separated into two general categories: 1) response encoded by germline genes of the host, and 2) response encoded by somatic rearrangements to assemble antigen-binding molecules (39). Our immune system has two major arms: the innate immune and the adaptive immune system (Fig. 1) (40). The innate immune system provides an immediate first-line defense, and adaptive immunity represents a more specialized protective immune mechanism. Both systems work in a dynamic interplay (40). The regular routes for a pathogenic organism to gain entry to the body are via our nose when we breathe or via our mouth while we eat food and drink water, else through the skin by injection or insect 


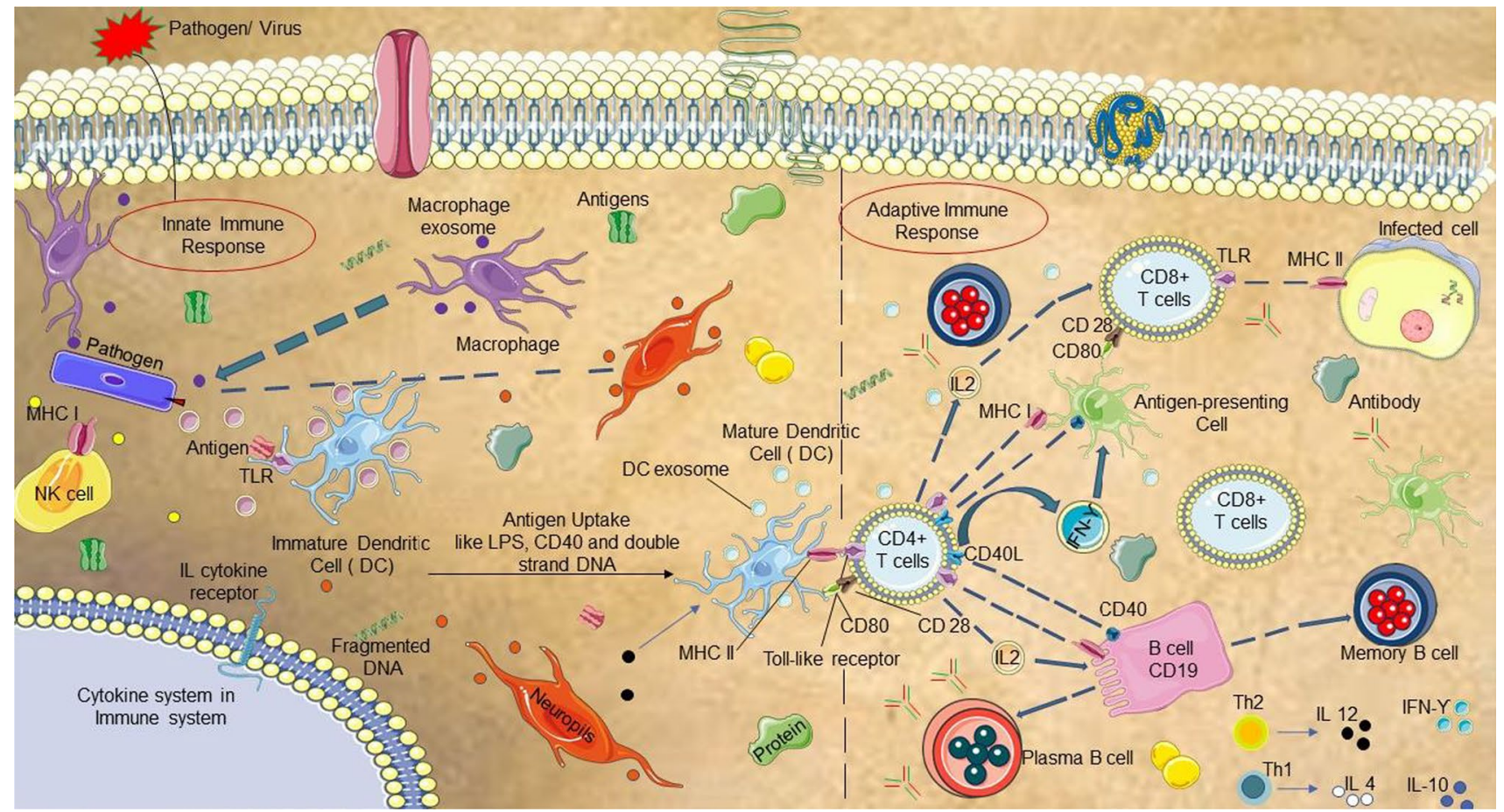

Fig. I The immune system is our first line of defense. The figure is inspired by the studies done in the immunology field (5I-54). The figure illustrates how innate and adaptive immune systems crosstalk each other against harmful chemicals or pathogens. When our body is invaded by any pathogen, our innate immune system responds to it first. Infected cells call for help, and macrophages, neutrophils, and NK cells induce the pathogen suppression cycle. Downstream signaling pathways activate our adaptive immune system. Antigen-presenting cells, like DCs carry pathogen antigen and present both helper T cells like ThI and Th2 and cytotoxic T cells CD4 ${ }^{+}$and $C D 8^{+}$cells. Then B cells produce an antibody with the help of CD4 ${ }^{+}$cells (55). B cells preserve or carry the memory of specific antigen via memory B cells with the help of $T$ cells. And our blood serum carries antibodies to protect our body from future invasion by the same pathogen.

bites (41). For example, a pathogen that we breathe into our nose and throat has to survive many chemical and physical assaults, including mucus, cilia on cells that line our airways, and predatory cells called phagocytes (42). All these defenses are designed to prevent viruses or pathogens from getting into blood circulation or our body cells. Even if the first-line defense mechanism does not work, our body still has plenty of other protections. Viruses must borrow cellular components required for their replication, and our innate defenses act against those cellinvading viruses (43). When a pathogen enters into a cell, it is quickly recognized as a foreign body (44). Infected cells also send signaling molecules to the neighboring cells for precaution and signaling our innate immune system (40). Cells also prevent the virus from being replicated inside it via the innate immune system. When all these defenses fail, the infected cell induces an apoptotic signal cascade. By doing so, cells can remove the resources required by the virus and inhibit it from transmitting to neighboring/distant cells (40). Our innate immune system is encoded in our genes, modeling physical and chemical barriers and activating chemical signals and pathogen-eating cells (45). While the innate immune response activates, it also enables more specialized lipids, cytokines, chemokines, and signaling cascade (46). The adaptive immune system develops as people are exposed to pathogens and other potentially harmful substances (46). If the immune defense is acquired, adaptive responses have a distinctive characteristic that the innate immune systems lack (47). Immunological memory is remarkable because this is how our body remembers or informs the cells to help eliminate the pathogen in the first infection, and to train our body to recognize it more quickly if we become infected again (48). When our body becomes infected by a pathogen, our adaptive immune system recognizes specific antigens encoded by that pathogen via creating immunological memory (49). Epitope fragments, a foreign body known as antigen, are found on pathogen surfaces, and bind with the receptor of immune cells (49). Antigen-presenting cells (DCs, and macrophage), which are part of the innate immune system, have the responsibility of surveying for antigens and if found carrying them to lymph nodes (50). In lymph nodes they present these antigens to $\mathrm{T}$ cells activating an adaptive 
immune response. The key players for recognizing foreign substances are called $\mathrm{T}$ lymphocytes and B lymphocytes originates from the bone marrow (50) (Figs. 2 and 3).

$\mathrm{T}$ or B cells start destroying the pathogen from which the epitope was obtained or killing cells that the pathogens are identified (60). Some other types of T cells regulate other immune cells and prevent the killing of healthy cells. Both T and B cell types can be recruited to the site of infection by chemical signals that cascade during the early stages of the disease by innate immune responses (61). Our adaptive immune response clears a pathogen by killing infected cells and the pathogen circulating in the blood with the help of T and B-cells (60). The most advanced feature of the adaptive immune response is that they can remember the epitope of each pathogen that attacks our body and can respond more rapidly in the future; if that specific pathogen or its strains infects us. Immunological memory is crucial in preventing us from getting infected by a pathogen always present in the population (62). Therefore, we are protected from viruses like measles or chickenpox if we were infected in our earlier life. In some cases, we are protected for life, but in other cases, the $\mathrm{T}$ and $\mathrm{B}$ cells that provide the long-term memory either do not develop well or do not seem to live as long (63). For example, many upper respiratory tract diseases caused by viral infections do not confer good long-term memory (64). In such cases, vaccines act in part as a proxy for the primary infection so that you obtain memory cells without getting infected. We understand vaccine development is a significant success for immunization from the above discussion, especially against infections, cancer, and immune diseases (65).

\section{IMPORTANCE AND CHALLENGES OF VACCINE DEVELOPMENT}

Prevention and treatment are both relative terms in vaccine development. Prevention has two facets, including avoiding contact with an infectious agent and abrogating further spread. Efficient prevention depends on a solid understanding of the dynamics of transmission of contagious disease. Treatment has fundamentally different goals, including improving patient quality of life, reducing the spread of infection, and curing the infection. In the 18th and 19th centuries, smallpox was one of the major killers of the human species (66). In the eighteenth century, variolation (inoculation of a scratch wound with material from a smallpox pustule) became common to protect people from the deadly effects of natural smallpox disease (67). Then famous English physician Edward Jenner first observed a strain of the cowpox virus circulating, which caused a mild infection in humans and gave immunity against smallpox (68). Cowpox inoculation protected people from smallpox and displayed lesser side effects than variolation (68). From that idea, the term vaccine evolved, which allows immunization to stimulate protective immunity (68).

According to a 1998 report from the CDC, there was $>95 \%$ decline in the eight most common infections in the US due to the introduction of vaccines (69). However, incremental changes due to the seasonal prevalence of infectious or respiratory diseases
Fig. 2 We summarized some challenges for vaccine development across the globe. The most critical factors that hinder the vaccine development industry are illustrated. Many vaccines fail due to excessive immune response or inadequate immune response in the human body, and some deadly diseases have different pathology across the world. Some pathogens include multiple strains and continuously bring new mutations across the globe. Due to time limitations, some vaccine studies are suspended due to the decline of funding support. We also found that some vaccine studies fail due to a suboptimal clinical trial design.

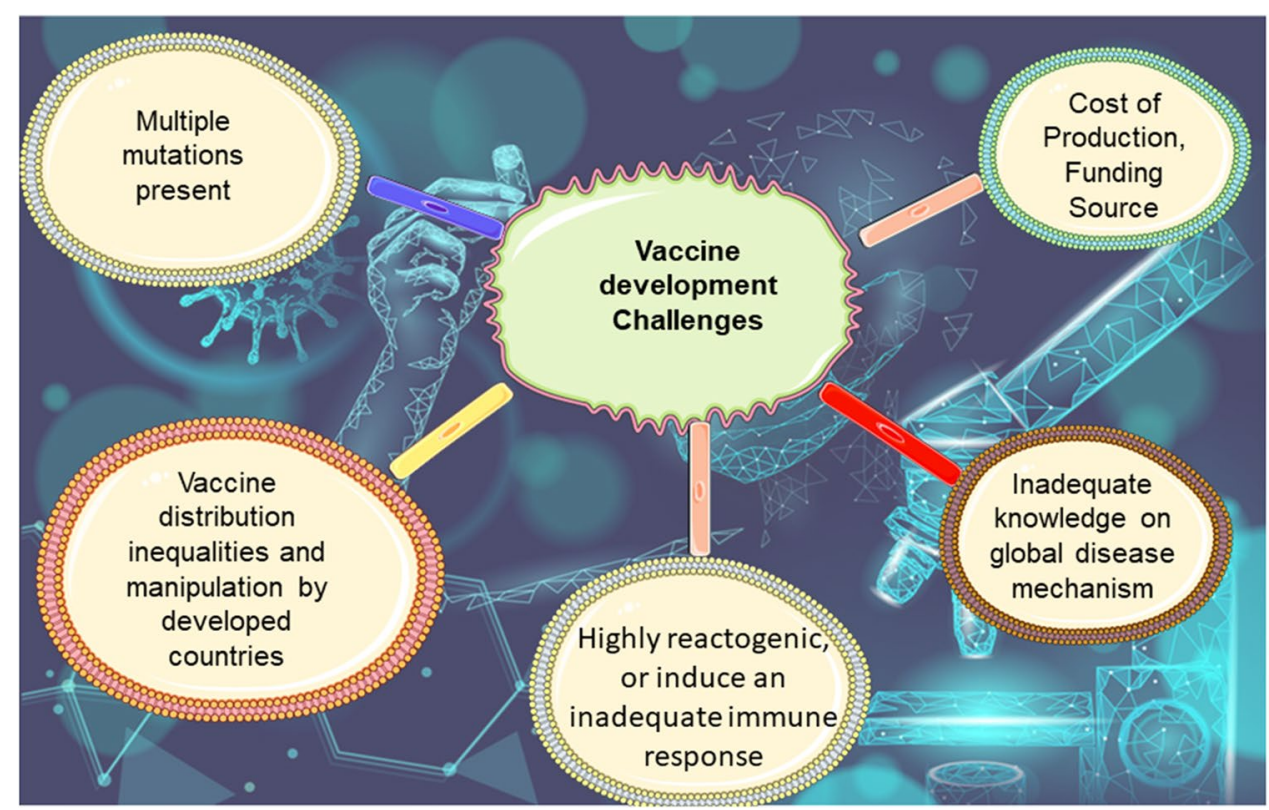




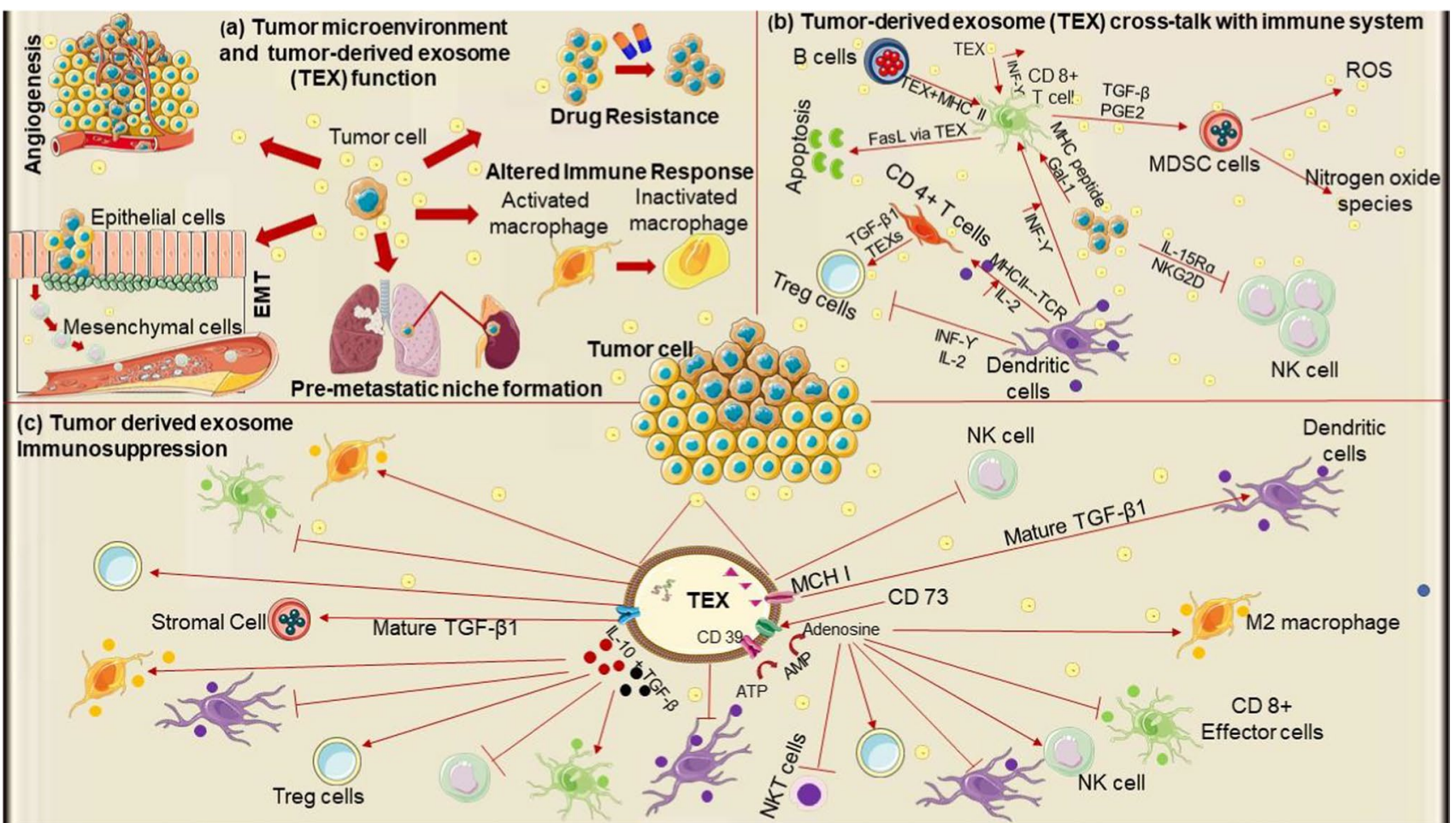

Fig. 3 Tumor microenvironment is a very dynamic and complex structure. In Fig. 3, we are inspired by recent studies on how tumors escape the immune system, tumor-derived exosome (TEX) role in immune modulation, and finally, how tumor exosomes have both excitatory and excitatory tumors inhibitory mechanisms towards our immune modulation (56-59). (a). Most tumor cells escape immune networks via proliferating angiogenesis, EMT, altered immune cell activation state, and drug resistance. TEX plays a crucial role in this dynamic tumor microenvironment. (b). both types of immune cells interact with tumor-derived exosomes and have activated downstream signaling pathways. TEX inhibits NK cell function but activates $C D 8+T$ cell immune activity via $M H C$ I receptor. TEX also plays a role in CD 4+ T cell activation by the antigen-presenting DC via conjugating the TCR-MHC II receptor. CD $8+$ cells induce ROS and NOS signaling in MDSC with the influence of TEX. (c) In figure c, we summarized how TEX modulates the immune cell's activation state and function depending on the type of receptor interaction and cytokines presence. For example, TEX inhibits NK cell activity, but other TEX activity activates NK cell activity via adenosine signaling pathways. Similarly, TEX's effector T cell activity inhibits, but IL-IO and mature TGF- $\beta$ activate effector T cell's function. Figure 3 demonstrates how TEX interacts with our immune system in every step and guides us DC or mesenchymal stem cell-derived exosome could utilize as vaccine delivery and platform in the future.

often make vaccine development more challenging. Vaccines confer protection through a variety of mechanisms, which extend beyond protecting the immunized individual from infection. Firstly, many vaccines (such as the influenza vaccine) effectively prevent severe disease, despite conferring only moderate protection against infection (reference: https:// www.cdc.gov/flu/vaccines-work/vaccineeffect.htm). Secondly, vaccines given to the infant's mother will transiently protect a breastfed child, even though they will not develop their own immune protection (70). Thirdly, vaccinated individuals are less likely to transmit the disease to others. Thus, the impact of global vaccination on mortality rate reduction is muchmore significant than its effect on reducing the number of cases among vaccinated people (71). The Global Alliance for vaccine and immunization organization estimates that immunity to Hemophilus influenza type $B$ has averted nearly 700,000 future deaths (72). The WHO estimates that one in five children would have died before age five due to vaccine-preventable diseases (73). Thus, vaccine development has an immeasurable positive potential impact on health worldwide. The Coalition for Epidemic Preparedness Innovation (CEPI), an international nongovernmental organization funded by the Wellcome Trust, the European Commission, eight countries (Australia, Belgium, Canada, Ethiopia, Germany, Japan, Norway, and the United Kingdom), and the Gates Foundation support the development of vaccines against a prioritized list of infectious diseases (including COVID-19, Lassa fever, MERS, Nipah, Ebola, Rift Valley fever and Chikungunya). CEPI supports platform technologies with the potential to accelerate vaccine development in response to outbreaks of infectious disease, proposing to release a product for clinical trials within 16 weeks of the identification of an antigen and demonstrating effectiveness in large-scale manufacturing and suitable elimination of typical unpredicted immune response across pathogens (74). 
Despite a better understanding of the immune response to infectious diseases and cancer immunotherapy, many vaccine candidates fail due to a high degree of reactogenicity, creating safety issues, or failure of the candidate vaccine to elicit an appropriate immune response for protection. Although animal models like mice, guinea pigs, and rabbits may exhibit protective immunity after vaccination, immunodominant antigen recognition may differ in these models compared to humans (75). Immune cells like DCs and macrophages are activated by pattern recognition receptors, such as TLRs, and activate multiple downstream pathways to influence the adaptive immune response; this process shows some variation between humans and rodents $(76$, 77). Rodents tolerate much higher doses of endotoxin (100,000-fold) compared to humans (78). The balance of circulating leukocytes and neutrophils shows significant differences in rodents $v s$. humans, with humans showing a higher proportion of neutrophils (76). In terms of adaptive immunity, there are some minor differences in antibody sub-classes between humans and rodents (e.g., IgA1 \& IgA2 in human serum versus IgA in murine serum) (79). There are many other differences between the immune system of humans and rodents, too numerous (76). Besides, physiological differences between humans and animals can lead to disparity when well-controlled animal studies advance human trials $(75,80)$. Despite these differences, the rodent response to vaccines is broadly like that of humans, and mouse and rat models have proved to be a critical tool in the early vaccine development pipeline (81). The use of additional animal models, including rabbits, guinea pigs, ferrets, and non-human primates, may generate additional confidence in the vaccine's performance before proceeding to clinical trials in humans (81).

Over the last decade, scientific advancements have allowed for identifying vaccine antigens for new emerging viruses and pathogens. Most of the time, antibody responses against surface molecule markers determine the vaccine's efficiency for preventing infection (82). For example, in a bacterial infection, the antibody which binds with a surface antigen undergoes opsonization and complement-mediated lysis for phagocytosis (83). Thus, vaccine targeting surface antigens need to be strain-specific and have a multivariant formulation, which is mutated frequently $(84,85)$. A new generation of vaccine adjuvants has emerged via interaction with pathogen-associated molecular patterns (PAMPs) like bacterial DNA fragments and cell wall components, including lipopolysaccharide and peptidoglycan, which activate pattern-recognition receptors (PRRs), including Toll-like receptors (TLR), NOD-like receptors, and C-type lectin receptors $(86,87)$.
However, conventional vaccine development may not be feasible during a pandemic or epidemic situation. The unpredictable nature of emerging pathogens poses a significant problem in this context. For example, in a new influenza pandemic, a known pathogen mutates and adapts to a new host environment with unpredictable outcomes for its immunization. The same is true for SARS-CoV-2, which required expedited, concurrent vaccine safety and efficacy trials. In the current COVID19 pandemic situation, multiple virus variants have been identified worldwide (88). Coronavirus can also be spread through the air as tiny aerosols. In addition to bigger droplets, coughing and sneezing produce microscopic particles called aerosols, which linger in the air for prolonged periods. A person can become infected from a distance of more than two meters in this case. During an epidemic situation like the current COVID19 pandemic, the timeline to development of a new vaccine candidate can be reduced using next-generation sequencing by identifying antigens, comparatively in short period of time.

In contrast to the typical duration of vaccine development, which takes many years, the FDA approved 3 COVID-19 vaccines for emergency use within one year of the WHO declaration of the COVID-19 pandemic, and one of these vaccines recently received full approval. The mRNA vaccines for COVID-19 were developed more quickly than any other vaccine in history. The first one is from Pfizer/BioNTech mRNA vaccine (BNT162b2) with $95 \%$ efficacy in neutralizing COVID-19 symptoms in 44,000 participants (89). The second vaccination, known as Moderna mRNA-1273 vaccine, was found $94.1 \%$ effective in a study conducted in 30,000 subjects (90). The third is from the Janssen COVID-19 vaccine Ad26.COV2.S with $66.3 \%$ effective trial and trial participant number 44325 (91). None of the vaccines trial or participants receiving a single or double dose of vaccines has reported any severe side effects associated with the vaccine. Recently, the vaccine of Janssen company was temporarily paused due to 6 observations of rare blood clots in vaccine recipients. However, after an investigation by the FDA and CDC approved a single booster dose of the Janssen (Johnson and Johnson) COVID-19 Vaccine for individuals 18 years and older on October 20, 2021. Respective safety monitoring boards have been established for each vaccine, and FDA and other specialist panels have regularly evaluated safety data.

As of October 2021, in total, 190,793,100 persons have been fully vaccinated, accounting for $58 \%$ of the population. Vaccine hesitancy remains a significant barrier to fully vaccinating our population. Additionally, we await authorization for children under 12 to 
receive these vaccines. On a global scale, however, some developing countries have limited access to vaccines. Another factor that limits the distribution is the cost of production. Using current technologies, the cost of establishing facilities containing the necessary equipment ranges from approximately 600 to 1200 million dollars (92). A further challenge is the specific methods and techniques used, which often are insufficient to support global vaccination (71). Inadequate access to vaccines can cause two million deaths each year, and two-thirds of this number are children under five years old (93). Currently, 93\% of the 260,000 annual deaths from cervical cancer and over $99 \%$ of the 440,000 yearly deaths from rotavirus-associated diarrhea occur outside the 60 wealthiest countries (94). Thus, scientific, ethical, and financial challenges against vaccine development are considerable, and we must continue to break through these barriers to fight against future epidemics.

\section{KEY STRATEGIES OF VACCINE DEVELOPMENT}

Vaccine development against infectious, autoimmune, respiratory diseases, and cancer immunotherapy have changed human history by reducing mortality (95). Two prime examples include eradicating polio in the USA and the near eradication of smallpox globally (96). To date, all vaccine development strategies reduce disease progression by achieving active immunity via the targeted population's adaptive immune system and vaccine effectiveness (97).

We are bringing the SARS-CoV-2 vaccine development strategies as an example. In December 2019, a severe illness causing pneumonia and death was first reported in Wuhan, Hubei, China. After that, this illness spread across 200 countries, causing $244 \mathrm{M}$ people to be infected and $4.9 \mathrm{M}$ deaths to date (98). These numbers are increasing every day until we find a complete cure for this deadly disease. The WHO announced "coronavirus disease 2019 (COVID-19)" as its official name (99). Viral genome analysis reveals its phylogenetic similarity with SARS-CoV; thus, the International Committee on Taxonomy of Viruses (ICTV) designated it "SARS-CoV-2" (100). During this initial stage of the COVID-19 outbreak, some potential antiviral drugs, steroids, and monoclonal antibodies are administered to patients depending on the variation of symptoms. Some examples include favipiravir (T-705) $(101,102)$, remdesivir (Veklury)(GS-5734) (103-105), chloroquine/Hydroxychloroquine (106, 107), lopinavir, dexamethasone, bamlanivimab (LY-CoV555), Casirivimab and imdevimab (REGN-COV2), and ritonavir
(108, 109). All these drugs, antibodies, and antibiotics are currently under clinical trials or administered to patients with FDA approval. But after getting data from patients' critical conditions and side-effect of some drugs in COVID-19 patients, FDA has revised their authorization (110). For example, Lopinavir/ritonavir, and darunavir/cobicistat haven't demonstrated clinical benefit in patients with COVID-19 (111). Adverse effect for lopinavir/ritonavir includes Nausea, vomiting, diarrhea (typical), QTc prolongation, and hepatotoxicity. FDA approves Remdesivir approves Remdesivir to administer to hospitalized adult and pediatric patients (aged $\geq 12$ years and weighing $\geq 40 \mathrm{~kg}$ ). Due to severe side-effect both hydroxychloroquine and chloroquine, the FDA revoked both emergency use in June 2020. In a pandemic situation like COVID-19, vaccine development could only control the situation. For vaccine development, precise recognition between viral surface protein and host receptor is an important target and will reveal cross-species transmission and host tropism (112). The SARS-CoV-2 Spike (S) protein binds to ACE2, allowing the virus to infect human cells $(112,113)$. The $S 1$ subunit of the $S$ protein contains a receptor-binding domain (RBD), and the $\mathrm{S} 2$ subunit is necessary for membrane fusion between host cells and viruses $(15,114)$. Clover Biopharmaceuticals tests a recombinant subunit vaccine consisting of the trimeric S protein (S-Trimer) SARS-CoV-2 (115). GSK and Clover Biopharmaceuticals announced a partnership to improve immune response by introducing GSK's adjuvant system to S-Trimer. DNA vaccines directly injected plasmids encoding the antigens, applied with prophylactic vaccines and therapeutic vaccines (116). The DNA platform uses adjuvant to enhance the immune responses and electroporation to deliver plasmids (117). INOVIO Pharmaceuticals and Beijing Advaccine Biotechnology partnered to develop a DNA vaccine (INO-4800) against COVID-19 and start pre-clinical trials (118). The mRNA technique is another advanced vaccine platform that can treat infectious diseases and cancers. mRNA-based vaccines contain mRNAs encoding the antigens and are translated into the host cellular mechanism via vaccination $(119,120)$. mRNA vaccines have an advantage over traditional vaccines, including improvement of the immune response, absence of genomic integration, rapid development, and production of multimeric antigens (120). Moderna, Inc. has completed clinical trials in collaboration with the National Institute of Allergy and Infectious Diseases (NIAID) on the mRNA vaccine (mRNA-1273) encoding viral spike (S) protein of SARS-CoV-2 (121). Genexine Inc. is developing a COVID-9 vaccine based on the Hyleukin-7 platform, which enhances the immune 
responses by fusion of interleukin-7 (IL-7) to hyFc, and is designed to hybridize $\operatorname{IgD}$ and IgG4 for long-acting effects of Fc fusion proteins (122). Most vaccines available are based on inactivating/killing, live attenuated, or weakening technologies. Scientists now tune current vaccine technologies via isolated protein, subunit, split product, peptide, DNA tether, mRNA, and live vector technologies $(71,123-125)$. Together with the vaccine methods mentioned above and some hurdles to overcome, we can enhance vaccine development for diseases like SARS, MERS, COVID-19, infectious diseases, and cancer metastasis.

The development of the smallpox vaccine was a revolutionary achievement in the scientific world, and we will explain vaccine development strategies using the smallpox vaccine as an example. A more substantial variola DNA virus can cause a smallpox infection (126). Several important observations made during the smallpox outbreak helped to rationalize vaccine development. First, an individual who recovers from smallpox was resistant to the subsequent disease. Second, Inoculated into a scratch wound (variolation)may prevent further infection (127). The observations conclude that our defense system is versatile at recognizing and invading foreign bodies (128). While designing a vaccine, the immune defense system could be primed with a miniature, weakened version of the pathogen. In the past, health care professionals from Asia used variolation methods using inoculation of a small amount of dried or fresh smallpox materials from the nose or skin. Data suggest that the inoculation method was exceptionally effective (128)

Before the variolation concept was present in Asia, England physician Edward Jenner proved the first vaccine concept. According to the journal Baylor University Medical Proceedings 2005 report, Edward in 1996 vaccinated a child named James Phipps with pus taken from a cowpox pustule (128). However, this treatment concluded that a milkmaid infected with cowpox did not get infected with smallpox. Jenner's treatment went down in history as he first introduced vaccination for infectious diseases. These observations above led to an intense vaccination campaign conducted between 1960 and 1970 to help eradicate smallpox from the USA (127). The pathogen collected for vaccine application was prepared by inactivating or killing the virus by overheating (129). For example, the hepatitis A vaccine is also an inactive virus. When the virus is inactivated, scientists sometimes reverse or rearrange the structures. Some vaccines allow the pathogen to replicate, which helps with further recognition by T-memory cells (129). Another exciting field uses a vaccine carrying a subunit of pathogen structure to guide the vaccine to identify critical molecules of virus or bacterial structure (52). The hepatitis B virus vaccine is a prime example of this approach. Due to infection or vaccines, individuals produce antibodies in the immunization process, which results in direct protection against subsequent infection (130).

The incorporation of nanoparticles as a vaccine delivery vehicle can enhance vaccine efficiency by improving blood circulation half-life and reducing immunogenicity (131). Surface contact, encapsulation, and surface adsorption, related to vaccine design, are the foundations of this nanoparticle coating (132). Antigen adsorption depends on the surface hydrophobicity of nanoparticles (131), whereas encapsulation depends on both the physical and chemical interaction of vaccine carriers and nanoparticles (133). For example, the H1N1 antigen of influenza conjugate with chitosan NP and Yersinia pestis F1-antigen coated gold NPs (AuNPs) demonstrate a higher antibody level and cytokine response than unconjugated vaccines (134). Also, the studies showed that nanoparticle-delivered vaccines offer better antigen presentation and delivery (135). In the Moderna mRNA Covid-19 vaccine, four different fatty molecules have formed a protective capsule around the RNA, ensuring safer delivery and preventing degradation (136). We will discuss some factors that need to be considered while preparing nanoparticles for vaccine delivery.

Better reproduction and effectiveness can be achieved by taking advantage of the effects of physicochemical properties. Although the physiological and morphological properties are the critical parameters for vaccine stability and delivery, a challenge is the scaleup of the production of particles with uniform size and vaccines carrying nanoparticles are also required to be under a particular dimension (137). A study by Wendorf et al. showed that 100-110 nm PLG nanoparticles carrying antigens from Neisseria meningitides type B (MenB) results in higher efficiency in targeting and comparable immune response compared with naïve vaccine antigens (137). Another study by Benne et al. reviewed nanoparticles' size, shape, and rigidity loaded with vaccine tether or antigens, how these factors enhance $\mathrm{T}$ cell immune response, and how nanoparticles provide a roadmap to rational delivery of efficient vaccine (138). The surface charge affects the distribution and cellular uptake of particles. The surface charge plays a critical role in determining the type and amount of particle coronas. Given that the cell membrane is negatively charged, the antigen delivery of particles is influenced by the particles with a different charge (positive) (139). Although the positively charged particle should be attracted to the negatively charged 
cell membrane, there have been discrepancies in the correlation between particle charge and cell interaction. Cationic liposome-regulated immune responses rely on surface charge density (140). Negatively charged liposomes can act as an adjuvant to promote cell-mediated responses (141). Particle charges on the APCs responses compared with three kinds of nanoparticles (NP); negatively charged N-NP, neutrally charged M-NP, and positively charged P-NP (141), excluding the surface charge, uniform size, and physicochemical properties were assured in the study. The amount of cellular uptake correlated with the surface charge of the particle (142). Cationic NPs cause more reliable mitochondrial and lysosomal damage and disruption of plasma membrane integrity than negative NPs (142). Surface charge and shape can be implemented into one single particle with the concept of component control. Cell membrane potential varies from -40 to $-70 \mathrm{mV}$ depending on its physiological condition. Nanoparticle coating and the process will differ depending on the type of vaccine delivery and the target site. The shape is an essential property of natural bio-particles. Viruses and bacteria have qualities that determine their infection efficacy and replication. The investigation for shape effect has been lagged the size and charge of the particles (133). The shape has become an important parameter to consider when designing micro and nanoscale particles. Non-spherical forms of particles have limited material choices and complicated techniques. Though the method for preparing non- spherical shaped particles are complicated, wormshaped particles have prolonged blood circulation that enhanced organ accumulation (143). Nanospheres and nanorods can be seen to interplay with different types of cells. Rod-shaped particles have the advantage of being quickly internalized by cells. Particle internalization can be a complicated process, but micropinocytosis and phagocytosis were the predominant methods that mediate uptake of these non-spherical particles (144). Particle shape regulated intracellular distribution as well as the cytokine profile response. Altering the shape or charge of a single particle can achieve a specific function, carrier, or targeting stimulation (145). Hydrophobicity plays an essential role in the interaction between APCs and vaccine particles (146). Cell membranes are comprised of a lipid bilayer, which means that they have both a hydrophilic exterior and interior membrane which interact with water molecules. Particles that are prepared with hydrophobic and high molecular weight polymers tend to be more effective in cell interaction (147). To understand the interaction relationship, PLA, PLGA, and PEG-b-PLA were compared; in the results, the hydrophobicity gradually increased, indicating a decrease in macrophage internalization (148). The particles compared above were similar in size but different in hydrophobicity. The comparison of the particles shows that the higher the hydrophobicity, the greater the interaction between particles and cell membranes. Not only does the hydrophobicity increase the exchange, but it promotes the internalization of particles and thereby facilitates vaccine delivery (149). Nanoparticles have chemical functional groups that come from the original component of particle material. The surface modification also modulates the performances of particulate adjuvants. Antibodies have been used to target DCs since DCs are moving targets; the strategy was a practical use of a tumor vaccine (150). When using adjuvants in a vaccine, the particles can induce an effective adaptive immune response and increase survival rates in mice (151). Particle adjuvants can pave the way for vaccines with their promising effects (151). Nanoparticles can be used to prolong immune efficacy, longevity and provide a design concept that can maximize efficiency and decrease any adverse effects. The design of the nanoparticle mediated vehicle for vaccine can be seen to tailor to the high antigen payload, and the potentially enhance effectiveness $(133,152)$.

So, an effective vaccine induces an immune response, replaces immune potentiators, and primes the immune response against associated antigens. And nanoparticles as a vaccine vehicle can result in higher therapeutic intervention and a more robust immune response. Additionally, surface modification of NPs allows targeting of specific cell types and systematic transport (153). A recent study reveals targeting antigen to DCs is a powerful and novel strategy for vaccination. Of the main types of APC (B cell, macrophages, and DCS), the DCs are the most vigorous and are responsible for initiating all antigen-specific immune responses (152, 153). Additionally, these types of vaccine strategies efficiently extend nanoparticle-trafficking time in vessels and enhance transport.

\section{WHY EXOSOME IS BETTER CANDIDATE FOR VACCINE DEVELOPMENT AND DELIVERY}

\section{Exosomes Composition and its Role in the Immune Response and Multiple Diseases Signaling Pathway}

Almost all living organisms, including viruses and bacteria, shed exosomes into the extracellular environment (154). Proteomic analysis of the biological fluid reveals that exosomes contain numerous immune 
response molecules on the surface and carry biological messengers like proteins, chaperons, mRNA, and DNA fragments (155) (156). Lipids, proteins, nucleic acid-like signal transducer, membrane trafficking, T cell stimulation, and anti-apoptosis molecules found on the exosome surface also have some immune-modulatory effects $(157,158)$. Additionally, a new study reported that the exosomes are present in the lymph as well. One needs to remember; immune cells receive signals from exosomes of other immune cells, microbes, tumors, and non-immune cells (159). Exosome release from immune cells via Fc gamma receptor, cytokine receptors, TCR, and BCR, helps to raise cytosolic calcium ion concentration.

Exosome biogenesis begins when the endosomal membrane transforms to generate intraluminal vesicles (ILVs) in the lumen of the organelles via- first, with the maturation of the early endosomes to microvesicles (MVB), and second, late endosomes to exosome (160). For transportation, most studied endosomal pathways are associated with endosomal complex (ESCRT-0, ESCRT-I, ESCRT-II, ESCRT-III) and AAA ATPase Vps4 associated complex $(161,162)$. One study has shown that the depletion of ESCRT-0 protein Hrs and ESCRT-1 protein STAM1 reduces exosomal secretion (163). ESCRT-0 proteins like Hrs, Vsp27/ STAM 1, 2 binds with a ubiquitin-protein programmed for degradation, executing a sorting of MVB in the first steps (164). ESCRT -I (TSG101, Vps28, MVB12a) and ESCRT-II (Vps22,25 and 36) promote the budding process and start the enzymatic de-ubiquitous cargo protein before the formation of MVBs in the intracellular compartment and ILVs (165) (156). On the contrary, knockdown of ESCRT-III and associated protein-such as VSP4B, VTA1, and ALIX resulted in increased exosome secretion (163). Many studies have shown lipids like sphingomyelin (SM), glycosphingolipids, cholesterol, and phosphatidylinositol (PS) $(166,167)$. Exosome surface contains a high level of triacylglycerol (TAG), cholesterol (CE), cardiolipin, a lipid found within the mitochondrial membrane (168), and TAG and CE were found in the lipid droplet core (166). Several lipids and lipid metabolism enzymes have shown a critical role in the release and formation of exosomes. Neutral sphingomyelinase (nSMase) contributes to forming cone-shaped ceramide, which is essential for exosome secretion $(163,169)$. Both cell-specific and ubiquitous proteins selectively express exosomes from their native cells. They also include cytosolic proteins like tubulin, actin, flotillin, membrane transport protein like annexin, and RAB proteins (170). They (exosome) also contain signal transduction protein-like protein kinase, heterotrimeric $G$ protein. Even metabolic enzymes like pyruvate and lipid kinase, peroxidase is also present on the exosome surface. Western blot analysis of Exosome reveals less expression of tubulin and actin as these cytoskeleton proteins have a higher expression on the cell surface. Exosomes also carry heat shock proteins like HSP20, HSP27, HSP70, and HSP90 (171), involved in antigen presentation, loading, and binding antigen peptides onto MHC molecules, maturation of DCs, and translocation of NF- $\kappa \beta$ into the nucleus through CD91 $(156,172)$. Interestingly, T cell stimulators like MCH I, MCH II, and CD81 are also available on exosome surfaces, originating from antigen-presenting cells (173). These T stimulatory molecules play a critical role in antigen-specific interaction between $\mathrm{B}$ and $\mathrm{T}$ cells. DC-derived exosomes carry T cell co-stimulatory molecules CD81 and carry $\mathrm{T}$ cell receptors on their surface to activate T-cells (174). Monocytes also release pro-inflammatory cytokines in the presence of soluble HSP70 via CD14 signaling pathways, Nk-cells target HSP70 for cytosolic attack (175). Even high expression HSP70 within tumor cells can kill NK cells compared to the lower expressed HSP70 tumor cells (176). HSP70 participates in inhibiting key effort signaling lings associated with apoptosis and autophagy. Thus in tumors, abnormal expression of HSP70 may participate in resistance to chemotherapeutics and oncogenesis (177). Flotillin is another exosomal protein marker found on the surface in most healthy and cancer cells T-cells express Flotillin-1 \& 2, in the absence of added chemokines, forming a large preassemble platform in lymphocyte cell lines (178). Flotillin's C-terminal interactions lead to the heterodimer of FLOT1 and FLOT2, both in naïve and activated T cells (179). Flotillin has been implicated in various cellular functions, including cell-cell adhesion, regulation of $\mathrm{G}$ protein coupled receptor signaling, endocytosis, and modulation of the actomyosin cytoskeleton of leukocytes $(180,181)$. Tetraspanin is another abundant protein family that is available on the exosome surface. Tetraspanin, such as CD9, CD63, CD81, and CD82, interacts with many protein types, including integrin's and MHC class proteins, indicating they involve in large molecular complex organizations and membrane subdomains (182). Among them, CD63 and CD81 are localized to lipid raft in the plasma membrane, and this process is called palmitoylation (183). Tetraspanin is also associated with integrins of exosomes and cell surfaces. Rana $e t$ al. has demonstrated that preferential interaction between Tspan 8 with $\alpha 4$ and $\beta 8$ integrin chain and colonies of tetraspanin and integrin proteins strongly influence targeting cell selection in vitro and in vivo (184). In the integrin family, exosome contains a series of transmembrane protein including immunoglobulin-family 
members (185) such as A33 antigen on enterocytes (186) and P-selectin on platelets, intercellular adhesion molecule 1 (ICAM1)/CD54 on B cells (187)), $\alpha$ and $\beta$-chains of integrins (such as $\alpha \mathrm{M}$ on DCs, $\beta 2$ on DCs (188) and T cells, and $\alpha 4 \beta 1$ on reticulocytes), cell surface peptidases (189) (such as dipeptidyl peptidase IV/ CD26 on enterocytes and aminopeptidase N/CD13 on mastocytes). Moreover, scientists have been able to identify multiple Rab GTPase such as Rab27a, Rab27b, Rab2, Rab7, Rab11, Rab35, etc., using RNAi screening that promotes exosome secretion in a wide range of cell lines (190).

Exosome release from viral cells also carries viral miRNA, proteins, and even entire virion modulates adjacent cells and impacts immune recognition by the virus. Hepatitis $\mathrm{C}$ virus (HCV) membrane of the Flaviviridae, exosome isolated from $\mathrm{HCV}$ infected human blood, contains viral RNA co-localize with CD81 and transmit viral RNA to uninfected cells. Exosomes from HCV-infected cells induce natural interferon (INF)- $\square$ response to neighboring DC cells via viral RNA. In contrast, natural circulating HCV infection delivers viral RNA to cells, but with the help of viral NS3/4 protease, it downregulates TLR and RLR signaling (191). These exosomes from $\mathrm{HCV}$-infected cells protect uninfected cells during infection by transmitting viral RNA, not viral protein, which antagonizes the innate immune system. Circulating exosomes that contain HCV virion may possess a pro-viral role, which spreads the disease in the presence of neutralizing antibody (192). The major oncoprotein of EVB (a gamma herpes virus) and latent membrane protein 1 (LMP1) were identified in exosomes isolated from EVB infected cells (193). B lymphocytes transformation required LMP1 proteins. Exosome from B-cells contains LMP1 that inhibits NKcells cytotoxicity and T cell proliferation (193). Also, exosomes deliver EGFR, PI3CA, and LMP1 induced growth-stimulating signaling pathways in recipient cells and activate the ERK1, PI3 kinase target, and Akt (194). For specific protein expression, we can find out on the ExoCarta website (http://exocarta.org/gene_summa ry? gene_id=11461). ExoCarta database has around 64,246 exosomal protein, mRNA, miRNA, and lipids entries, including both published and unpublished work. This database contains valuable information describing the characterization, biomarker screening, targeted drug delivery, and vaccine development studies.

This section will discuss studies related to exosome and their immune response during health and disease conditions. Neutrophil-derived exosomes have both anti-inflammatory and pro-inflammatory effects (195). Bacteria can interact with neuropil-derived exosomes, and surprisingly, neutrophil exosomes can bind to bacteria and reduce bacterial growth. NK cell-derived exosomes carry NK cell markers FasL and perforin, depending on cellular homeostasis and physiological condition (196). Antigen-presenting monocytes and macrophages produce abundant exosomes, which plays a vital role in antigen presentation and affects myeloid cell differentiation and proliferation (197). It has been reported that infected macrophage-derived exosomes can transfer pyroptotic caspase-1 (198). Thus caspase-1 can initiate the pyroptotic cycle in recipient cells due to infection. Mast cell-derived exosomes carry functional RNA and can trigger DC maturation. Also, mast cell exosomes induce $\mathrm{T}$ and $\mathrm{B}$ cell proliferation, contain multiple immune-modulatory proteins, and play a role in antigen delivery of immune cells (198).

DC-derived exosomes actively prime $\mathrm{T}$ cells and contribute to antigen presentation. Both mature DC and B cells are required to activate naïve T cells. DCs act as both innate and adaptive immune cells (199). Depending on the type of DC and its activation status, the exosome population changes its surface composition and payload. Mature DCs exosomes are enriched with MHC class II, ICAM-1, B7.2, and depleted in MFGE8 have a stronger ability to induce an antigen-specific immune response the immature DCs derived exosome (200). Exosomes also modulate different immune cells; for example, mast cell-derived exosomes can cause degranulation and induce $\mathrm{T}$ cell proliferation (201). Interestingly, $\mathrm{T}$ cell-derived exosomes were found in extracellular spaces and immune synapses (between antigen-presenting cells and T cells). During antigen presentation, B cell-derived exosomes first interact with antigens and modulate cytokine secretion and T-cell activation (201, 202). A distinctive feature of B cellderived exosomes is that they carry immunoglobulin, which delivers native antigens to neighboring cells. Sometimes, immune cell-derived exosomes carry different pathogen-associated dangerous messages like PAMPs and DAMPs (203). A recent study also shows that immune-derived exosomes carry cytokines like TNF, TGF- $\beta$, IL- $1 \alpha$, and IL- $1 \beta$. On the contrary, infected cell-derived exosomes can carry viral and bacterial particles $(22,204)$. These infected cell-derived exosomes can accelerate the acute inflammatory process by recruiting a significant player to regulate inflammation (205). For example, bacterial component fMLP can induce neutrophilic exosomes containing leukotriene B4 and activate neutrophils. This leukotriene B4 is necessary for neutrophil recruitment at the site of inflammation (206). When acute inflammation begins, pro-inflammatory cytokines, for instance IL-1 are predominantly found in exosomes of infected cells (206). Further 
evidence shows that other pro-inflammatory cytokines like TNF and its complementary regulatory protein are also released via exosomes (207).

Exosomes also play a critical role in the chronic inflammatory process. For example, DC-derived exosomes perpetuate Th2 cells' responses and behave as antigen-presenting molecules (208). Mast and B cellderived exosomes drive Th2 responses and promote the Th2 environment. Microphyte-derived exosomes contain LT and recruiting granulocytes, functional inflammatory enzymes, and synthesis leukotriene (209). $\mathrm{T}$ cells-derived exosomes stimulate the release of proinflammatory cytokines like IFN- $\gamma$ from Th1 cells (209). IFN- $\gamma$ is crucial for immunity against tumor and intercellular pathogens. Because IFN- $\gamma$ is predominantly produced by NK and NKT cells and produced by Th1 CD4 and CD8 cytotoxic T lymphocyte (CTL) effector T cells. Airway epithelium cell-derived exosomes increase the release of cytokines like interleukin 13 (IL-13) from Th2 cells (210). IL-13 is a critical regulator of IgG synthesis, mucus hypersecretion, goblet cell hyperplasia, and fibrosis $(210,211)$. Exosomes also play a role in auto-immune diseases like type-1 diabetes, hepatitis B, multiple sclerosis, and inflammatory bowel diseases. These exosomes membrane proteins and lipids are essential when we study disease-specific biomarkers and models for vaccine development. Rather than working on a single cell, we can research exosomes derived from cells that provide us with a plethora of information regarding disease conditions.

\section{Role of Exosome Biomarker in Vaccine Delivery}

In recent years finding biomarkers for detecting suitable disease target and vaccine delivery have grown exponentially. Biomarker study is based on a biological source like urine, blood, plasma, serum, and body fluid exosome analysis. Exosome contains disease pathogens, antigens, fragmented DNA, miRNA, non-coding RNA, lncRNA, and circRNA are fascinating potential biomarkers $(212,213)$. Biomarker analysis also applies to tumor diagnosis, metastasis prediction, evaluation of prognosis, and treatment effectiveness. For instance, the level of miR-21, miR150, miR-223, and miR-1229 in colon cancer patients' serum exosomes was significantly higher than healthy control (214). Therefore, the exosome could be used for noninvasive tumor diagnosis. In lymph node metastasis, the concentration of miR217 level in serum exosomes is considerably low (215). miR-127 acts as a tumor-suppressing agent in multiple cancer models. Thus, serum exosome can act as a biomarker and be utilized to diagnosis the metastasis state. Hoshino et al. has found higher expression of ITG $\beta 4$ in the exosome of lung metastasis patients $v s$ liver metastasis patients (216). PD-1 and PD-L1 are major cancer immune checkpoint biomarkers and have been studied extensively. In triple-negative breast cancer patients, the tumor exosome expresses a higher level of PD-L1 (217). PD-1 level is associated with poor prognosis via exosome analysis of classical Hodgkin's lymphoma, and inhibiting PD-1 can potentially improve patients' prognoses (218). Immunological biomarkers are a critical part of cancer vaccine application. These biomarkers can utilize a potential targeted vaccine delivery via exosomes and avoid unspecific binding and immunosuppression via immune cells. Patients with glioblastoma multiform have different RNA content of serum exosomes compared with the healthy subject (219). Again, circulating exosomes collected from glioblastoma patients showed a higher EGFRvIII mRNA level, which can be considered a diagnostic tool readout (220). Along the same lines, the presence of EGFR on the exosome surface may be considered a possible marker for lung cancer (221). Proteoglycan glypican-1 (GP1) positive exosome have prevalent in the serum of pancreatic cancer patient (222). In breast cancer, exosome biomarkers like miR-130a target TGF- $\beta$ genes responsible for tumorigenesis, miR-328 related to CD44, reduced cell adhesion, and enhanced cell migration (223). Exosomemediated miR-10b suppresses the protein level of its target genes KLF4 and HOXD 10, which induce invasiveness in breast cancer cells (224). Circular exosomes and their miRNA content open a new horizon for cancer biomarkers to study both drug and vaccine targeting delivery. For example, miR-200b-5p can be used as a novel biomarker for lung cancer patients after surgical resection to analyze the risk of recurrence of small-cell lung tumors (225). Even two primary colorectal cancer and basal cell carcinoma oncogene PPP3CA and FZD, expression is primarily regulated by miR-100, miR-378a, and miR-629, are found in exosomes (226). Some miRNA plays a vital role in potential long-term pathways like miR-30a by inhibiting the epithelial/mesenchymal transition and targeting gene Snail, which is involved in metastasis and cell invasion in cancer progression (227). The above discussion suggests that profiling mRNA and miRNA of circulating exosomes can be used as a substitute biomarker compared to biopsy profiling for asymptomatic populations. In another exosome protein profiling study, it was found that higher expression of cell adhesion molecules CD171 and tetraspanin CD151 and TSPAN8 in lung cancer patients compared to that of non-cancer control patients (228). Therefore, the higher-level detection of CD151 signifies the aggression of lung cancer. Exosomal CD151 and TSPAN8 are correlated to initiate metastasis behavior by 
modulating EMC to associate molecules. CD171 related to EMT, prognosis, and metastasis are also observed in lung cancer patients (228). The Gng2 gene (one of the gamma subunits of a guanine nucleotide-binding protein) and Fox1 gene (role in regulating tissue and cellspecific gene transcription during development) are significantly upregulated in serum-derived exosome of pancreatic tumor-bearing mice compared with healthy control (229). Exosome plays an important role in cancer progression by promoting cell metastasis and intercellular communication. Exosome has also been studied for non-cancer diseases, including liver (230), lung (231), kidney (232), arteries (233), and CNS (234). Yang et al. has found miR-135a (repressed the expression and activity of BACE1) and miR-384 (regulates both amyloid precursor protein and $\beta$-site APP cleaving enzyme (BACE-1)) are upregulated, and miR-193b (regulator of amyloid precursor protein (APP) in the cerebrospinal fluid and the blood) are downregulated in serum exosome of Alzheimer's disease patients compared with controls (235). In the idiopathic pulmonary fibrosis study, it has been found that there is a negative correlation between the lungs' carbon monoxide/ alveolar volume diffusion capacity and the saliva-derived exosome containing miR-142-3p (236). miR-142-3p inhibits apoptosis and induced inflammation via downregulation of CoX-2 in bleomycin-induced pulmonary fibrosis model. Goetzl $e t$ al. found an altered level of LAMP-1, cathepsin D, and HSP70 in preclinical Alzheimer's diseases years before disease onset (237). Pusic et al. have demonstrated that interferon $\Upsilon$-stimulated rat bone marrow DC-derived exosome contains miRNA219 stimulate in vivo myelination and that can be used for multiple sclerosis diagnosis (238). ,Barutta and colleagues has showed that expression of miR-130, miR145 , miR-424, and miR-155 are significantly altered in diabetic nephropathy patients with type- 1 diabetic (239). miR-130 promotes cancer cell invasion and migration via AKT and FAK phosphorylation by activating PTEN (240). miR-145 serves as a tumor suppressor gene in various tumor models like ovarian, breast, and colorectal cancers (241). Interestingly, type-2 diabetes is associated with an increased risk of developing cancer of the colon, liver, breast, and bladder.

Exosomes secreted by the tumor cells carry different content and critical molecules than that of exosomes secreted by healthy tissue. Exosomes are abundantly releases from cancer cells and broadly distributed throughout the body via systemic circulation. The exosome maintains its stability and carries the disease fragments from one location to the other. Studies have shown that exosomes possess intrinsic advantages in predicting prognosis, metastasis, and therapeutic intervention on tumors (19). Despite numerous reports of significant exosome biomarkers associated with various diseases, unfortunately, studies reported by the individual groups match poorly. Different extraction, isolation, and purification methods and handling contribute to this mismatch. For a biomarker study, it is important to check the specificity and sensitivity of the design study to assure reproducibility and consistency.

\section{Role of Exosome in Stress Response}

In recent times application of exosomes in delivery, science has been getting more attention due to their ability to mediate intercellular communication, maintaining cellular and systematic homeostasis. More importantly, exosomes may have improved biosafety compared to polymer-based drug delivery approaches (156). Cellular stress contributes to various environmental stressors like osmotic stress, oxidative stress, hypoxia, infection, and ionic radiation (242). Exosome content and its role vary between the stress conditions and the native state. These stress conditions are resulted in due to DNA damage response or stress-induced protein synthesis (243). In one study, the authors demonstrate that exposure to cyanobacteria with UVA and UVB increases bacterial exosome released in the culture medium. Stress changes the number of exosomes released and alters the molecular composition of exosomes (244). For example, eukaryotic cells trigger exosomes expressing an HSP molecule on the surface due to environmental stress. Due to endoplasmic reticulum stress, BeWo cells carry pro-inflammatory cytokines, DAMPs, HSP70, Histone H3, and HMGB1 (245). In another study, authors exposed cultured endothelial cells with hypoxia, high glucose, and TNF-alpha induce stresses (246). After microarray, immunoblotting, qPCR, and quantitative proteomic analysis, the authors confirm alteration expression in several molecules and mRNAs (246). Even stress-induced exosomes can activate different signaling cascade and apoptosis pathways in healthy cells (246). A recent report, naive MCF-7 and TILA cells with heat-induced exosomes, resulting in apoptosis via DNA damage (247). Another feature of this stress exosomes is that it prolonged distant signaling among organs or tissues (248). For example, in chronic Epstein-Barr virus (EBV) infection, EVB related RNA was detected in circulating exosomes. Exosomes carry cellular waste outside of cells and maintain cellular homeostasis. Under inflammation or stress conditions, cells remove modified fragmented via released exosome (249). Also, exosomes do not release cargo in the blood without distant and neighboring cells (250). Therefore, blood is not infected due to disease 
cell-derived exosome. Exosomes also carry an anti-coagulant protein called platelet tissue factor, released at the site of the wound.

Another critical function of exosomes is antigen presentation via MHC-I and-II, alerting the immune system to the presence of infectious stress (251). Additionally, stress-induced exosomes also play a vital role in activating immune cell chemotaxis. A study reported in 2010 shows that oxidatively stressed exosomes from donor cells are capable of preconditioning and protecting oxidative stress via modifying mRNA delivery (252). Up-regulation of HSP proteins occurs when a cell is under stress conditions. Expression of HSP within exosomes can cause protein aggregation in the recipient cells (252). Therefore, exosomes sometimes act as a trojan horse to other cells through transferring harmful molecules- including prion protein, amyloid-beta deposition to neurons, injection of the toll-like receptors, and sensitization of the adaptive immune system. These properties of exosomes carrying stress molecules can be utilized as a liquid biopsy for cancer detection.

These local tissue damages and physiological stressors increase inflammatory proteins in the blood and tissue of the animal body. Our literature review suggests that stress-evoked cytokines and chemokines can both facilitate host survival and endanger our health. Recent studies confirm that exosomes play a vital role in reducing the content of immune inhibitory mRNA and immune stimulatory damage-associated molecular patterns (DAMPs) from systemic circulation (253). Thus, circulating exosomes play a fundamental role in immune homeostasis during stress conditions and vice versa, depending on cellular conditions.

\section{Role of Exosome in Tumor Microenvironment (TME) and Immune Crosstalk}

The tumor microenvironment is a very dynamic and complex adaptive system. The intra-cellular exosomes play a role in inducing angiogenesis, tumor growth metastasis, and stromal cell activation (254). Cellular stress in healthy cells can increase exosomes release but cause stress conditions in cancer cells, mainly due to pathological changes (254). Cancer cells bring changes to the neighboring environments like nutrient deficiency, remodeling of the extracellular matrix, and hypoxia. Such changes in the tumor environment trigger changes in exosome molecular cargo (255). One of the hallmarks of cancer cells is vasculature that enhances the transportation of oxygen and nutrients (256). Tumor growth induces hypoxia and triggers the release of pro-angiogenic and anti-angiogenic cytokines like vascular endothelial, fibroblast, pericytes, and endothelial growth factors-continuous remodeling results in leaky blood vessels poor structural organization (257). Cancer cells become non-responsive to radiation and chemotherapeutics, where exosome plays a major role in the defensive mechanism (256). Chemotherapeutics reflux from the exosome through exocytosis process. For example, pancreatic cell-derived exosomes carrying tetraspanin-8 promote vessel branching (258). Tetraspanin-8 also modulates the binding and uptake of cancer exosomes by endothelial cells (56). Prostate cancer exosomes contain insulin growth factor receptor-1, CSEC tyrosine kinase, and focal adhesion kinase FAK, previously reported as angiogenesis promoter (57). Nedawi et al. has reported the finding that lung cancer-derived exosomes deliver mutated endothelial growth factor receptor to pulmonary endothelial cells, activated EGF receptor, and signaling through AKT and MAP kinase pathways. This AKT and MAP kinase pathway activation is misleading to VEGF secretion and endothelial cell's response to tumor progression (58). The same research group later demonstrated that exosome treatment could inhibit the angiogenesis of endothelial cells (259). Therefore, cancer cell-derived exosomes could potentially provide effective anti-angiogenic treatment (259). Lucero et al. demonstrated that glioblastoma cell exosomes mediated delivery of angiogenic mRNA translated into protein within the recipient cells (260). Another recent study reported that colorectal exosomes deliver angiogenic mRNA to endothelial cells and enhance the proliferation, migration, and tube-like formation (261). The study confirms the exosome capability of delivering pro-/anti-angiogenic factors mRNA in endothelial cells.

The tumor microenvironment is very complex and consists of multiple cells (detail in Fig. 3). Cancerassociated fibroblasts (CAF) undergo differentiation to myofibroblast, facilitating tumor proliferation and CAF manipulation by cancer cell-derived exosomes (262). Cancer cell-derived exosomes can promote the acquisition of CAF and stromal cells. Cancer cellderived exosomes can also activate MAP kinase pathways via TGF- $\beta$ (263). Luga et al. have shown that CD81 positive exosomes from stromal cells activated multiple signaling pathways in the breast cancer cell. This signaling promotes cancer cell motility, metastasis, and tumor growth (264). Boelen et al. have that stromal cellderived exosomes transfer mRNA to breast cancer cells, resulting in the activation of RIG-1 antiviral signaling, resistant to both chemotherapy and radiotherapy (265). Therefore, this mechanism of cross-communication seems to aggravate cancer disease. Cancer cell progression also depends on extracellular matrix remodeling. 
Cancer-associated fibroblast secretes both proteins and glycoproteins that regulate ECM composition (266). Matrix metalloproteinase (MMPs) enzyme plays a critical role in maintaining the ECM structure, and the tumor-holding MMPs helps them to bind with ECM and facilitate remodeling (266). Several groups have reported that circulating exosomes from cancer cells invoke changes in a specific organ and prepare a niche for metastasis (267). Along the same line, multiple studies show that the exosomes hold the immune activation property as well.

However, some exosomes have shown the potential of suppressing $\mathrm{T}$ cell activation via $\mathrm{HSP}$ protein and mRNA (201). Cancer exosomes significantly induce the differentiation of DCs without its antigen presentation to the myeloid cell, which produces TGF- $\beta$ for $\mathrm{T}$ cell suppression (268). Further evidence is supported by tumor growth, causing the transition of monocyte to M2 macrophage phenotype (269). Cancer exosomes also partake in metastasis via organ tropism and involve the epithelium-to-mesenchymal transition of multiple cell types (269). There is also substantial evidence that exosomes can transfer various growth factors, fibroblast growth, and epidermal growth, and activate numerous signaling pathways in the recipient cells. Al Nedawi et $a l$. report exosomes can transfer oncogenic protein EGFR from cancer cells. Recipient cells, after receiving EGFR activates Map-kinase, AKT, and protein kinase B signaling pathways and induce morphological remodeling and accelerate cancer growth (259). This cellular transformation is downstream of EGFRvIII, increases the expression of anti-apoptotic protein BCL-xL. EGFR containing exosomes also triggers VEGF release and activates VEGFR2, and endothelium cells promote angiogenesis (259).

The immune system attacks tumor cells via NK cells, CD8 T cell, antibodies from B cells, macrophages, and neutrophils (270). But tumor cells develop a different invading mechanism to escape immune attack (271). Natural killer cells decrease their cytotoxicity via TGF- $\beta$ and NKG2DL and inhibit $\mathrm{T}$ cell activation and T cell's killing capacity via NK cell-derived exosomes (272). NK cells can promote the M2 phenotype over M1, which boosts immune escape and tumor growth. NKG2D ligand ULPB2 release ULPB3 containing exosomes and downregulate the NKG2D receptor by their metalloproteinase ADAM10 and 17 (273). Tumor exosomes containing Gelatin9 and LMP1 inhibit T-cells proliferation (274). Melanoma cell exosomes carry FasL, which kills/inhibit T-cells. Also, cancer exosomes provide CD39 and CD73, suppress T-cells via adenosine release, and monocytes differentiate into macrophages with the tumor-promoting ability (275). M1 macrophage produces IL-10 stimulates anti-tumor cytotoxic T-cells, and M2 macrophage release IL-12 and stimulate T-reg cells. Co-culture of CD45 positive leukocyte and GR1 expressing CD11B positive myeloid cells derived exosomes inhibits immune cells like T-cells, NK, macrophage, and DCs (276). Tumor cells expressing the upregulation of PDL1, TGF- $\beta$, and Arginase- 1 . When DCs are treated with tumor exosomes, they impair LPS mediated maturation of DCs. Again, tumor-derived exosomes (TEX) carrying HSP70 and HSP105 activates DCs and induces IL-6 releases via troll-like receptors 2 \& 4 (TLR3 \& TLR4) (277). Thus, tumor exosomes promote tumor metastasis via STAT3 dependent metalloproteinase-9 (278).

Circulating exosomes from tumor cells interfere with different treatments of cancers. Tumor exosomes carry tumor cell surface receptors to decoy tumor-targeting antibodies (279). For example, HER/HER2 overexpressing exosomes could counteract the effect of tumor therapy. Then exosomes bearing NKG2D ligand A \& B and ULBP1 \& 2 act as chemiflux against NK cells and impair NK cell function (280). TEX plays an important role in a different stage of the metastasis cascade and invasion via promoting angiogenesis, migration, EMT transition, induced drug resistance, and establishing a pre-metastatic niche $(31,281)$ (Illustrate in Fig. 3 a). Angiogenesis is a multi-step process, beginning with vascular endothelial growth factor VEGF/VEGF receptor activation to develop new vasculature for tumor growth and metastasis (282). TEX carry angiogenesis stimulatory factors like VEGF, tumor necrosis factor- $\alpha$ (TNF- $\alpha$ ), fibroblast growth factor (FGF), transforming growth factor- $\beta$ (TGF- $\beta$ ), and interleukin-8 (IL-8) (283). For example, human tumors, including pancreatic, glioblastoma, and nasopharyngeal carcinomas exosomes, induce angiogenesis both in vivo and in vitro (220). TEX also contains a high level of miR-221, syndecan-4, and glypican-1 that proliferates from endothelial cells and tubules via revascularization (284). When a tumor cell becomes more aggressive, it needs to migrate to a distant site. And process initially by developing a new metastatic niche by epithelial to mesenchymal transition (EMT) (285). TEX carry EMT element like EMTinducer miRNAs, TGF- $\beta$, $\beta$-catenin, IL- 6 , HIF $1 \alpha$, and caveolin-1 or vimentin, which induce EMT transition via ECM degradation and tumor endothelium cell behave more invasive (286). In the process, tumor cells lose E-cadherin and cell polarity and gain twist, snail, N-cadherin, and vimentin (287). Again hypoxia-induced TEX carries miR-301a-3p to enhance the transition of macrophage to M2 phenotype due to activation of PTEN/ PI3K pathway (288). These reports validate TEX plays a key role in EMT transition. Innate, acquired, and de 
novo drug resistance remains a major obstacle for most therapies to achieve therapeutic intervention against cancer. Innate drug resistance achieves via drug efflux pumps that include P-glycoprotein and multidrug resistance protein, overexpression of ABC transporter. In case of De Novo drug resistance transiently acquired by signaling cascade in tumor microenvironment by celladhesion mediated drug resistance (CAM-DR) or soluble factor-mediated drug resistance (SFM-DR) (289). Cancer cells employ like increased drug metabolism and detoxification, increased drug efflux, decreased apoptosis, and decreased drug influx. Cancer cells further defend against chemotherapeutic and radiation via poor drug penetration and epigenetic modification (290). Exosome contact of both stromal and breast cancer cells via paracrine and juxtacrine signaling, for example, further downregulate chemo- and radio-therapeutic insults, according to a study by Boelens et al (265) The local inflammatory microenvironment is one of the factors for the formation of a pre-metastatic niche (216). The local inflammatory microenvironment can induce tumor cells to produce tumor-derived secreted factors (TDSFs), such as transforming growth factor- $\beta$ (TGF- $\beta$ ), vascular endothelial growth factor (VEGF), interleukin (IL), and tumor necrosis factor-alpha (TNF$\alpha)$ (291). Tumor-derived exosome carries PD-1 incorporate with PD-L1, inhibiting the proliferation of $\mathrm{CD}^{+} \mathrm{T}$ cells. TEX also recruits tumor-associated neutrophils (TANs), tumor-associated macrophages (TAMs), and regulatory $\mathrm{T}$ (Treg) cells, which may inhibit antitumor immune responses (292). TEX also contains a substance that may inhibit immune cell function, NK cell dysfunction, block $\mathrm{T}$ cell activation, inhibit antigen-presenting cells, and enhance $\mathrm{T}$ cell apoptosis to block adaptive immune responses $(268,293)$. Another study reports that TEX carrying ARG1 and reactive oxygen species (ROS) in the pre-metastatic niche inhibits antitumor $\mathrm{T}$ cells and B-cells via TGF- $\beta \mathrm{R} 1 / \mathrm{TGF}-\beta \mathrm{R} 2$ signaling pathway (294). Further, cancer-induced regulatory B $\left(B_{\text {reg }}\right)$ cell exosomes mediate the immunosuppression and metastasis function of MDSCs by producing more ROS and NO to inhibit CD8 ${ }^{+} \mathrm{T}$ cells (295). The premetastasis niche matrix environment comprises fibroblast, extracellular matrix (ECM), and endothelial cells. Fibroblasts produce growth and inflammatory factors and matrix metalloproteinase (MMP) and fibronectin (FN) (296). So, TEX exchanges information between cells to promote pre-metastatic niches. Multiple studies report TEX can promote tumor angiogenesis, vascularization, drug resistance, and pre-metastatic niches. And TEX biomarkers have great potential in liquid diagnostic and able to track tumor progression (297). Exosome function potent to signaling between cancer and surrounding cells consists of the tumor microenvironment. Thus, exosomes derived from both stromal and tumor cells have implications in therapy resistances and all stages of cancer progression. Due to their intrinsic nature of cell-cell communication, exosomes play an important part in TME proliferation and TME therapy resistance.

\section{Role of Exosome in Infectious and Respiratory Diseases}

Infectious disease is the leading cause of death for children and a significant burden for the health care system. When a pathogen enters the host body, they face hostile environments. The pathogen has a sense of extracellular vesicle signals and communicates with other cells (298). Pathogens use exosomes differentiation, growth control, transmission, and virulence coordination (299). There are two subtypes of exosomes, and one is for the pathogen to the pathogen and the next pathogen to host intercommunication. According to the WHO, malaria is one of the most devastating parasitic diseases (300). In the human body, the parasite has a complex life cycle. Malaria parasites invade human cells like hepatocytes, red blood cells, bone marrow, midgut endothelium, and saliva glands (301). Cerebral malaria is the most common clinical cause and cause of death in infection (302). Scientists found high numbers of exosomes from patients isolated circulating exosomes from $P$. Falciparum and P. vivax Plasmodium infection (299). In the pioneer study, the authors have shown TNF induced endothelium cell injection in healthy control invade malaria-like damage in the lung and brain REF. In 2013, two separate reviews demonstrated that $P$. Falciparum derived exosomes induce gametocyte formation in the host, is an essential step for disease transmission $(303,304)$. Exosomes from malaria are actively endocytic by endothelium and monocytes. Eventually, malaria parasites change vascular properties, stimulate DNA-sensing pathways via microRNA, and promote virulence via malaria exosomes (304). In 2011, malaria-infected reticulocyte exosomes were used as vaccine applications (305). These exosomes contain HLA class I and parasite antigen, and immunization promotes an effector phenotype by increasing non-exhaustive memory T-cells (305). Another dangerous disease is Chagas disease caused by T. Cruzi. They gain access to the human body via insect bites, and the mucosa membrane carries it via exosomes. The parasite is multiplying into amastigotes in the cell cytosol. Then they again transform into trypomastigotes to reach blood circulation via breaking host cell membranes. The trypomastigotes surface is composed 
of glycoprotein and TC85, which can provoke the host immune response. The cellular response produces a set of immune cells and a humoral response in producing lytic antibodies, and both help control invading infection (306). Multiple studies confirm the role of exosomes in the pathogenesis of Chagas diseases (307).

Virus enveloped viruses are a class of exosomes, and these individual exosomes from cells are under the influence of viral genetics. The host cellular component is an envelope in exosomes, and the virus encodes an only specific protein and nucleic acid sequences. On the virion, the virus fuses its part into host cells (308). For example, the HIV trimmer consists of glycoprotein (GP) 120, surrounded by hydrophobic GP41. When HIV interacts with the target cell via receptor CD4 and CCR5, HIV drills into the host cell membrane with the help of GP41 (309), some viruses rely on host enzymatic genomic replication to transfer exosomes without actual virion required (310). Most virus exosomes carry viral components that can conceal viral presence from the immune system (274). In latent HIV infection, accessory protein negative regulatory factor (Nef) is released via exosomes, which conceal the presence of the latent infection. Even viral fragment carries via exosomes can manipulate host immune dynamics (310). Exosomes also have specific receptors that can internalize the viral component signifying exosomes as a vaccine for inducing antiviral immunity (308).

In one study of fungal exosomes, 200 proteins were identified in proteomic analysis (311). Fungal exosomes in the host body become biologically active during infection (312). In the case of bacteria, most bacteria exosomes are gram-negative. Bacterial exosomes have a variety of roles, including producing pathogenicity in the host. However, there are commercially available bacterial exosomes that can protect the host from inflammatory bowel disease (313). .The host immune system can detect bacterial exosomes via TLR; after the detection host, the immune system induces a proinflammatory reaction and recruit an innate immune system. However, bacterial exosomes has potential to damage cell membrane by destroying endothelium cell walls (313). After uptaken by cell, bacterial exosomes are detected by NADH 1 that facilitates activation of antimicrobial human beta defense NF- $\beta \beta$ (314). Thus, bacterial exosomes are recognized by the immune system, provide multiple advantages to the parent bacterium. Those advantages of addressing acquire nutrients, removing toxic, and degrading antibodies.

Role of exosomes in various lung diseases, like COPD, and IPF, has also been studied by utilizing the disease model. COPD and IPF are both age-related lung diseases and PDF can be characterized by measuring the presence of fibrotic cell and excess extracellular matrix (315). Bronchial epithelium cells and macrophages play a critical role in exosomes mediated communication in the lung (316). The alveolar macrophagederived exosomes can mediate cellular homeostasis in the airway and cellular differentiation via miR-223. Macrophage-derived exosomes can control inflammation communication with lung epithelium cells via releasing SOCS protein (317). Epithelium cell-derived exosomes involve modulating the innate immune system and maintaining the balance between epithelium and mesenchymal cells of the lung (317). Bourdonnay et al. showed (318) macrophage-derived exosomes carry SOCS-1 and SOCS-3 to epithelial cells to suppress the signal due to the activation of cytokines. Authors further show that exposure to smoking reduces both SOCS-1 \& 3 expressions, thus reducing inflammation response. Kasimer et al. demonstrated that bronchial epithelium cell-derived exosomes carry mucins and play a specific role in interacting with inhaled substances and exosomes. Also, authors have shown MUNC1, 4 \& 16 contribute endothelium-derived exosomes structure $(319,320)$. These findings conclude mucin acts as an innate defense for the lung. Exposure to stress conditions like smoking, infection, oxidative stress, and DNA damage can modify the structure of exosomes and enhance or diminish exosome release. Cigarette smoking causes airway remodeling: epithelium-damaged cells secrete exosomes. Endothelium cell-derived exosomes carrying miR-210, suppress autophagy resulting in airway remodeling (321). Exosomes from lung cells exposed to smoking taking cleaved CCN1 activate the secretion of MMP-1, promote changes in lung emphysema (321). Hence, exosomes exposed to smoking secrete miR-210 to promote myofibroblast differentiation explaining bacterially derived exosomes in COPD. Another study demonstrates pulmonary inflammation of neutrophils can induce by repeated inhalation of bacterially derived exosomes (322). Recently, Kim $e t$ $a l$. have shown distinctive bacterial-derived exosomes profile of non-smoker, healthy smokers, and COPD patients. Bacterial exosomes can activate polymorphonuclear leukocytes, such as neutrophils, which can bind ECM via MAC-1 protein. This process degrades the matrix and leads to right ventricle hypertrophy and emphysema in the mice model (323). Idiopathic pulmonary fibrosis (IPF), another deadly lung disease, is also contributed by exosomes. Ochiya group found mitochondria damage of epithelium cells treatment with exosomes derived from lung fibroblast cells of IPF patients (324). They also have shown DNA damage and accelerated epithelium cell senescence in lung fibroblasts (324). Another study by Martin-Medina et al. 
demonstrated bronchial lavage fluid exosomes contain WNT5A, induce proliferation of lung fibroblasts, and contribute to IPF (325). There are multiple studies of exosome application for IPF treatment. For example, bone marrow-derived exosomes inhibit BCL-2 protein and induce reverse fibrosis in IPF (326). Mesenchymal stem cell-derived (MSC) exosome has been considered novel therapeutic applications against multiple diseases, including fibrosis. Shentu et al. showed injection of human MSC exosomes in the IPF mouse model for therapeutic efficiency and showed Th-1 dependent uptake of MSC-derived exosome from blocking myofibroblast differentiation $(327,328)$. The above discussions validate the exosome's role in infectious and respiratory diseases and a solid platform for vaccine research.

This section has summarized the overall research update on exosome application in cancer, infectious and respiratory diseases. Exosomes carry myriad innate cells bioactive molecules like proteins, lipids, and RNAs (mRNA, microRNA, IncRNA) and deliver them to neighboring and distant cells. Thus exosome research is getting more attention for cancer immunotherapy. Most exosomes relate to infectious biology, either spread or limit infection based on targeting cells and types of pathogens. Exosomes and exosomal RNAs in diseases have promise in biomarker study enabling noninvasive diagnosis, better therapeutic targeting efficiency in treatment, and inducing an immune response in the disease model. Therefore, the exosome is an appropriate candidate for vaccine development and delivery in preclinical models.

\section{LABORATORY RESEARCH AND CLINICAL TRIAL UPDATE ON EXOSOMAL VACCINE PLATFORM}

\section{Natural Functions of Exosomes Modulating Immunity during Infection and Disease}

Extracellular vesicles can classify into three groups, exosomes (30-120 $\mathrm{nm}$ diameter), microvesicles $(100-1000 \mathrm{~nm})$, and apoptotic bodies $(200-500 \mathrm{~nm})$ (329). Exosome exocytosis and secretion depend on lipids or membrane trafficking molecules like Rab11, Rab27, Rab35, etc. $(330,331)$ Both in vivo and in vitro data confirms the exosome can facilitate internalization and promote cellular communication to all cells. There are multiple protein markers specific to cellular origin identified by numerous investigators. Exosomes also carry proteins, lipids, small non-coding, micro regulatory RNA (miRNA) molecules, and more abundant functional messenger RNAs (mRNA) (23). Exosomes are abundant, maintain a longer half-life, are stable, and capable of short or long-distance communication, and these features make them a suitable candidate for therapeutic application. The exosome is the viable delivery system for macro, micro molecules, and genetic delivery (DNA, mRNA, miRNA) in vivo and in vitro $(29,332)$. As an immunotherapeutic agent, exosomes derived from B cells and DCs can load with proteins (antigens) or peptides, demonstrating the ability to induce systematic antigen-specific B- and T cells response (333, 334). Exosomes from DCs also promise to initiate an immune response against tumor cells more precisely and accurately compared to cell therapy and other non-cell-based therapy (334). Specifically, mature and activated DC-derived exosomes carry MHC-I and MHCII molecules and co-stimulatory molecules like CD40, CD80, CD86, active cytotoxic T- and natural killer (NK) cells in vitro and in vivo via potent antigen-specific $\mathrm{T}$ and $\mathrm{B}$ cell responses $(170,335)$. And this stimulation required direct interaction of exosome's MHC-I and MHC-II and T cell receptors with $\mathrm{CD}^{+}$or $\mathrm{CD}^{+}$on T cells, respectively (336). Furthermore, DC-derived exosomes can activate innate and adaptive immune responses due to tumor cells inducing antigen-specific responses to overcome tumor-induced immunosuppression $(337,338)$. Another study also reports exosomes derived from mature DCs to induce a Th1 polarized by producing and secretion of IFN- $\gamma$ and cytotoxic $\mathrm{T}$ lymphocyte proliferation responsible for the antigenspecific killing tumors in vivo immune response (339). Two-phase I clinical trials of DCs derived exosome therapy in melanoma and non-small cell lung cancer patients have been completed with no toxicity issue and better efficiency $(339,340)$. In both studies, patients with melanoma-associated antigen (MAGE) expressing late-stage/metastatic melanoma or non-small cell lung cancer (stage IIIb or IV) were given DC-derived exosomes loaded with MAGE MHC class I and class II-restricted peptides (339). New immunomodulatory drugs may reverse the tumor metastasis in advanced cancer patients; strategies to tolerate cancer inhibition are essential for cancer vaccine development, which can apply to a wide range of cancer patients. A previous study showed doxorubicin-treated cancer cells release HSP90 and HMGB1, act as TLR agonists in innate immune cells, and potentiate antitumor immunity (341, 342). Kitai et al. demonstrated that excess TPT inhibits innate immune activation because it promotes excessive cell death and produces insufficient immunostimulatory DNA or induces topoisomerase I-mediated nucleosome remodeling. The authors show DNA containing exosomes from E0771 cells delivered to the cytoplasm of GM-DCs to activate a STING-dependent 
pathway to optimize antitumor immunity. The authors showed TPT activation and suppression could be controlled against antitumor immunity (343). Chemotherapeutic remains a primary treatment against anti-tumor via various mechanisms. It has a cytotoxic effect like pro-inflammatory cytokine secretion, T-cell activation, and myeloid cell activation and recruitment (344). Immunogenic reaction via cytotoxic agents released by tumor cells like protein B1 and DAMPs (345). Another issue is self-DNA, the critical cause of inflammatory and autoimmune diseases (346). Self-DNA via cytosol of DCs activates the interferon gene-dependent cytokine production stimulator by cytosolic DNA sensor cGAS (347). And another side effect of chemotherapeutic is a gastrointestinal syndrome. Authors in this study demonstrate that chemotherapeutics like irinotecan (CPT-11) and fluorouracil (5FU) can induce intestinal inflammation through dsDNA in HCT-116 exosomes by promoting IL-1 $\beta$ and IL-18 maturation in an absent in melanoma 2 (AIM2)-dependent manner inflammasome activation (348). This study also visualizes the AIM2 targeting vaccine platform due to chemotherapeutic induce inflammation against the anti-tumor effect. Infectious disease antigens are circulating in blood circulation and can capture by antigen-presenting cells (APCs). Vaccine delivers the inactive or natural form of proper antigen adjuvant, typically eliciting a potent immune response. In cancer research, field identification of tumor-associated antigens (TAA) in human cancers triggers a platform for cancer vaccine (349, 350). Some TAA targeting proteins are CEA, HER2, p53, MUC1, RAS (351). But generally, these TAA proteins are immunosuppressive environments and poorly antigenic. On top of it, most TAA is cell-specific, and most vaccines are not cell targeting (352). In the case of the cancer vaccine, it is a mechanism mainly on a state of TAA immune resistance is established. It has also been reported exosomes transfer intercellular antigen to APCs and induce immunogenicity (353). Hartman et al. suggested creating recombinant adenoviral vectors expressing into the extracellular domain (ECD) of human epidermal growth factor receptor 2 (HER2) or carcinoembryonic antigen (CEA) that linked to the C1C2 domain of lactadherin in addition to native unlinked ECD versions of CEA and HER2. Authors conclude higher protein expression in exosome fraction in the transgenic murine model due to surface modification of adenovirus expressing C1C2 modified CEA/ECD, and HER2/ECD. This study validate low immunogenicity of soluble TAAs in cancer patients and opens the platform for cancer vaccine via cancer biomarker analysis and improving anti-tumor immune response (354). Next, hepatocellular carcinoma (HCC) one of the most lethal malignancies worldwide due to high mortality, inadequate response to treatment, and aggressive nature. Immunotherapy based on DCs is promising, but it costly, and isolation and preparation are tedious. Also, DC has a very low half-life. Exosome derived from DC carrying protein like MHC class-I and class-II and other co-stimulatory molecules can utilize as alternate for DCs for cancer immunotherapeutic (334). Previously, Zitvogel et al. demonstrated that tumor antigenic peptide-pulsed DCs derived exosomes induce strong immune suppression and elicit immune response in mastocytoma and mammary carcinoma mice (337). Recent clinical study of DC derived exosome, conducted on advance melanoma patients, shows promising result (339). Lu et al. also shows in their paper, exosomes from HCC antigen-modified DCs could be used as cell-free vaccines for HCC and opens window for HCC immunotherapy (355). Another study by Geis-Asteggiante et al. demonstrate Myeloid-derived suppressor cells (MDSC) derived exosomes can induce immune suppression function via differential content of protein, lipids, mRNA, and miRNA (356). Inflammation caused by MDSC is associated by its abundance and suppression activity enhance tumor progression (357). Authors identified mechanism of MDSC cells for immune suppression via analyzing both MDSC and MDSC derived exosomes. This comprehensive study identified multiple miRNAs and mRNAs whose known or predicted function is consistent with their involvement in MDSC-mediated immune suppression.

Parasite or virus-infected cells or even the parasite itself can release exosomes to activate $\mathrm{T}$ cells via antigen presentation. In contrast, exosomes derived from microbial molecules that carry HIV Nef or leishmania GP63 can inhibit T cells activation or initiate apoptosis of immune effector cells like helper T-cell or effector B cells (21). Interestingly, macrophages infected by bacteria carry antigens that activate both $\mathrm{CD} 8^{+}$and $\mathrm{CD} 4^{+}$ $\mathrm{T}$ cells via cross-priming. In comparison, some infected cells release exosomes carrying PAMS, DAMS, limiting macrophages to respond to INF- $Y$ stimulation or stimulating macrophages to produce TNF- $\alpha$ (205). Roier $e t$ $a l$. show how Gram-negative bacteria are forming outer membrane vesicles (OMV) emerging as OMV based vaccine vesicles. Heterologous $\mathrm{H}$. influenza strains derived OMVs with thorough characterization and size distribution, the quantity of vesicle production among strains Rd. KW20, NTHi 2019-R strain, and Hib strain Eagan. The biomarker screening study of $H$. influenza OMV identifies 13 ATP-binding cassettes (ABC) transporters proteins and eight lipoproteins as potential vaccine targeting sites against Haemophilus influenzae infections. In contrast, important virulence factors like vaccine 
candidates OMP 26 and protein $\mathrm{D}$ and serine protease $\mathrm{HtrA}$ on exosome derived from $\mathrm{H}$. influenzas can utilize as a vaccine delivery platform (358). Pertussis is a respiratory infectious disease that has prevailed for a decade in the world (359). Many types of vaccines are available, like multi-antigen whole-cell pertussis $(\mathrm{wP})$ vaccines, acellular pertussis $(\mathrm{aP})$ vaccines. Zurita $e t$ al. has shown in their paper using pertussis outer membrane vesicle or exosomes containing multiple vaccines against lung infection with a circulating pertactin (PRN)-deficient isolate in mice. The traditional vaccine failed against these circulating clinical isolates due to the deficiency of PRN. Authors demonstrate long-lasting immunity effectively prevents infection against Bordetella pertussis. Authors also showed that two doses of OMV vaccine CD4 T cells with a tissue-resident memory (TRM) cell phenotype $\left(\mathrm{CD} 44^{+} \mathrm{CD} 62 \mathrm{~L}^{\text {low }} \mathrm{CD} 69^{+}\right.$and $\left.\mathrm{CD} 103^{+}\right)$accumulated in the lungs of mice 14 days after immunization (360). Exosomes are getting much more attention recently due to their intrinsic properties as a drug carrier and immune-modulatory mechanism. Anticoli et al. use engineer the Human Papilloma Virus (HPV) E7 protein with exosome. E7 protein elicited both effective and strong antigen-specific cytotoxic T lymphocyte (CTL) immunity (361). Author's injection of a DNA vector expressing HPV-E7 fused at the C-terminus of an exosome-anchoring protein name $\mathrm{Nef}^{\text {mut }}$ (Nef is the name of the protein, and when it is mutated or engineered, it is written as $\mathrm{Nef}^{\mathrm{mut}}$ ) (362). Authors also run immunogenicity studies in a broad array of viral products, including ebolavirus VP24, VP40, and NP, influenza virus NP, Crimean-Congo hemorrhagic fever NP, west nile virus NS3, and hepatitis C virus NS3. All antigen appears stable and detectable antigen-specific $\mathrm{CD}^{+}$ T cell treatment with exosome carrying $\mathrm{Nef}^{\text {mut }}$ tether with DNA vector HPV-E7. Authors propose this versatile CTL vaccine platform exhibit exosome carrying DNA vector-induced antigen-specific $\mathrm{CD} 8^{+} \mathrm{T}$ cell response as vaccine application (363). This cytotoxic response is enough to kill antigen-expressing/peptide-loaded syngeneic cells. Genetically engineered allogeneic or autologous $\mathrm{T}$ cells expressing $\mathrm{T}$ cell receptors (TCRs) or chimeric antigen receptors (CARs) as cellular immunotherapy is promising as a new treatment method for multiple range of cancers (364). Despite T cell therapy efficiency, $\mathrm{T}$ cell therapies show unique toxicities like CAR-T-related encephalopathy syndrome (CRES) and cytokine release syndrome (CRS). Multiple studies also describe the benefit of human T cell-derived exosomes targeting cytotoxic T lymphocytes (CTL) in cancer immunotherapy application (367). CTL-cell-derived exosomes contain surface membrane molecules (CD3, CD8, and the TCRs) trigger tumor cell death by the interaction between proper antigen/MHC combination and the TCR. The author's data validate CAR-T cell-derived exosomes can be used as cancer-targeting agents and improve therapeutic efficacy and potential cancer vaccine platform (368). Li et al. also demonstrate that exosomes derived from Toxoplasma gondii after co-incubation can modulate the immune response in macrophage RAW264.7 cells. After T. Gondii exosome treatment, authors using enzyme-linked immunosorbent assay (ELISA) found higher production of IL-12, TNF- $\alpha$, and IFN- $\gamma$ and lower IL-10 in macrophage cells. Authors conclude T. Gondii exosome modulate macrophage activation from M1 to M2 in vitro and triggers cellular and humoral immune responses. This immune response can partially protect against acute parasite infection in mice models and stipulate exosomes may act as a potential vaccine candidate against toxoplasmosis (369). In another study, the authors have shown the donor antigen-specific regulatory $\mathrm{T}$ cells $\left(\mathrm{T}_{\text {reg }}\right.$ cells $)$ inhibit the immune inflammation in the allograft heart (369). We found exosome research applications on organ transplantation. One of the effective treatments for end-stage heart failure patients is allograft transplantation (370). An important drawback is an allographic rejection, and it is vital for the long-term survival of grafts (371). Immuno-suppressant may reduce the incidence of rejection, but long-term use can have adverse side effects like renal failure, malignancy, and infections (372). We also know that chronic cardiac allograft vasculopathy results in allographic failure via ischemia (373). This rejection is also associated with the $\mathrm{CD} 4^{+}$ $\mathrm{T}$ cell-mediated delayed-type hypersensitivity (DTH) (374). Drugs or molecules can induce immune tolerance via de novo differentiation of naive $\mathrm{CD} 4^{+} \mathrm{T}$ cells into Treg cells by blocking the mTOR-dependent inhibition of foxp3 transcription (375). Integrin $\alpha v \beta 6$ can convert the latent transforming growth factor (TGF)- $\beta$ to promote Treg cells (376). The authors show the delivery of cardiovascular exosome carrying integrin $\alpha v \beta 6$ promotes the generation of the donor antigenspecific immune tolerance. Another study also shows DCs derived exosomes promote heart allograft survival $(365,366)$. The authors finally validate donor-derived peripheral exosomes carried MMP1a promoted the allograft heart survival via inducing donor antigenspecific Treg to attenuate the $\mathrm{T}$ helper $(\mathrm{Th}) 2$ pattern inflammation $(372,373)$. With recent incidence we also found being immunosuppressant makes someone vulnerable to infectious disease like SARs-CoV-2 and cancer progression. In Fang Huang et al. paper on leukemia study, authors have shown TGF- $\beta 1$ level in leukemia cell-derived exosomes (LEX) downregulated due to lentiviral shRNA silencing of TGF- $\beta 1$ in parental leukemia 
cells. Then authors incubate LEX ${ }_{\text {TGF- } \beta 1 \text { si }}$ with DC cells and promote the upregulation of surface expression of costimulatory factors and MHC class II molecules and inducing secretion of IL-12p70 and TNF- $\alpha$. Further immunization with LEX TGF- $\beta 1$ si compare with naïve LEX, stimulated stronger specific cytotoxic lymphocyte (CTL) response and nature killer (NK) cell cytotoxicity, and facilitated $\mathrm{CD} 4^{+} \mathrm{T}$ cell proliferation and $\mathrm{Th} 1$ cytokine secretion. Authors successfully induce antitumor immunity by downregulating exosomal TGF- $\beta$ expression. This leukemia immunotherapy holds potential exosome vaccine platforms in future. This exosome research field is very dynamic and changing drastically with demands. We have summarized current development of this exosome field in vaccine research and delivery. Exosome will increase efficiency of vaccine against multiple diseases and is a versatile platform to bring more vaccines for human race.

\section{Clinical Updates}

In clinical trials, only four vaccine studies have been conducted using exosomes, and these are in different clinical phases. These four trials are summarized in Table I. The above discussion focuses on exosomes as promising vaccine platforms for diseases like cancer, immune disorders, cardiac and diabetes, etc. Table I The first clinical trial was based on DC cell-derived exosome vaccine development to treat NSCL cancer. It is in phase 2 and holds promising data to start clinical trial phase 3 and vaccine production. The phase 2 study is complete and has data on the server. The study consisted of 41 participants (18 to 70 years) and maintenance immunotherapy in 41 advanced unresectable NSCLC patients responding or stabilized after induction chemotherapy with DOX-based treatment to improve PFS rate at four months. The study is based on aerosol inhalation of mesenchymal stem cells exosome. Authors have evaluated tumor antigen-loaded DCderived exosomes on patients with unresponsive chemotherapeutic patients with NSC lung cancer. Second, in the list, the clinical trial is in phase 1 to assess the safety of MSC-derived exosomes in aerosol inhalation form. The clinical trial was conducted on 27 healthy volunteers and concluded by May 31, 2020. The results found from this study can be used to explore the safety and efficiency of MSC-exosomes aerosol inhalation for.

severe lung diseases (acute respiratory distress syndrome (ARDS), chronic obstructive pulmonary disease (COPD), and including severe lung infection, etc.). Scientists found significantly reduced pathological impairment and lung inflammation from different types of lung injury. Additionally, scientists found therapeutic

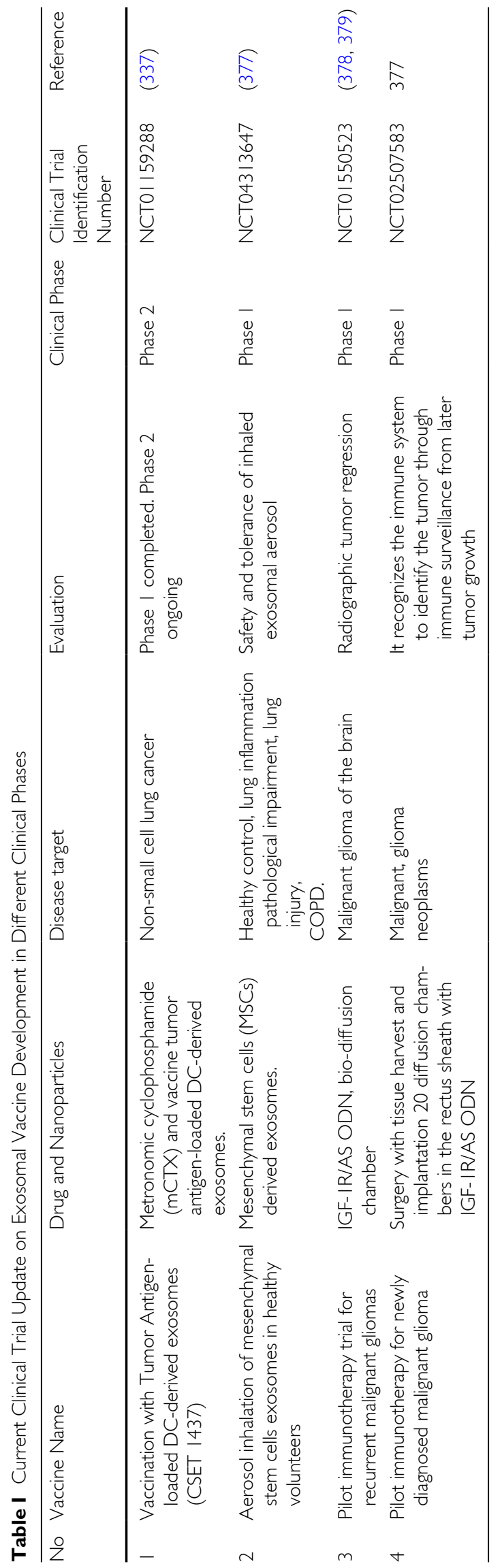


outcomes, bacterial killing, and macrophage phagocytosis. Phase 1 study has been completed by 4 th August 2021 and the result is available publicly in online. Number 3 trial based on pilot clinical trial of immunotherapy for malignant gliomas. This phase 1 study is recruiting and is complete; the investigation is ongoing. The study targets malignant gliomas of the brain via exosome-carrying tumor antigens. Along with antisense molecules, exosomes work together to activate the immune system against the tumor (380). This combination product, therefore, acts as a slow-release antigen depot. Exosomes with antisense will initiate our immune response and activating immune system T cells that attack and eliminate the tumor (381). By training our immune system, the patient will have an immune memory of tumor antigen and protect them in the future from other tumors that carry the same antigen (382). This approach can also be potentially used for vaccine delivery for anti-tumor immunogenicity and adaptive immune system memory to prevent tumor progression. Based on the previous one, the last study also found on antisense 102: Pilot immunotherapy for newly diagnosed malignant glioma. This study is phase 1 and has a total of 32 participants. This study is also targeting malignant glioma and Neoplasms. The delivery of exosomes with antisense molecules together will activate the immune system against the tumor. We have found only four clinical trials related to exosome vaccine application, but this number will go beyond a hundred if we consider exosome cancer immunotherapy.

(https:/ / www.clinicaltrials.gov/ct2/results?recrs $=\&$. cond $=$ Cancer\&term $=$ exosome $+\&$ cntry $=\&$ state $=\&$ city $=\&$ dist=). These data validate how exosomes could be a gamechanger for vaccination and immunotherapy. Recently exosome-based product has materialized to initiate biomedical start-up, and some of the product is being evaluated through clinical trials. For instance, Lonza pharma, and Organicell Regenerative Medicine are working on exosome-based therapies. These products are in the early pre-clinical or clinical stage and already in the GMP process for their exosome therapy product from mid-2020 (383). Takara has a high purity exosome isolation kit for RNA purification for RT-qPCR and NGS analysis. Our literature review gives us a better picture of exosome capability and the future of precision or personalized medicine and vaccine application. We hope exosomes will help scientists envelop the limitation of immunotherapy.

\section{Clinical Challenges of Exosome Translational Application}

Similar to other biomedical research, exosome-based applications also suffer significantly from being translating bench to bedside. The most difficult aspects of exosome research are reproducibility, translation and scalling up from in vitro to in vivo while maintaining the consistency.

Exosomes generated by cells and collected from their supernatants were used in the majority of the early exosome research (384). Multiple conditions associated with exosome production must be optimized for validation and reproducibility. Exosomes released from tumor cells are responsible for immune suppression function (385). Exosomes produced by cancer cells that contain tumor-associated antigens and are discharged into body fluids signal the presence of a tumor. Using this property, exosomes are analysed for pancreatic cancer cell proteomes and the finding of enrichment in GPC1 proteoglycan in both pancreatic cancer cells and exosomes derived by them (glypican 1) (222). The presence of GPC1+ exosomes (crExos) in patient serum can be measured using the fluorescence-activated cell sorting (FACS) technology. It was shown that using GPC1+ exosomes can facilitate for the early diagnosis of pancreatic cancer and differentiating patients at different phases of the disease's progression (222). The ability to modulate lymphocyte activities depends on the disease activity of HNC patients, according to an investigation of exosomes found in the plasma of patients with head and neck cancer (HNC) (293). However, little is known about the reproducibility, efficiency, and reliability of the protocols routinely used to quantify exosomes in the human serum. If the generalized and ptimized protocol can be introduced and applied, the reproducibility issue likely be overcomed.

Exosome isolation and characterization techniques are evolving and adaptive. Different scientific groups establish a protocol to isolate and preserve exosomes. However, the mass production of exosomes is challenging in preclinical stage with non-human primates. Therefore, exosomes scale up with cGMP guidelines still at the early phase. However, various studies reported on the pathways of exosome biogenesis to manipulate some genes to increase exosomes production $(385,386)$. Generally, two major strategies are employed to increase the production of exosomes. First, oogenesis pathways that are genetically manipulated to overexpress activator genes that play a role in exosome biogenesis and downregulate the genes involved in exosome recycling pathways (387). Second, adjustment of the cell culture medium, treatment with specific therapeutics, and limiting certain physiological conditions that can force the cell to produce more exosomes (388). The potential for adjustments in cellular phenotype, during scaleup and equipment change, must be considered. As 
the dynamics of exosome biogenesis are only at the beginning, alterations in any factors might alter the exosomes' production, composition, surface marker, or function. As mentioned, beyond cell-mass expansion requirements, it is essential to control pre-identified production environmental parameters such that the cell's phenotype, culture $\mathrm{pH}, \mathrm{CO}_{2}$ percentage, and therefore secreted exosome characteristics $(389,390)$.

Exosome proteomics has unquestionably made significant development in recent years. The advancement of exosome isolation methods was a key element in this phenomenon, but the advancement of improved instrumentation for proteome analysis, as well as its increased sensitivity allowed for a significant improvement in the exosome research. Despite significant advancement over the last decade, there are still a lot of unsolved gaps to be addressed. There are still no universal exosome markers, for example, that allow for precise identification of these vesicles and differentiation from other EVs. Furthermore, standard methods for tracking and characterizing exosome in vitro and in vivo studies are still unavailable. However, the subject of exosome study is still in its infancy due to the vast technical disparities between present methods for isolation and characterization. These technical obstacles must be solved to be able to use exosomes for diagnostic or prognostic monitoring of cancer and infectious disorders and to build innovative exosome-based personalized therapeutics. The International Society for Extracellular Vesicles is a worldwide society of driving extracellular vesicles, exosomes, and microvesicle analysts. With more than 2,000 all out individuals, ISEV's main goal is to progress extracellular vesicle research internationally.

With substantial efforts in exosome translation, it is crucial to understand the progress made and the persisting challenges in clinical translation. Although exosome analysis methods have tremendously evolved, the exact mechanisms of biogenesis are still unknown. Conversely, improvements in the isolation methods and purifications are needed to study the cargo contents, markers, and functions, which would shed light on the biogenesis mechanism and disease condition in return. Once such drawbacks are overcomed, new biomarkers can be identified for characterization, exosome can be used in diagnostic and drug delivery applications. Moreover, with more research on exosome biogenesis and functions, there would be significant opportunities to manipulate their composition, properties, biogenesis mechanism, and cell interactions to advance their clinical applications further. The potential use of exosomes as a diagnostic, detection and therapeutic applications are demonstrated in our earlier review (156). In conclusion, developing efficient, reproducible, scaleup, and reliable isolation methods is urgent to further advance in this field. To fully utilize the potentials of primary research, clinical data and emerging new technologies need to be integrated, setting the foundations for clinical translation, therapeutic applications of exosome.

\section{CONCLUSION AND FUTURE REMARK}

Pandemics like SARS-CoV-2, HIV, malaria, and Ebola have raised global health awareness and directed us to prepare for future outbreaks. Cancer itself is a life-long threat to the human population. Vaccine development and understanding the pathogens of these emerging diseases and cancer will be critical to saving us in the future. New vaccine platforms such as DNA, mRNA, and live vector technologies overcome some of the limitations of traditional vaccines and will allow faster vaccine production. Each vaccine platform has both advantages and disadvantages. It is unlikely that a single technology will suffice to save humanity from all cancers and infectious diseases. We need to rethink how to make the currently available vaccines more effective-one of the emerging platforms of targeted vaccine delivery involves exosomes. Understanding the role of the exosome in immune responses to many deadly diseases and its pathogenesis will be a pivotal challenge to utilize exosomes for vaccine development. Exosome, as a vaccine delivery vehicle, emerges as a novel platform for cancers and infectious diseases. Cancer immunotherapies, including CAR-T or ICI, have transformed the thinking capability of scientists, and exosomes could potentially play a critical role in cancer immunotherapy development. Some of the vaccines are not efficient enough due to their lack of target specificity. Over the years, nanoparticles-based platforms have been investigated in vaccine delivery as a non-viral vector-based viral delivery vehicle. Out of many nanoparticles, exosomes hold unique preferences due to their intrinsic cellcell communication and interaction with the human immune system in most pathological conditions. This review focuses on the role of exosomes in cancer immunotherapy, vaccine application for infectious and respiratory diseases. How the immune system is modified and adapted during new emerging disease conditions is still unclear, but it has been found that exosome interacts with our immune system. We believe that merging with new technologies like DNA, live vector, and mRNA delivered using an exosome-based vehicle can open a new window for vaccine research and development. We envision the personalized vaccine for specific diseases 
will be available sooner rather than the letter to accelerate immunization with enhanced potency. More costeffective vaccines will facilitate distribution to the large population of developing countries who urgently need protection from infectious diseases and cancer.

\section{ACKNOWLEDGMENTS AND DISCLOSURES}

Research reported in this publication was supported by the National Institute On Minority Health And Health Disparities of the National Institutes of Health under Award No. U54MD007592. The content is solely the responsibility of the authors and does not necessarily represent the official views of the National Institutes of Health. We also acknowledge funding by Cancer Prevention Research Institute of Texas (CPRIT) through Texas Regional Excellence in Cancer Award (TREC) under Award No. PR210153. The authors report no conflict of interest.

\section{REFERENCES}

1. Francis MJ. Recent advances in vaccine technologies. Vet Clin North Am Small Anim Pract. 2018;48(2):231-41. https://doi.org/10.1016/j.cvsm.2017.10.002.

2. Coelingh K, Olajide IR, MacDonald P, Yogev R. Efficacy and effectiveness of live attenuated influenza vaccine in schoolage children. Expert Rev Vaccines. 2015;14(10):1331-46. https://doi.org/10.1586/14760584.2015.1078732.

3. Barrett ADT. Yellow fever live attenuated vaccine: a very successful live attenuated vaccine but still we have problems controlling the disease. Vaccine. 2017;35(44):5951-5. https://doi.org/10.1016/j.vaccine.2017.03.032.

4. Booth FW, Roberts CK, Thyfault JP, Ruegsegger GN, Toedebusch RG. Role of inactivity in chronic diseases: evolutionary insight and pathophysiological mechanisms. Physiol Rev. 2017;97(4):1351-402. https://doi.org/10.1152/physr ev.00019.2016.

5. de Roux A, Schmöele-Thoma B, Siber GR, et al. Comparison of pneumococcal conjugate polysaccharide and free polysaccharide vaccines in elderly adults: conjugate vaccine elicits improved antibacterial immune responses and immunological memory. Clin Infect Dis. 2008;46(7):1015-23. https://doi.org/10.1086/529142.

6. Tripathi NK, Shrivastava A. Recent developments in recombinant protein-based dengue vaccines. Front Immunol. 2018;9:1919. https://doi.org/10.3389/fimmu.2018.01919.

7. McArthur DB. Emerging infectious diseases. Nurs Clin North Am. 2019;54(2):297-311. https://doi.org/10.1016/j. cnur.2019.02.006.

8. Fortune Business Insight. The Global Vaccines Market Size Is Projected to Reach USD 104.87 Billion by 2027, Exhibiting a CAGR of $10.7 \%$ during the Forecast Period [20202027]... Read More at:- https://www.fortunebusinessinsig hts.com/Industry-Reports/Vaccines-Market-101769.; 2020. https://www.fortunebusinessinsights.com/industry-repor ts/vaccines-market-101769.

9. Ten great public health achievements-United States, 19001999. MMWR Morb Mortal Wkly Rep 1999;48(12):241-243.

10. Hajj Hussein I, Chams N, Chams S, et al. Vaccines through centuries: major cornerstones of Global Health. Front public Heal. 2015;3:269. https://doi.org/10.3389/fpubh.2015. 00269.

11. Andre F, Booy R, Bock H, et al. Vaccination greatly reduces disease, disability, death and inequity worldwide. Bull World
Health Organ. 2008;86:140-6. https://doi.org/10.2471/ BLT.07.040089.

12. Hardt K, Bonanni P, King S, et al. Vaccine strategies: optimising outcomes. Vaccine. 2016;34(52):6691-9. https:// doi.org/10.1016/j.vaccine.2016.10.078.

13. Shrivastava SR, Shrivastava PS, Ramasamy J. WHO and UNICEF: updates on immunization coverage and how can we improve upon? J Res Med Sci. 2015;20(12):1216-7. https://doi.org/10.4103/1735-1995.172992.

14. Utazi CE, Thorley J, Alegana VA, et al. Mapping vaccination coverage to explore the effects of delivery mechanisms and inform vaccination strategies. Nat Commun. 2019;10(1):1633. https://doi.org/10.1038/ s41467-019-09611-1.

15. Ahn D-G, Shin H-J, Kim M-H, et al. Current status of epidemiology, diagnosis, therapeutics, and vaccines for novel coronavirus disease 2019 (COVID-19). J Microbiol Biotechnol. 2020;30(3):313-24. https://doi.org/10.4014/jmb.2003. 03011.

16. Yu X, Odenthal M, Fries JWU. Exosomes as miRNA carriers: formation-function-future. Int J Mol Sci. 2016;17(12). https://doi.org/10.3390/ijms17122028

17. Vojtech L, Woo S, Hughes S, et al. Exosomes in human semen carry a distinctive repertoire of small non-coding RNAs with potential regulatory functions. Nucleic Acids Res. 2014;42(11):7290-304. https://doi.org/10.1093/nar/ gku347.

18. Kalamvoki M, Du T, Roizman B. Cells infected with herpes simplex virus 1 export to uninfected cells exosomes containing STING, viral mRNAs, and microRNAs. Proc Natl Acad Sci. 2014;111(46):E4991 LP-E4996. https://doi.org/ $10.1073 /$ pnas.1419338111

19. Zhang Y, Liu Y, Liu H, Tang WH. Exosomes: biogenesis, biologic function and clinical potential. Cell Biosci. 2019;9(1):19. https://doi.org/10.1186/s13578-019-0282-2.

20. Petrik J. Immunomodulatory effects of exosomes produced by virus-infected cells. Transfus Apher Sci Off J World Apher Assoc Off J Eur Soc Haemapheresis. 2016;55(1):8491. https://doi.org/10.1016/j.transci.2016.07.014.

21. Schorey JS, Cheng Y, Singh PP, Smith VL. Exosomes and other extracellular vesicles in host-pathogen interactions. EMBO Rep. 2015;16(1):24-43. https://doi.org/10.15252/ embr.201439363

22. Assil S, Webster B, Dreux M. Regulation of the host antiviral state by intercellular communications. Viruses. 2015;7(8):4707-33. https://doi.org/10.3390/v7082840.

23. Valadi H, Ekström K, Bossios A, Sjöstrand M, Lee JJ, Lötvall JO. Exosome-mediated transfer of mRNAs and microRNAs is a novel mechanism of genetic exchange between cells. Nat Cell Biol. 2007;9(6):654-9. https://doi.org/10.1038/ ncb1596.

24. Raab-Traub N, Dittmer DP. Viral effects on the content and function of extracellular vesicles. Nat Rev Microbiol. 2017;15(9):559-72. https://doi.org/10.1038/nrmicro.2017.60.

25. Ramakrishnaiah V, Thumann C, Fofana I, et al. Exosome-mediated transmission of hepatitis $\mathrm{C}$ virus between human hepatoma Huh7.5 cells. Proc Natl Acad Sci U S A. 2013;110(32):13109-13. https://doi.org/10.1073/pnas. 1221899110.

26. Lenassi M, Cagney G, Liao M, et al. HIV Nef is secreted in exosomes and triggers apoptosis in bystander CD4+ T cells. Traffic. 2010;11(1):110-22. https://doi.org/10.1111/j. 1600-0854.2009.01006.x.

27. Zhou R, Chen KK, Zhang J, et al. The decade of exosomal long RNA species: an emerging cancer antagonist. 
Mol Cancer. 2018;17(1):75. https://doi.org/10.1186/ s12943-018-0823-z.

28. Li J, Liu K, Liu Y, et al. Exosomes mediate the cell-to-cell transmission of IFN- $\alpha$-induced antiviral activity. Nat Immunol. 2013;14(8):793-803. https://doi.org/10.1038/ni.2647.

29. Pegtel DM, Cosmopoulos K, Thorley-Lawson DA, et al. Functional delivery of viral miRNAs via exosomes. Proc Natl Acad Sci. 2010;107(14):6328-33. https://doi.org/10.1073/pnas. 0914843107.

30. Cheng Y, Schorey JS. Exosomes carrying mycobacterial antigens can protect mice against mycobacterium tuberculosis infection. Eur J Immunol. 2013;43(12):3279-90. https://doi.org/10.1002/eji.201343727.

31. Syn N, Wang L, Sethi G, Thiery J-P, Goh B-C. Exosomemediated metastasis: from epithelial-mesenchymal transition to escape from Immunosurveillance. Trends Pharmacol Sci. 2016;37(7):606-17. https://doi.org/10.1016/j. tips.2016.04.006.

32. Wolfers J, Lozier A, Raposo G, et al. Tumor-derived exosomes are a source of shared tumor rejection antigens for CTL cross-priming. Nat Med. 2001;7 (3):297-303. https://doi.org/10.1038/85438.

33. André F, Schartz NEC, Chaput N, et al. Tumor-derived exosomes: a new source of tumor rejection antigens. Vaccine. 2002;20 (Suppl 4):A28-31. https://doi.org/10.1016/ s0264-410x (02)00384-5.

34. Yang B, Jeang J, Yang A, Wu TC, Hung C-F. DNA vaccine for cancer immunotherapy. Hum Vaccin Immunother. 2014;10(11):3153-64. https://doi.org/10.4161/21645 515.2014 .980686 .

35. Koyama Y, Ito T, Hasegawa A, et al. Exosomes derived from tumor cells genetically modified to express mycobacterium tuberculosis antigen: a novel vaccine for cancer therapy. Biotechnol Lett. 2016;38(11):1857-66. https:// doi.org/10.1007/s10529-016-2185-1.

36. Sallusto F, Lanzavecchia A, Araki K, Ahmed R. From vaccines to memory and back. Immunity. 2010;33(4):451-63. https://doi.org/10.1016/j.immuni.2010.10.008.

37. Wang R, Xu A, Zhang X, et al. Novel exosome-targeted T-cell-based vaccine counteracts T-cell anergy and converts CTL exhaustion in chronic infection via CD40L signaling through the mTORC1 pathway. Cell Mol Immunol. 2017;14(6):529-45. https://doi.org/10.1038/cmi.2016.23.

38. Staples JE, Breiman RF, Powers AM. Chikungunya fever: an epidemiological review of a re-emerging infectious disease. Clin Infect Dis. 2009;49(6):942-8. https://doi.org/10.1086/ 605496.

39. Doyle TJ, Glynn MK, Groseclose SL. Completeness of notifiable infectious disease reporting in the United States: an analytical literature review. Am J Epidemiol. 2002;155(9):866-74. https://doi.org/10.1093/aje/155.9. 866.

40. Chaplin DD. Overview of the immune response. J Allergy Clin Immunol. 2010;125(2):S3-S23. https://doi.org/10. 1016/j.jaci.2009.12.980.

41. Matilla MA, Krell T. The effect of bacterial chemotaxis on host infection and pathogenicity. FEMS Microbiol Rev. 2018;42(1). https://doi.org/10.1093/femsre/fux052

42. Raghunathan D, Radford PM, Gell C, et al. Engulfment, persistence and fate of Bdellovibrio bacteriovorus predators inside human phagocytic cells informs their future therapeutic potential. Sci Rep. 2019;9(1):4293. https://doi.org/ 10.1038/s41598-019-40223-3.

43. Mogensen TH. Pathogen recognition and inflammatory signaling in innate immune defenses. Clin Microbiol
Rev. 2009;22(2):240-73. https://doi.org/10.1128/CMR. 00046-08.

44. Nicholson LB. The immune system. Essays Biochem. 2016;60(3):275-301. https://doi.org/10.1042/EBC20 160017.

45. Gasteiger G, D'Osualdo A, Schubert DA, Weber A, Bruscia EM, Hartl D. Cellular innate immunity: an old game with new players. J Innate Immun. 2017;9(2):111-25. https:// doi.org/10.1159/000453397.

46. Mantovani A, Cassatella MA, Costantini C, Jaillon S. Neutrophils in the activation and regulation of innate and adaptive immunity. Nat Rev Immunol. 2011;11(8):519-31. https:// doi.org/10.1038/nri3024.

47. Turvey SE, Broide DH. Innate immunity. J Allergy Clin Immunol. 2010;125(2 Suppl 2):S24-32. https://doi.org/ 10.1016/j.jaci.2009.07.016.

48. Belkaid Y, Hand TW. Role of the microbiota in immunity and inflammation. Cell. 2014;157(1):121-41. https://doi. org/10.1016/j.cell.2014.03.011.

49. Wherry EJ, Masopust D. Chapter 5 - adaptive immunity: neutralizing, eliminating, and remembering for the next time. In: Katze MG, Korth MJ, Law GL, Nathanson NBT-VP (third E, eds. Boston: Academic Press; 2016:57-69. https:// doi.org/10.1016/B978-0-12-800964-2.00005-7.

50. Liao S, von der Weid PY. Lymphatic system: an active pathway for immune protection. Semin Cell Dev Biol. 2015;38:83-9. https://doi.org/10.1016/j.semcdb.2014.11. 012 .

51. Quaresma JAS. Organization of the Skin Immune System and Compartmentalized Immune Responses in infectious diseases. Clin Microbiol Rev. 2019;32(4):e00034-18. https://doi.org/10.1128/CMR.00034-18.

52. Buonaguro L, Pulendran B. Immunogenomics and systems biology of vaccines. Immunol Rev. 2011;239(1):197-208. https://doi.org/10.1111/j.1600-065X.2010.00971.x.

53. Netea MG, Schlitzer A, Placek K, Joosten LAB, Schultze JL. Innate and adaptive immune memory: an evolutionary continuum in the Host's response to pathogens. Cell Host Microbe. 2019;25(1):13-26. https://doi.org/10.1016/j. chom.2018.12.006.

54. Obaid A, Naz A, Ikram A, et al. Model of the adaptive immune response system against HCV infection reveals potential immunomodulatory agents for combination therapy. Sci Rep. 2018;8(1):8874. https://doi.org/10.1038/ s41598-018-27163-0.

55. Tay C, Kanellakis P, Hosseini H, Cao A, Toh B-H, Bobik A, Kyaw T. B Cell and CD4 T cell interactions promote development of atherosclerosis. Front Immunol. 2020. https:/ / doi.org/10.3389/fimmu.2019.03046

56. Becker A, Thakur BK, Weiss JM, Kim HS, Peinado H, Lyden D. Extracellular vesicles in Cancer: cell-to-cell mediators of metastasis. Cancer Cell. 2016. https://doi.org/10.1016/j. ccell.2016.10.009.

57. DeRita RM, Zerlanko B, Singh A, et al. C-Src, insulin-like growth factor I receptor, G-protein-coupled receptor kinases and focal adhesion kinase are enriched into prostate Cancer cell exosomes. J Cell Biochem. 2017;118(1):66-73. https://doi.org/10.1002/jcb.25611.

58. Al-Nedawi K, Meehan B, Kerbel RS, Allison AC, Rak J. Endothelial expression of autocrine VEGF upon the uptake of tumor-derived microvesicles containing oncogenic EGFR. Proc Natl Acad Sci U S A. 2009;106(10):3794-9. https://doi. org/10.1073/pnas.0804543106.

59. Krishn SR, Singh A, Bowler N, et al. Prostate cancer sheds the $\alpha v \beta 3$ integrin in vivo through exosomes. Matrix Biol. 
2019;77:41-57. https://doi.org/10.1016/j.matbio.2018.08. 004.

60. Tarlinton D. B cells still front and Centre in immunology. Nat Rev Immunol. 2019;19(2):85-6. https://doi.org/10. 1038/s41577-018-0107-2.

61. Hafid A-O, P. SA, Ziad M, Alain T. adaptive ( T and B cells) immunity and control by dendritic cells in atherosclerosis. Circ Res 2014;114(10):1640-1660. https://doi.org/10. 1161/CIRCRESAHA.114.302761.

62. Martin MD, Badovinac VP. Defining memory CD8 T cell. Front Immunol . 2018;9:2692. https:/ /www.frontiersin.org/ article/10.3389/fimmu.2018.02692.

63. Steinbach K, Vincenti I, Merkler D. Resident-memory T cells in tissue-restricted immune responses: for better or worse? Front Immunol. 2018;9:2827 https:/ /www.frontiersin.org/ article/10.3389/fimmu.2018.02827.

64. Woodland DL, Kohlmeier JE. Migration, maintenance and recall of memory $\mathrm{T}$ cells in peripheral tissues. Nat Rev Immunol. 2009;9(3):153-61. https://doi.org/10.1038/ nri2496.

65. Tanel A, Fonseca SG, Yassine-Diab B, et al. Cellular and molecular mechanisms of memory T-cell survival. Expert Rev Vaccines. 2009;8(3):299-312. https://doi.org/10.1586/ 14760584.8.3.299.

66. Thèves C, Crubézy E, Biagini P. History of Smallpox and Its Spread in Human Populations. Microbiol Spectr. 2016;4(4). doi:https://doi.org/10.1128/microbiolspec.PoH-0004-2014

67. Esparza J, Schrick L, Damaso CR, Nitsche A. Equination (inoculation of horsepox): an early alternative to vaccination (inoculation of cowpox) and the potential role of horsepox virus in the origin of the smallpox vaccine. Vaccine. 2017;35(52):7222-30. https://doi.org/10.1016/j.vacci ne.2017.11.003.

68. Andreani J, Arnault J-P, Bou Khalil JY, et al. Atypical cowpox virus infection in smallpox-vaccinated patient, France. Emerg Infect Dis. 2019;25(2):212-9. https://doi.org/10. 3201/eid2502.171433.

69. National Immunization Program C. Achievements in Public Health, 1900-1999 Impact of Vaccines Universally Recommended for Children - United States, 1990-1998. Morbidity and Mortality Weekly Report. https://www.cdc.gov/mmwr/ preview/mmwrhtml/00056803.htm. Published 1999.

70. Dretler AW, Rouphael NG, Stephens DS. Progress toward the global control of Neisseria meningitidis: 21st century vaccines, current guidelines, and challenges for future vaccine development. Hum Vaccin Immunother. 2018;14(5):1146-60. https://doi.org/10.1080/21645515. 2018.1451810 .

71. Rauch S, Jasny E, Schmidt KE, Petsch B. New vaccine technologies to combat outbreak situations. Front Immunol. 2018;9:1963. https://doi.org/10.3389/fimmu.2018.01963.

72. Jackson C, Mann A, Mangtani P, Fine P. Effectiveness of Haemophilus influenzae type $b$ vaccines administered according to various schedules: systematic review and meta-analysis of observational data. Pediatr Infect Dis J. 2013;32(11):1261-9. https://doi.org/10.1097/INF.0b013 e3182a14e 57.

73. UNICEEF. Under-Five Mortality.; 2021. https://data.unicef. org/topic/child-survival/under-five-mortality/.

74. Lurie N, Saville M, Hatchett R, Halton J. Developing Covid19 vaccines at pandemic speed. N Engl J Med March 2020. https://doi.org/10.1056/NEJMp2005630.

75. Dannenberg AMJ. Perspectives on clinical and preclinical testing of new tuberculosis vaccines. Clin Microbiol Rev. 2010;23(4):781-94. https://doi.org/10.1128/CMR. 00005-10.
76. Mestas J, Hughes CCW. Of mice and not men: differences between mouse and human immunology. J Immunol. 2004;172(5):2731-8. https://doi.org/10.4049/jimmunol. 172.5.2731.

77. Bernuth H, Picard C, Jin Z, et al. Pyogenic bacterial infections in humans with MyD88 deficiency. Science. 2008;321:691-6. https://doi.org/10.1126/science.1158298.

78. Munford RS. Murine responses to endotoxin: another dirty little secret? J Infect Dis. 2010;201(2):175-7. https://doi. org/10.1086/649558.

79. Gibbons DL, Spencer J. Mouse and human intestinal immunity: same ballpark, different players; different rules, same score. Mucosal Immunol. 2011;4(2):148-57. https://doi.org/10.1038/mi.2010.85.

80. Sauerwein RW, Roestenberg M, Moorthy VS. Experimental human challenge infections can accelerate clinical malaria vaccine development. Nat Rev Immunol. 2011;11(1):57-64. https://doi.org/10.1038/nri2902.

81. Kiros TG, Levast B, Auray G, Strom S, van Kessel J, Gerdts $\mathrm{V}$. The importance of animal models in the development of vaccines. Baschieri S, ed. Innov Vaccinol from Des through to Deliv Test. March 2012:251-264. https://doi. org/10.1007/978-94-007-4543-8_11.

82. Li L, Petrovsky N. Molecular mechanisms for enhanced DNA vaccine immunogenicity. Expert Rev Vaccines. 2016;15(3):313-29. https://doi.org/10.1586/14760584. 2016.1124762.

83. Corti D, Voss J, Gamblin SJ, et al. A neutralizing antibody selected from plasma cells that binds to group 1 and group 2 influenza a hemagglutinins. Science. 2011;333(6044):8506. https://doi.org/10.1126/science.1205669.

84. Houser K, Subbarao K. Influenza vaccines: challenges and solutions. Cell Host Microbe. 2015;17(3):295-300. https:// doi.org/10.1016/j.chom.2015.02.012.

85. Wei C-J, Crank MC, Shiver J, Graham BS, Mascola JR, Nabel GJ. Next-generation influenza vaccines: opportunities and challenges. Nat Rev Drug Discov. 2020;19(4):239-52. https://doi.org/10.1038/s41573-019-0056-x.

86. Schreibelt G, Benitez-Ribas D, Schuurhuis D, et al. Commonly used prophylactic vaccines as an alternative for synthetically produced TLR ligands to mature monocytederived dendritic cells. Blood. 2010;116(4):564-74. https:/ / doi.org/10.1182/blood-2009-11-251884.

87. Higgins SC, Mills KHG. TLR, NLR agonists, and other immune modulators as infectious disease vaccine adjuvants. Curr Infect Dis Rep. 2010;12(1):4-12. https://doi.org/10. 1007/s11908-009-0080-9.

88. Hoffmann M, Kleine-Weber H, Schroeder S, et al. SARSCoV-2 cell entry depends on ACE2 and TMPRSS2 and is blocked by a clinically proven protease inhibitor. Cell. 2020;181 (2):271-280.e8. https://doi.org/10.1016/j.cell. 2020.02.052

89. Rahav G, Lustig Y, Lavee J, et al. BNT162b2 mRNA COVID19 vaccination in immunocompromised patients: a prospective cohort study. EClinicalMedicine. 2021;41:101158. https://doi.org/10.1016/j.eclinm.2021.101158.

90. Baden LR, El Sahly HM, Essink B, et al. Efficacy and safety of the mRNA-1273 SARS-CoV-2 vaccine. N Engl J Med. 2020;384(5):403-16. https://doi.org/10.1056/NEJMoa2035 389.

91. B.V. JV\& P. A Study of Ad26.COV2.S for the Prevention of SARS-CoV-2-Mediated COVID-19 in Adult Participants (ENSEMBLE).; 2021. https://clinicaltrials.gov/ct2/show/ NCT04505722.

92. Kis Z, Shattock R, Shah N, Kontoravdi C. Emerging technologies for low-cost, rapid vaccine manufacture. Biotechnol J. 
2019;14(1):e1800376. https://doi.org/10.1002/biot.20180 0376.

93. World Health Organization. World Health Report. Make every mother and child count Geneva: WHO, 2005. Geneva. 2005;2005 www.who.int/whr/2005/en/index.html.

94. Parashar UD, Gibson CJ, Bresee JS, Glass RI. Rotavirus and severe childhood diarrhea. Emerg Infect Dis. 2006;12(2):304-6. https://doi.org/10.3201/eid1202. 050006 .

95. Rappuoli R, Pizza M, Del Giudice G, De Gregorio E. Vaccines, new opportunities for a new society. Proc Natl Acad Sci U S A. 2014;111(34):12288-93. https://doi.org/10. 1073/pnas.1402981111.

96. Greenwood B. The contribution of vaccination to global health: past, present and future. Philos Trans R Soc Lond Ser B Biol Sci. 2014;369(1645):20130433. https:/ / doi.org/ 10.1098/rstb.2013.0433.

97. Furman D, Davis MM. New approaches to understanding the immune response to vaccination and infection. Vaccine. 2015;33(40):5271-81. https://doi.org/10.1016/j.vaccine. 2015.06.117.

98. COVID-19 CORONAVIRUS PANDEMIC. Crona Virus Worldmeter. https://www.worldometers.info/coronavirus/.

99. Lu R, Zhao X, Li J, et al. Genomic characterisation and epidemiology of 2019 novel coronavirus: implications for virus origins and receptor binding. Lancet (London, England). 2020;395(10224):565-574. https://doi.org/10.1016/S01406736(20)30251-8

100. Gorbalenya AE, Baker SC, Baric RS, et al. $<$ em $>$ Severe acute respiratory syndrome-related coronavirus $</ \mathrm{em}>$ : The species and its viruses - a statement of the Coronavirus Study Group. bioRxiv. January 2020:2020.02.07.937862. :https:// doi.org/10.1101/2020.02.07.937862.

101. De Clercq E. New nucleoside analogues for the treatment of hemorrhagic fever virus infections. Chem Asian J. 2019;14(22):3962-8. https://doi.org/10.1002/asia.20190 0841.

102. Wang Y, Wang W, Xu L, et al. Cross talk between nucleotide synthesis pathways with cellular immunity in constraining hepatitis E virus replication. Antimicrob Agents Chemother. 2016;60(5):2834-48. https://doi.org/10.1128/AAC. 02700-15.

103. Sheahan TP, Sims AC, Graham RL, et al. Broad-spectrum antiviral GS-5734 inhibits both epidemic and zoonotic coronaviruses. Sci Transl Med. 2017;9(396). https://doi.org/10. 1126/scitranslmed.aal3653

104. Mulangu S, Dodd LE, Davey RTJ, et al. A randomized, controlled trial of Ebola virus disease therapeutics. N Engl J Med. 2019;381 (24):2293-303. https://doi.org/10.1056/ NEJMoa1910993.

105. Holshue ML, DeBolt C, Lindquist S, et al. First case of 2019 novel coronavirus in the United States. N Engl J Med. 2020;382(10):929-36. https://doi.org/10.1056/NEJMo a2001191.

106. Yan Y, Zou Z, Sun Y, et al. Anti-malaria drug chloroquine is highly effective in treating avian influenza a $\mathrm{H} 5 \mathrm{~N} 1$ virus infection in an animal model. Cell Res. 2013;23(2):300-2. https://doi.org/10.1038/cr.2012.165.

107. Savarino A, Di Trani L, Donatelli I, Cauda R, Cassone A. New insights into the antiviral effects of chloroquine. Lancet Infect Dis. 2006;6(2):67-9. https://doi.org/10.1016/ S1473-3099(06)70361-9.

108. Chu CM, Cheng VCC, Hung IFN, et al. Role of lopinavir/ ritonavir in the treatment of SARS: initial virological and clinical findings. Thorax. 2004;59(3):252-6. https://doi. org/10.1136/thorax.2003.012658.
109. Chan KS, Lai ST, Chu CM, et al. Treatment of severe acute respiratory syndrome with lopinavir/ritonavir: a multicentre retrospective matched cohort study. Hong Kong Med J = Xianggang yi xue za zhi. 2003;9(6):399-406.

110. Natonal Institute of Health. COVID-19 Treatment Guidelines.; 2021. https://www.covid19treatmentguidelines.nih. gov/therapies/antiviral-therapy/lopinavir-ritonavir-andother-hiv-protease-inhibitors/.

111. COVID-19 Treatment Guidelines. Lopinavir/Ritonavir and Other HIV Protease Inhibitors. https://www.covid19tre atmentguidelines.nih.gov/therapies/antiviral-therapy/ lopinavir-ritonavir-and-other-hiv-protease-inhibitors/.

112. Coutard B, Valle C, de Lamballerie X, Canard B, Seidah NG, Decroly E. The spike glycoprotein of the new coronavirus 2019-nCoV contains a furin-like cleavage site absent in CoV of the same clade. Antivir Res. 2020;176:104742. https:// doi.org/10.1016/j.antiviral.2020.104742.

113. Du L, He Y, Zhou Y, Liu S, Zheng B-J, Jiang S. The spike protein of SARS-CoV-a target for vaccine and therapeutic development. Nat Rev Microbiol. 2009;7(3):226-36. https://doi.org/10.1038/nrmicro2090.

114. He Y, Zhou Y, Liu S, et al. Receptor-binding domain of SARS-CoV spike protein induces highly potent neutralizing antibodies: implication for developing subunit vaccine. Biochem Biophys Res Commun. 2004;324(2):773-81. https:// doi.org/10.1016/j.bbrc.2004.09.106.

115. Clover Produces Subunit Vaccine Candidate S-Trimer for Coronavirus. https://www.bioworld.com/articles/433055clover-produces-subunit-vaccine-candidate-s-trimer-forcoronavirus.

116. Yang Z-Y, Kong W-P, Huang Y, et al. A DNA vaccine induces SARS coronavirus neutralization and protective immunity in mice. Nature. 2004;428(6982):561-4. https://doi.org/ 10.1038 / nature 02463 .

117. Sardesai NY, Weiner DB. Electroporation delivery of DNA vaccines: prospects for success. Curr Opin Immunol. 2011;23(3):421-9. https://doi.org/10.1016/j.coi.2011.03. 008.

118. Inovio pharmaceuticals and beijing advaccine biotechnology partnership to develop DNA Vaccine (INO-4800) against COVID-19 and Start Pre-Clinical Trials. http:// ir.inovio.com/news-releases/news-releases-details/2020/ INOVIO-Expands-Manufacturing-of-COVID-19-DNAVaccine-INO-4800-With-New-Funding-from-CEPI/defau lt.aspx.

119. Zhang C, Maruggi G, Shan H, Li J. Advances in mRNA vaccines for infectious diseases. Front Immunol. 2019;10:594. https://doi.org/10.3389/fimmu.2019.00594.

120. Pardi N, Hogan MJ, Porter FW, Weissman D. mRNA vaccines - a new era in vaccinology. Nat Rev Drug Discov. 2018;17(4):261-79. https://doi.org/10.1038/nrd.2017.243.

121. Moderna Ships MRNA Vaccine against novel coronavirus (MRNA-1273) for Phase 1 Study. https://investors.moder natx.com/news-releases/news-release-details/modernaships-mrna-vaccine-against-novel-coronavirus-mrna-1273.

122. Seo YB, Im SJ, Namkoong $\mathrm{H}$, et al. Crucial roles of interleukin-7 in the development of $\mathrm{T}$ follicular helper cells and in the induction of humoral immunity. J Virol. 2014;88(16):8998-9009. https://doi.org/10.1128/JVI. 00534-14.

123. McCullers JA, Dunn JD. Advances in vaccine technology and their impact on managed care. P T. 2008;33(1):35-41 https://pubmed.ncbi.nlm.nih.gov/19749990.

124. Loomis RJ, Johnson PR. Emerging vaccine technologies. Vaccines. 2015;3(2):429-47. https://doi.org/10.3390/vacci nes3020429. 
125. Srinivasan KN, Brusic V, August TJ. New technologies for vaccine development. Drug Dev Res. 2004;62(4):383-92. https://doi.org/10.1002/ddr.10393.

126. Belongia EA, Naleway AL. Smallpox vaccine: the good, the bad, and the ugly. Clin Med Res. 2003;1(2):87-92. https:/ / doi.org/10.3121/cmr.1.2.87.

127. Mazumder DN, Mitra AC, Mukherjee MK. Clinical observations on smallpox: a study of 1233 patients admitted to the infectious diseases hospital, Calcutta, during 1973. Bull World Health Organ. 1975;52(3):301-6 https://pubmed. ncbi.nlm.nih.gov/1084800.

128. Riedel S. Edward Jenner and the history of smallpox and vaccination. Proc (Bayl Univ Med Cent). 2005;18(1):21-5. https://doi.org/10.1080/08998280.2005.11928028.

129. Morens DM, Folkers GK, Fauci AS. The challenge of emerging and re-emerging infectious diseases. Nature. 2004;430(6996):242-9. https://doi.org/10.1038/natur $\mathrm{e} 02759$.

130. Dimitrov DS. Therapeutic antibodies, vaccines and antibodyomes. MAbs. 2010;2(3):347-56. https://doi.org/10. $4161 /$ mabs.2.3.11779.

131. Gregory AE, Titball R, Williamson D. Vaccine delivery using nanoparticles. Front Cell Infect Microbiol. 2013;3:13. https://doi.org/10.3389/fcimb.2013.00013.

132. Singh M, Chakrapani A, O'Hagan D. Nanoparticles and microparticles as vaccine-delivery systems. Expert Rev Vaccines. 2007;6(5):797-808. https://doi.org/10.1586/14760 584.6.5.797.

133. Pati R, Shevtsov M, Sonawane A. Nanoparticle vaccines against infectious diseases. Front Immunol. 2018;9:2224. https://doi.org/10.3389/fimmu.2018.02224.

134. Gregory AE, Williamson ED, Prior JL, et al. Conjugation of Y. pestis F1-antigen to gold nanoparticles improves immunogenicity. Vaccine. 2012;30(48):6777-82. https://doi. org/10.1016/j.vaccine.2012.09.021.

135. Diaz-Arévalo D, Zeng M. Nanoparticle-based vaccines: opportunities and limitations. Shegokar R, ed. Nanopharmaceuticals. 2020:135-150. https://doi.org/10.1016/ B978-0-12-817778-5.00007-5

136. Understanding MRNA COVID-19 Vaccines.; 2020. https://www.cdc.gov/coronavirus/2019-ncov/vaccines/ different-vaccines/mrna.html.

137. Wendorf J, Chesko J, Kazzaz J, et al. A comparison of anionic nanoparticles and microparticles as vaccine delivery systems. Hum Vaccin. 2008;4(1):44-9. https://doi.org/ 10.4161/hv.4.1.4886.

138. Benne N, van Duijn J, Kuiper J, Jiskoot W, Slütter B. Orchestrating immune responses: how size, shape and rigidity affect the immunogenicity of particulate vaccines. J Control Release. 2016;234:124-34. https://doi.org/10. 1016/j.jconrel.2016.05.033.

139. Fromen CA, Rahhal TB, Robbins GR, et al. Nanoparticle surface charge impacts distribution, uptake and lymph node trafficking by pulmonary antigen-presenting cells. Nanomedicine. 2016;12(3):677-87. https://doi.org/10. 1016/j.nano.2015.11.002.

140. Ma Y, Zhuang Y, Xie X, et al. The role of surface charge density in cationic liposome-promoted dendritic cell maturation and vaccine-induced immune responses. Nanoscale. 2011;3(5):2307-14. https://doi.org/10.1039/c1nr10166h.

141. Tandrup Schmidt S, Foged C, Korsholm KS, Rades T, Christensen D. Liposome-based adjuvants for subunit vaccines: formulation strategies for subunit antigens and Immunostimulators. Pharmaceutics. 2016;8(1):7. https://doi. org/10.3390/pharmaceutics8010007.
142. Fröhlich E. The role of surface charge in cellular uptake and cytotoxicity of medical nanoparticles. Int J Nanomedicine. 2012;7:5577-91. https://doi.org/10.2147/IJN.S36111.

143. Marques Neto LM, Kipnis A, Junqueira-Kipnis AP. Role of metallic nanoparticles in vaccinology: implications for infectious disease vaccine development. Front Immunol. 2017;8:239. https://doi.org/10.3389/fimmu.2017.00239.

144. Gomes AC, Mohsen M, Bachmann MF. Harnessing nanoparticles for immunomodulation and vaccines. Vaccines. 2017;5(1):6. https://doi.org/10.3390/vaccines5010006.

145. Khalaj-Hedayati A, Chua CLL, Smooker P, Lee KW. Nanoparticles in influenza subunit vaccine development: immunogenicity enhancement. Influenza Other Respir Viruses. 2020;14(1):92-101. https://doi.org/10.1111/irv.12697.

146. Liu Y, Yin Y, Wang L, et al. Surface hydrophobicity of microparticles modulates adjuvanticity. J Mater Chem B. 2013;1 (32):3888-96. https://doi.org/10.1039/C3TB2 0383B.

147. Poon K, Castellino V, Cheng Y-L. 2 - Polymeric hydrophilic polymers in targeted drug delivery. In: Prakash Cell Engineering and Therapy SBT-AC, ed. Woodhead Publishing Series in Biomaterials. Woodhead Publishing; 2007:42-71. https://doi.org/10.1533/9781845693077.1.42.

148. Suk JS, Xu Q, Kim N, Hanes J, Ensign LM. PEGylation as a strategy for improving nanoparticle-based drug and gene delivery. Adv Drug Deliv Rev. 2016;99(Pt A):28-51. https:/ / doi.org/10.1016/j.addr.2015.09.012

149. Farris E, Brown DM, Ramer-Tait AE, Pannier AK. Micro- and nanoparticulates for DNA vaccine delivery. Exp Biol Med (Maywood). 2016;241 (9):919-29. https://doi.org/10.1177/ 1535370216643771.

150. Janikashvili N, Larmonier N, Katsanis E. Personalized dendritic cell-based tumor immunotherapy. Immunotherapy. 2010;2(1):57-68. https://doi.org/10.2217/imt.09.78.

151. Mohan T, Verma P, Rao DN. Novel adjuvants \& delivery vehicles for vaccines development: a road ahead. Indian J Med Res. 2013;138(5):779-95 https://pubmed.ncbi.nlm. nih.gov/24434331.

152. Fahmy TM, Demento SL, Caplan MJ, Mellman I, Saltzman WM. Design opportunities for actively targeted nanoparticle vaccines. Nanomedicine (Lond). 2008;3(3):343-55. https:// doi.org/10.2217/17435889.3.3.343.

153. Zhao L, Seth A, Wibowo N, et al. Nanoparticle vaccines. Vaccine. 2014;32(3):327-37. https://doi.org/10.1016/j.vacci ne.2013.11.069.

154. Yáñez-Mó M, Siljander PRM, Andreu Z, et al. Biological properties of extracellular vesicles and their physiological functions. J Extracell Vesicles. 2015;4(1):27066. https:/ / doi. org/10.3402/jev.v4.27066.

155. Conigliaro A, Fontana S, Raimondo S, Alessandro R. Exosomes: Nanocarriers of biological messages. Adv Exp Med Biol. 2017;998:23-43. https://doi.org/10.1007/ 978-981-10-4397-0_2.

156. Huda MN, Nafiujjaman M, Deaguero IG, et al. Potential use of exosomes as diagnostic biomarkers and in targeted drug delivery: progress in clinical and preclinical applications. ACS Biomater Sci Eng. May 2021:acsbiomaterials.1c00217. https://doi.org/10.1021/acsbiomaterials.1c00217

157. Jan AT, Rahman S, Khan S, Tasduq SA, Choi I. Biology, pathophysiological role, and clinical implications of exosomes: a critical appraisal. Cells. 2019;8(2):99. https:// doi.org/10.3390/cells8020099.

158. Théry C, Zitvogel L, Amigorena S. Exosomes: composition, biogenesis and function. Nat Rev Immunol. 2002;2(8):56979. https://doi.org/10.1038/nri855. 
159. Antimisiaris S, Mourtas S, Marazioti A. Exosomes and exosome-inspired vesicles for targeted drug delivery. Pharmaceutics. 2018;10(4):218. https://doi.org/10.3390/pharm aceutics 10040218 .

160. Huotari J, Helenius A. Endosome maturation. EMBO J. 2011;30(17):3481-500. https://doi.org/10.1038/emboj. 2011.286.

161. Henne WM, Stenmark H, Emr SD. Molecular mechanisms of the membrane sculpting ESCRT pathway. Cold Spring Harb Perspect Biol. 2013;5(9):a016766-6. https://doi.org/ 10.1101/cshperspect.a016766.

162. Trajkovic K, Hsu C, Chiantia S, et al. Ceramide triggers budding of exosome vesicles into multivesicular endosomes. Science (80- ). 2008;319(5867):1244-1247. https://doi.org/10.1126/science.1153124

163. Colombo M, Moita C, van Niel G, et al. Analysis of ESCRT functions in exosome biogenesis, composition and secretion highlights the heterogeneity of extracellular vesicles. J Cell Sci. 2013;126(24):5553-65. https://doi.org/10. $1242 /$ jcs. 128868 .

164. Schmidt O, Teis D. The ESCRT machinery. Curr Biol. 2012;22(4):R116-20. https://doi.org/10.1016/j.cub.2012. 01.028 .

165. Piper RC, Katzmann DJ. Biogenesis and function of multivesicular bodies. Annu Rev Cell Dev Biol. 2007;23(1):51947. https://doi.org/10.1146/annurev.cellbio.23.090506. 123319.

166. van Meer G, Voelker DR, Feigenson GW. Membrane lipids: where they are and how they behave. Nat Rev Mol Cell Biol. 2008;9(2):112-24. https://doi.org/10.1038/nrm2330.

167. Skotland T, Hessvik NP, Sandvig K, Llorente A. Exosomal lipid composition and the role of ether lipids and phosphoinositides in exosome biology. J Lipid Res. 2019;60(1):9-18. https://doi.org/10.1194/jlr.R084343.

168. Horvath SE, Daum G. Lipids of mitochondria. Prog Lipid Res. 2013;52(4):590-614. https://doi.org/10.1016/j.plipr es.2013.07.002.

169. van Niel G, Charrin S, Simoes S, et al. The Tetraspanin CD63 regulates ESCRT-independent and -dependent endosomal sorting during Melanogenesis. Dev Cell. 2011;21 (4):708-21. https://doi.org/10.1016/j.devcel.2011.08.019.

170. Théry C, Regnault A, Garin J, et al. Molecular characterization of dendritic cell-derived exosomes. Selective accumulation of the heat shock protein hsc73. J Cell Biol. 1999;147(3):599610. https://doi.org/10.1083/jcb.147.3.599.

171. Gastpar R, Gehrmann M, Bausero MA, et al. Heat shock protein 70 surface-positive tumor exosomes stimulate migratory and cytolytic activity of natural killer cells. Cancer Res. 2005;65(12):5238 LP - 5247. https://doi.org/10.1158/00085472.CAN-04-3804

172. Srivastava P. Interaction of heat shock proteins with peptides and antigen presenting cells: chaperoning of the innate and adaptive immune responses. Annu Rev Immunol. 2002;20:395-425. https://doi.org/10.1146/annurev. immunol.20.100301.064801.

173. Muntasell A, Berger AC, Roche PA. T cell-induced secretion of MHC class II-peptide complexes on B cell exosomes. EMBO J. 2007;26(19):4263-72. https://doi.org/10.1038/ sj.emboj.7601842.

174. Admyre C, Johansson SM, Paulie S, Gabrielsson S. Direct exosome stimulation of peripheral human $\mathrm{T}$ cells detected by ELISPOT. Eur J Immunol. 2006;36(7):1772-81. https:/ / doi.org/10.1002/ eji.200535615.

175. Asea A, Kraeft SK, Kurt-Jones EA, et al. HSP70 stimulates cytokine production through a CD14-dependant pathway, demonstrating its dual role as a chaperone and cytokine.
Nat Med. 2000;6(4):435-42. https://doi.org/10.1038/ 74697.

176. Asea A, Rehli M, Kabingu E, et al. Novel signal transduction pathway utilized by extracellular HSP70: role of toll-like receptor (TLR) 2 and TLR4. J Biol Chem. 2002;277(17):15028-34. https://doi.org/10.1074/jbc. M200497200.

177. Boudesco C, Cause S, Jego G, Garrido C. Hsp70: a Cancer target inside and outside the cell. Methods Mol Biol. 1709;2018:371-96. https://doi.org/10.1007/978-1-49397477-1_27.

178. Langhorst MF, Reuter A, Stuermer CAO. Scaffolding microdomains and beyond: the function of reggie/flotillin proteins. Cell Mol Life Sci. 2005;62(19-20):2228-40. https:// doi.org/10.1007/s00018-005-5166-4.

179. Mathis L, Wernimont S, Affentranger S, Huttenlocher A, Niggli V. Determinants of phosphatidylinositol-4-phosphate 5-kinase type I $\gamma 90$ uropod location in T-lymphocytes and its role in uropod formation. PeerJ. 2013;1:e131-1. https:// doi.org/10.7717/peerj.131.

180. Bodin S, Planchon D, Rios Morris E, Comunale F, GauthierRouvière C. Flotillins in intercellular adhesion - from cellular physiology to human diseases. J Cell Sci. 2014;127(Pt 24):5139-47. https://doi.org/10.1242/jcs.159764.

181. Otto GP, Nichols BJ. The roles of flotillin microdomains endocytosis and beyond. J Cell Sci. 2011;124(23):3933 LP - 3940. https://doi.org/10.1242/jcs.092015

182. Perez-Hernandez D, Gutiérrez-Vázquez C, Jorge I, et al. The intracellular interactome of tetraspanin-enriched microdomains reveals their function as sorting machineries toward exosomes. J Biol Chem. 2013;288(17):11649-61. https:// doi.org/10.1074/jbc.M112.445304.

183. Verweij FJ, de Heus C, Kroeze S, et al. Exosomal sorting of the viral oncoprotein LMP1 is restrained by TRAF2 association at signalling endosomes. J Extracell vesicles. 2015;4:26334. https://doi.org/10.3402/jev.v4.26334.

184. Rana S, Yue S, Stadel D, Zöller M. Toward tailored exosomes: the exosomal tetraspanin web contributes to target cell selection. Int J Biochem Cell Biol. 2012;44(9):157484. https://doi.org/10.1016/j.biocel.2012.06.018.

185. Nazarenko I, Rana S, Baumann A, et al. Cell surface tetraspanin Tspan 8 contributes to molecular pathways of exosome-induced endothelial cell activation. Cancer Res. 2010;70 (4):1668 LP - 1678. https://doi.org/10.1158/00085472.CAN-09-2470

186. Ackerman ME, Chalouni C, Schmidt MM, et al. A33 antigen displays persistent surface expression. Cancer Immunol Immunother. 2008;57(7):1017-27. https://doi.org/10. $1007 / \mathrm{s} 00262-007-0433-x$.

187. Haghayegh Jahromi N, Marchetti L, Moalli F, et al. Intercellular adhesion Molecule-1 (ICAM-1) and ICAM-2 differentially contribute to peripheral activation and CNS entry of autoaggressive Th1 and Th17 cells in experimental autoimmune encephalomyelitis . Front Immunol . 2020;10:3056. https://www.frontiersin.org/article/10.3389/fimmu.2019. 03056.

188. Lee HD, Kim YH, Kim D-S. Exosomes derived from human macrophages suppress endothelial cell migration by controlling integrin trafficking. Eur J Immunol. 2014;44(4):115669. https://doi.org/10.1002/eji.201343660.

189. Carney RP, Hazari S, Rojalin T, et al. Targeting tumor-associated exosomes with integrin-binding peptides. Adv Biosyst. 2017;1 (5):1600038. https://doi.org/10.1002/adbi.20160 0038.

190. Poliakov A, Spilman M, Dokland T, Amling CL, Mobley JA. Structural heterogeneity and protein composition 
of exosome-like vesicles (prostasomes) in human semen. Prostate. 2009;69(2):159-67. https://doi.org/10.1002/pros. 20860.

191. Xiao F, Fofana I, Heydmann L, et al. Hepatitis C virus cellcell transmission and resistance to direct-acting antiviral agents. PLoS Pathog. 2014;10(5):e1004128-8. https://doi. org/10.1371/journal.ppat.1004128.

192. Brimacombe CL, Grove J, Meredith LW, et al. Neutralizing antibody-resistant hepatitis $\mathrm{C}$ virus cell-to-cell transmission. J Virol. 2011;85(1):596-605. https://doi.org/10.1128/JVI. 01592-10.

193. Ahmed W, Philip PS, Attoub S, Khan G. Epstein-Barr virus-infected cells release Fas ligand in exosomal fractions and induce apoptosis in recipient cells via the extrinsic pathway. J Gen Virol. 2015;96(12):3646-59. https:// doi.org/10.1099/jgv.0.000313.

194. Meckes DGJ, Gunawardena HP, Dekroon RM, et al. Modulation of B-cell exosome proteins by gamma herpesvirus infection. Proc Natl Acad Sci U S A. 2013;110(31):E292533. https://doi.org/10.1073/pnas.1303906110.

195. Vogelpoel LTC, Baeten DLP, de Jong EC, den Dunnen J. Control of cytokine production by human fc gamma receptors: implications for pathogen defense and autoimmunity. Front Immunol. 2015;6:79. https://doi.org/10. 3389/fimmu.2015.00079.

196. Wu C-H, Li J, Li L, et al. Extracellular vesicles derived from natural killer cells use multiple cytotoxic proteins and killing mechanisms to target cancer cells. J Extracell vesicles. 2019;8(1):1588538. https://doi.org/10.1080/20013078. 2019.1588538.

197. Federici C, Shahaj E, Cecchetti S, et al. Natural-killerderived extracellular vesicles: immune sensors and interactors . Front Immunol . 2020;11:262. https://www.front iersin.org/article/10.3389/fimmu.2020.00262.

198. Zuo P, Lin X, Li X, Zhang Y. Macrophage-derived extracellular vesicles transfer inflammasome components to endothelial cells and induces endothelial injury. FASEB J. 2017;31 (1_supplement):825.13-825.13. https://doi.org/ 10.1096/fasebj.31.1_supplement.825.13

199. Lindenbergh MFS, Koerhuis DGJ, Borg EGF, et al. Bystander T-cells support clonal T-cell activation by controlling the release of dendritic cell-derived immunestimulatory extracellular vesicles. Front Immunol. 2019;10:448. https://doi.org/10.3389/fimmu.2019.00448.

200. Segura E, Amigorena S, Théry C. Mature dendritic cells secrete exosomes with strong ability to induce antigenspecific effector immune responses. Blood Cells Mol Dis. 2005;35(2):89-93. https://doi.org/10.1016/j.bcmd.2005. 05.003.

201. Gutiérrez-Vázquez C, Villarroya-Beltri C, Mittelbrunn M, Sánchez-Madrid F. Transfer of extracellular vesicles during immune cell-cell interactions. Immunol Rev. 2013;251(1):125-42. https://doi.org/10.1111/imr.12013.

202. Wen C, Seeger RC, Fabbri M, Wang L, Wayne AS, Jong AY. Biological roles and potential applications of immune cell-derived extracellular vesicles. J Extracell vesicles. 2017;6(1):1400370. https://doi.org/10.1080/20013078. 2017.1400370 .

203. Zhang Y, Jin X, Liang J, et al. Extracellular vesicles derived from ODN-stimulated macrophages transfer and activate Cdc42 in recipient cells and thereby increase cellular permissiveness to EV uptake. Sci Adv. 2019;5(7):eaav1564eaav1564. https://doi.org/10.1126/sciadv.aav1564

204. Schwab A, Meyering SS, Lepene B, et al. Extracellular vesicles from infected cells: potential for direct pathogenesis.
Front Microbiol. 2015;6:1132. https://doi.org/10.3389/ fmicb.2015.01132.

205. Robbins PD, Morelli AE. Regulation of immune responses by extracellular vesicles. Nat Rev Immunol. 2014;14(3):195-208. https://doi.org/10.1038/nri3622.

206. Hong C-W. Extracellular vesicles of neutrophils. Immune Netw. 2018;18(6):e43-3. https://doi.org/10.4110/in. 2018.18.e43.

207. Kany S, Vollrath JT, Relja B. Cytokines in inflammatory disease. Int J Mol Sci. 2019;20(23):6008. https:/ /doi.org/ $10.3390 / \mathrm{ijms} 20236008$.

208. Qian C, Cao X. Dendritic cells in the regulation of immunity and inflammation. Semin Immunol. 2018;35:3-11. https://doi.org/10.1016/j.smim.2017.12.002.

209. van Hezel ME, Nieuwland $R$, van Bruggen $R$, Juffermans NP. The ability of extracellular vesicles to induce a proinflammatory host response. Int J Mol Sci. 2017;18(6):1285. https://doi.org/10.3390/ijms18061285.

210. Mannon P, Reinisch W. Interleukin 13 and its role in gut defence and inflammation. Gut. 2012;61. https://doi.org/ 10.1136/gutjnl-2012-303461.

211. Marone G, Granata F, Pucino V, et al. The intriguing role of interleukin 13 in the pathophysiology of asthma. Front Pharmacol . 2019;10:1387. https://www.frontiersin.org/ article/10.3389/fphar.2019.01387.

212. Michael A, Bajracharya SD, Yuen PST, et al. Exosomes from human saliva as a source of microRNA biomarkers. Oral Dis. 2010;16(1):34-8. https://doi.org/10.1111/j.1601-0825. 2009.01604.x.

213. Dear JW, Street JM, Bailey MA. Urinary exosomes: a reservoir for biomarker discovery and potential mediators of intrarenal signalling. Proteomics. 2013;13(10-11):1572-80. https://doi.org/10.1002/pmic.201200285.

214. Ogata-Kawata H, Izumiya M, Kurioka D, et al. Circulating Exosomal microRNAs as biomarkers of Colon Cancer. PLoS One. 2014;9(4):e92921. https://doi.org/10.1371/journal. pone.0092921.

215. Yu B, Du Q, Li H, et al. Diagnostic potential of serum exosomal colorectal neoplasia differentially expressed long noncoding RNA (CRNDE-p) and microRNA-217 expression in colorectal carcinoma. Oncotarget. 2017;8(48):83745-83753. https://doi.org/10.18632/oncotarget.19407

216. Hoshino A, Costa-Silva B, Shen TL, et al. Tumour exosome integrins determine organotropic metastasis. Nature. 2015. https://doi.org/10.1038/nature15756.

217. Pan BJ, Xu C, Ping GQ, et al. [correlation analysis of PD-L1 expression and prognosis in triple-negative breast cancers]. Zhonghua bing li xue za zhi = Chinese. J Pathol. 2017;46(12):822-6. https://doi.org/10.3760/cma.j.issn. 0529-5807.2017.12.002.

218. Matsumura T, Sugimachi K, Iinuma H, et al. Exosomal microRNA in serum is a novel biomarker of recurrence in human colorectal cancer. Br J Cancer. 2015;113(2):275-81. https://doi.org/10.1038/bjc.2015.201.

219. Noerholm M, Balaj L, Limperg T, et al. RNA expression patterns in serum microvesicles from patients with glioblastoma multiforme and controls. BMC Cancer. 2012;12:22. https://doi.org/10.1186/1471-2407-12-22.

220. Skog J, Würdinger T, van Rijn S, et al. Glioblastoma microvesicles transport RNA and proteins that promote tumour growth and provide diagnostic biomarkers. Nat Cell Biol. 2008;10(12):1470-6. https://doi.org/10.1038/ncb18 00.

221. Yamashita T, Kamada H, Kanasaki S, et al. Epidermal growth factor receptor localized to exosome membranes as 
a possible biomarker for lung cancer diagnosis. Pharmazie. 2013;68(12):969-73.

222. Melo SA, Luecke LB, Kahlert C, et al. Glypican-1 identifies cancer exosomes and detects early pancreatic cancer. Nature. 2015;523(7559):177-82. https://doi.org/10.1038/ nature 14581.

223. Kruger S, Abd Elmageed ZY, Hawke DH, et al. Molecular characterization of exosome-like vesicles from breast cancer cells. BMC Cancer. 2014;14:44. https://doi.org/10.1186/ 1471-2407-14-44.

224. Singh R, Pochampally R, Watabe K, Lu Z, Mo Y-Y. Exosome-mediated transfer of miR-10b promotes cell invasion in breast cancer. Mol Cancer. 2014;13:256. https://doi. org/10.1186/1476-4598-13-256.

225. Patnaik SK, Kannisto E, Knudsen S, Yendamuri S. Evaluation of MicroRNA expression profiles that may predict recurrence of localized stage I non-small cell lung cancer after surgical resection. Cancer Res. 2010;70(1):36 LP - 45. https://doi.org/10.1158/0008-5472.CAN-09-3153

226. Navon R, Wang H, Steinfeld I, Tsalenko A, Ben-Dor A, Yakhini Z. Novel rank-based statistical methods reveal MicroRNAs with differential expression in multiple Cancer types. PLoS One. 2009;4(11):e8003. https://doi.org/ 10.1371/journal.pone.0008003.

227. Kumarswamy R, Mudduluru G, Ceppi P, et al. MicroRNA30a inhibits epithelial-to-mesenchymal transition by targeting Snail and is downregulated in non-small cell lung cancer. Int J Cancer. 2012;130(9):2044-53. https://doi. org/10.1002/ijc.26218.

228. Sandfeld-Paulsen B, Jakobsen KR, Bæk R, et al. Exosomal proteins as diagnostic biomarkers in lung Cancer. $\mathrm{J}$ Thorac Oncol. 2016;11(10):1701-10. https://doi.org/10. 1016/j.jtho.2016.05.034.

229. Lau C, Kim Y, Chia D, et al. Role of pancreatic cancerderived exosomes in salivary biomarker development. J Biol Chem. 2013;288(37):26888-97. https://doi.org/10. 1074/jbc.M113.452458.

230. Spanu S, van Roeyen CRC, Denecke B, Floege J, Mühlfeld AS. Urinary exosomes: a novel means to non-invasively assess changes in renal gene and protein expression. PLoS One. 2014;9(10):e109631-1. https://doi.org/10.1371/ journal.pone.0109631.

231. Masyuk AI, Masyuk TV, Larusso NF. Exosomes in the pathogenesis, diagnostics and therapeutics of liver diseases. J Hepatol. 2013;59(3):621-5. https://doi.org/10. 1016/j.jhep.2013.03.028.

232. Thongboonkerd V. Roles for exosome in various kidney diseases and disorders . Front Pharmacol . 2020;10:1655. https://www.frontiersin.org/article/10.3389/fphar.2019. 01655.

233. Gao X-F, Wang Z-M, Wang F, Gu Y, Zhang J-J, Chen S-L. Exosomes in coronary artery disease. Int J Biol Sci. 2019;15(11):2461-70. https://doi.org/10.7150/ijbs.36427.

234. Kawikova I, Askenase PW. Diagnostic and therapeutic potentials of exosomes in CNS diseases. Brain Res. 1617;2015:6371. https://doi.org/10.1016/j.brainres.2014.09.070.

235. YANG TT, LIU CG, GAO SC, ZHANG Y, WANG PC. The serum exosome derived MicroRNA-135a, -193b, and -384 were potential Alzheimer's disease biomarkers. Biomed Environ Sci. 2018;31(2):87-96. https://doi.org/10.3967/ bes2018.011.

236. Njock M-S, Guiot J, Henket MA, et al. Sputum exosomes: promising biomarkers for idiopathic pulmonary fibrosis. Thorax. 2019;74(3):309 LP - 312. doi:https://doi.org/10. 1136/thoraxjnl-2018-211897
237. Goetzl EJ, Boxer A, Schwartz JB, et al. Altered lysosomal proteins in neural-derived plasma exosomes in preclinical Alzheimer disease. Neurology. 2015;85(1):40-7. https:// doi.org/10.1212/WNL.0000000000001702.

238. Pusic AD, Pusic KM, Clayton BLL, Kraig RP. IFN $\gamma$-stimulated dendritic cell exosomes as a potential therapeutic for remyelination. J Neuroimmunol. 2014;266(1):12-23. https:// doi.org/10.1016/j.jneuroim.2013.10.014.

239. Barutta F, Tricarico M, Corbelli A, et al. Urinary Exosomal MicroRNAs in incipient diabetic nephropathy. PLoS One. 2013;8(11):e73798. https://doi.org/10.1371/journal.pone. 0073798 .

240. Egawa H, Jingushi K, Hirono T, et al. The miR-130 family promotes cell migration and invasion in bladder cancer through FAK and Akt phosphorylation by regulating PTEN. Sci Rep. 2016;6(1):20574. https://doi.org/10.1038/srep2 0574.

241. Ye D, Shen Z, Zhou S. Function of microRNA-145 and mechanisms underlying its role in malignant tumor diagnosis and treatment. Cancer Manag Res. 2019;11:969-79. https://doi. org/10.2147/CMAR.S191696.

242. Chovatiya R, Medzhitov R. Stress, inflammation, and defense of homeostasis. Mol Cell. 2014;54(2):281-8. https://doi. org/10.1016/j.molcel.2014.03.030.

243. Gorgoulis VG, Pefani D-E, Pateras IS, Trougakos IP. Integrating the DNA damage and protein stress responses during cancer development and treatment. J Pathol. 2018;246(1):12-40. https://doi.org/10.1002/path.5097.

244. Macia L, Nanan R, Hosseini-Beheshti E, Grau GE. Host- and microbiota-derived extracellular vesicles, immune function, and disease development. Int J Mol Sci. 2019;21(1):107. https://doi.org/10.3390/ijms21010107.

245. Zininga T, Ramatsui L, Shonhai A. Heat shock proteins as Immunomodulants. Molecules. 2018;23(11):2846. https:// doi.org/10.3390/molecules23112846.

246. de Jong O, Verhaar M, Chen Y, et al. Cellular stress conditions are reflected in the protein and RNA content of endothelial cell-derived exosomes. J Extracell vesicles. 2012;1. https://doi.org/10.3402/jev.vli0.18396.

247. Bewicke-Copley F, Mulcahy LA, Jacobs LA, et al. Extracellular vesicles released following heat stress induce bystander effect in unstressed populations. J Extracell vesicles. 2017;6(1):1340746. https://doi.org/10.1080/20013078. 2017.1340746.

248. O'Neill CP, Gilligan KE, Dwyer RM. Role of extracellular vesicles (EVs) in cell stress response and resistance to Cancer therapy. Cancers (Basel). 2019;11(2):136. https://doi. org/10.3390/cancers11020136.

249. Ramayanti O, Verkuijlen SAWM, Novianti P, et al. Vesicle-bound EBV-BART13-3p miRNA in circulation distinguishes nasopharyngeal from other head and neck cancer and asymptomatic EBV-infections. Int J Cancer. 2019;144(10):2555-66. https://doi.org/10.1002/ijc.31967.

250. Gleason AM, Woo EG, McKinney C, Sidransky E. The role of exosomes in lysosomal storage disorders. Biomolecules. 2021;11(4):576. https://doi.org/10.3390/biom11040576.

251. Hewitt EW. The MHC class I antigen presentation pathway: strategies for viral immune evasion. Immunology. 2003;110(2):163-9. https://doi.org/10.1046/j.1365-2567. 2003.01738.x.

252. Ikwegbue PC, Masamba P, Oyinloye BE, Kappo AP. Roles of heat shock proteins in apoptosis, oxidative stress, human inflammatory diseases, and Cancer. Pharmaceuticals (Basel). 2017;11(1):2. https://doi.org/10.3390/ph110 10002. 
253. Qiu P, Zhou J, Zhang J, Dong Y, Liu Y. Exosome: the regulator of the immune system in Sepsis. Front Pharmacol. 2021;12:880 https://www.frontiersin.org/article/10.3389/ fphar.2021.671164.

254. Wang M, Zhao J, Zhang L, et al. Role of tumor microenvironment in tumorigenesis. J Cancer. 2017;8(5):761-73. https:/ / doi.org/10.7150/jca.17648.

255. Poltavets V, Kochetkova M, Pitson SM, Samuel MS. The role of the extracellular matrix and its molecular and cellular regulators in Cancer cell plasticity. Front Oncol. 2018;8:431. https://doi.org/10.3389/fonc.2018.00431.

256. Rajabi M, Mousa SA. The role of angiogenesis in Cancer treatment. Biomedicines. 2017;5(2):34. https://doi.org/10. 3390/biomedicines5020034.

257. Teleanu RI, Chircov C, Grumezescu AM, Teleanu DM. Tumor angiogenesis and anti-Angiogenic strategies for Cancer treatment. J Clin Med. 2019;9(1):84. https://doi. org/10.3390/jcm9010084.

258. Malla RR, Pandrangi S, Kumari S, Gavara MM, Badana AK. Exosomal tetraspanins as regulators of cancer progression and metastasis and novel diagnostic markers. Asia Pac J Clin Oncol. 2018;14(6):383-91. https://doi.org/10.1111/ajco. 12869.

259. Al-Nedawi K, Meehan B, Micallef J, et al. Intercellular transfer of the oncogenic receptor EGFRvIII by microvesicles derived from tumour cells. Nat Cell Biol. 2008;10(5):61924. https://doi.org/10.1038/ncb1725.

260. Lucero R, Zappulli V, Sammarco A, et al. Glioma-Derived miRNA-Containing Extracellular Vesicles Induce Angiogenesis by Reprogramming Brain Endothelial Cells. Cell Rep. 2020;30 (7):2065-2074.e4. doi:https://doi.org/10.1016/j. celrep.2020.01.073

261. Todorova D, Simoncini S, Lacroix R, Sabatier F, DignatGeorge F. Extracellular vesicles in angiogenesis. Circ Res. 2017;120(10):1658-73. https://doi.org/10.1161/CIRCR ESAHA.117.309681.

262. Shiga K, Hara M, Nagasaki T, Sato T, Takahashi H, Takeyama H. Cancer-associated fibroblasts: their characteristics and their roles in tumor growth. Cancers (Basel). 2015;7 (4):2443-58. https://doi.org/10.3390/cancers704 0902.

263. Xing F, Saidou J, Watabe K. Cancer associated fibroblasts (CAFs) in tumor microenvironment. Front Biosci (Landmark Ed. 2010;15:166-179. https://doi.org/10.2741/3613

264. Desrochers LM, Antonyak MA, Cerione RA. Extracellular vesicles: satellites of information transfer in Cancer and stem cell biology. Dev Cell. 2016;37(4):301-9. https:/ / doi. org/10.1016/j.devcel.2016.04.019.

265. Boelens MC, Wu TJ, Nabet BY, et al. Exosome transfer from stromal to breast cancer cells regulates therapy resistance pathways. Cell. 2014;159(3):499-513. https://doi.org/10. 1016/j.cell.2014.09.051.

266. Bonnans C, Chou J, Werb Z. Remodelling the extracellular matrix in development and disease. Nat Rev Mol Cell Biol. 2014;15(12):786-801. https://doi.org/10.1038/nrm3904.

267. Maia J, Caja S, Strano Moraes MC, Couto N, Costa-Silva B. Exosome-based cell-cell communication in the tumor microenvironment. Front Cell Dev Biol. 2018. https://doi. org/10.3389/fcell.2018.00018.

268. Czernek L, Düchler M. Functions of Cancer-derived extracellular vesicles in immunosuppression. Arch Immunol Ther Exp. 2017;65(4):311-23. https://doi.org/10.1007/ s00005-016-0453-3.

269. Noy R, Pollard JW. Tumor-associated macrophages: from mechanisms to therapy. Immunity. 2014;41(1):49-61. https://doi.org/10.1016/j.immuni.2014.06.010.
270. Gonzalez H, Hagerling C, Werb Z. Roles of the immune system in cancer: from tumor initiation to metastatic progression. Genes Dev. 2018;32(19-20):1267-84. https://doi. org/10.1101/gad.314617.118.

271. Gun SY, Lee SWL, Sieow JL, Wong SC. Targeting immune cells for cancer therapy. Redox Biol. 2019;25:101174. https://doi.org/10.1016/j.redox.2019.101174.

272. Bassani B, Baci D, Gallazzi M, Poggi A, Bruno A, Mortara L. Natural killer cells as key players of tumor progression and angiogenesis: old and novel tools to divert their pro-tumor activities into potent anti-tumor effects. Cancers (Basel). 2019;11(4):461. https://doi.org/10.3390/cancers11040461.

273. Zingoni A, Vulpis E, Loconte L, Santoni A. NKG2D ligand shedding in response to stress: role of ADAM10. Front Immunol. 2020;11:447. https://doi.org/10.3389/fimmu. 2020.00447.

274. Rodrigues M, Fan J, Lyon C, Wan M, Hu Y. Role of extracellular vesicles in viral and bacterial infections: pathogenesis, diagnostics, and therapeutics. Theranostics. 2018;8(10):2709-21. https://doi.org/10.7150/thno.20576.

275. Gargiulo E, Paggetti J, Moussay E. Hematological malignancy-derived small extracellular vesicles and tumor microenvironment: the art of turning foes into friends. Cells. 2019;8(5):511. https://doi.org/10.3390/cells8050511.

276. Cao Q, Wang Y, Zheng D, et al. IL-10/TGF-beta-modified macrophages induce regulatory $\mathrm{T}$ cells and protect against adriamycin nephrosis. J Am Soc Nephrol. 2010;21 (6):93342. https://doi.org/10.1681/ASN.2009060592.

277. Markov O, Oshchepkova A, Mironova N. Immunotherapy based on dendritic cell-targeted/-derived extracellular vesicles-a novel strategy for enhancement of the anti-tumor immune response. Front Pharmacol. 2019;10:1152. https:// doi.org/10.3389/fphar.2019.01152.

278. Bhargava A, Mishra D, Banerjee S, Mishra P. Dendritic cell engineering for tumor immunotherapy: from biology to clinical translation. Immunotherapy. 2012;4:703-18. https://doi.org/10.2217/imt.12.40.

279. Sheehan C, D\&\#039;Souza-Schorey C. Tumor-derived extracellular vesicles: molecular parcels that enable regulation of the immune response in cancer. J Cell Sci. 2019;132(20):jcs235085. https://doi.org/10.1242/jcs. 235085

280. Liu H, Wang S, Xin J, Wang J, Yao C, Zhang Z. Role of NKG2D and its ligands in cancer immunotherapy. Am J Cancer Res. 2019;9(10):2064-78 https://pubmed.ncbi.nlm. nih.gov/31720075.

281. Becker A, Thakur BK, Weiss JM, Kim HS, Peinado H, Lyden D. Extracellular vesicles in Cancer: cell-to-cell mediators of metastasis. Cancer Cell. 2016;30(6):836-48. https://doi. org/10.1016/j.ccell.2016.10.009.

282. Hicklin DJ, Ellis LM. Role of the vascular endothelial growth factor pathway in tumor growth and angiogenesis. J Clin Oncol Off J Am Soc Clin Oncol. 2005;23(5):1011-27. https://doi.org/10.1200/JCO.2005.06.081.

283. Katoh M. Therapeutics targeting angiogenesis: genetics and epigenetics, extracellular miRNAs and signaling networks (review). Int J Mol Med. 2013;32(4):763-7. https://doi.org/ 10.3892/ijmm.2013.1444.

284. Monteforte A, Lam B, Sherman MB, et al. (*) glioblastoma exosomes for therapeutic angiogenesis in peripheral ischemia. Tissue Eng Part A. 2017;23(21-22):1251-61. https://doi.org/10.1089/ten.TEA.2016.0508.

285. Mani SA, Guo W, Liao M-J, et al. The epithelial-mesenchymal transition generates cells with properties of stem cells. Cell. 2008;133(4):704-15. https://doi.org/10.1016/j.cell.2008. 03.027 . 
286. Gout S, Huot J. Role of cancer microenvironment in metastasis: focus on colon cancer. Cancer Microenviron. 2008;1(1):69-83. https://doi.org/10.1007/ s12307-008-0007-2.

287. Whiteside TL. The role of tumor-derived exosomes in epithelial mesenchymal transition (EMT). Transl Cancer Res. 2017;6(Suppl 1):S90-S92. doi:https://doi.org/10.21037/tcr. 2017.02.13

288. Wang X, Luo G, Zhang K, et al. Hypoxic tumor-derived Exosomal miR-301a mediates M2 macrophage polarization via PTEN/PI3K $\gamma$ to promote pancreatic Cancer metastasis. Cancer Res. 2018;78(16):4586-98. https://doi.org/10. 1158/0008-5472.CAN-17-3841.

289. Meads MB, Gatenby RA, Dalton WS. Environment-mediated drug resistance: a major contributor to minimal residual disease. Nat Rev Cancer. 2009;9(9):665-74. https://doi.org/ $10.1038 /$ nrc2714.

290. Azmi AS, Bao B, Sarkar FH. Exosomes in cancer development, metastasis, and drug resistance: a comprehensive review. Cancer Metastasis Rev. 2013;32(3-4):623-42. https://doi.org/10.1007/s10555-013-9441-9.

291. Guo Y, Ji X, Liu J, et al. Effects of exosomes on pre-metastatic niche formation in tumors. Mol Cancer. 2019;18(1):39. https://doi.org/10.1186/s12943-019-0995-1.

292. McAllister SS, Weinberg RA. The tumour-induced systemic environment as a critical regulator of cancer progression and metastasis. Nat Cell Biol. 2014;16(8):717-27. https:// doi.org/10.1038/ncb3015.

293. Ludwig S, Floros T, Theodoraki M-N, et al. Suppression of lymphocyte functions by plasma exosomes correlates with disease activity in patients with head and neck Cancer. Clin cancer Res an Off J Am Assoc Cancer Res. 2017;23(16):4843-54. https://doi.org/10.1158/1078-0432. CCR-16-2819.

294. Tacke RS, Lee H-C, Goh C, et al. Myeloid suppressor cells induced by hepatitis $\mathrm{C}$ virus suppress $\mathrm{T}$-cell responses through the production of reactive oxygen species. Hepatology. 2012;55(2):343-53. https://doi.org/10.1002/hep. 24700.

295. Bodogai M, Moritoh K, Lee-Chang C, et al. Immunosuppressive and Prometastatic functions of myeloid-derived suppressive cells rely upon education from tumor-associated B cells. Cancer Res. 2015;75(17):3456-65. https://doi.org/ 10.1158/0008-5472.CAN-14-3077.

296. Yamamura Y, Asai N, Enomoto A, et al. Akt-Girdin Signaling in Cancer-Associated Fibroblasts Contributes to Tumor Progression. Cancer Res. 2015;75(5):813 LP - 823. doi:https:/ / doi.org/10.1158/0008-5472.CAN-14-1317

297. Samanta S, Rajasingh S, Drosos N, Zhou Z, Dawn B, Rajasingh J. Exosomes: new molecular targets of diseases. Acta Pharmacol Sin. 2018;39(4):501-13. https://doi.org/10. 1038/aps.2017.162.

298. Stenglein S, Ploper LD, Vizgarra O, Balatti PBT-A in AM. Angular Leaf Spot: A Disease Caused by the Fungus Phaeoisariopsis griseola (Sacc.) Ferraris on Phaseolus vulgaris L. In: Vol 52. Academic Press; 2003:209-243. https://doi.org/ 10.1016/S0065-2164(03)01009-8.

299. Miller JF, Mekalanos JJ, Falkow S. Coordinate regulation and sensory transduction in the control of bacterial virulence. Science (80- ). 1989;243(4893):916 LP - 922. doi:https:/ / doi. org/10.1126/science.2537530

300. Schantz-Dunn J, Nour NM. Malaria and pregnancy: a global health perspective. Rev Obstet Gynecol. 2009;2(3):186-92 https://pubmed.ncbi.nlm.nih.gov/19826576.

301. Dimopoulos G, Seeley D, Wolf A, Kafatos FC. Malaria infection of the mosquito Anopheles gambiae activates immune-responsive genes during critical transition stages of the parasite life cycle. EMBO J. 1998;17(21):6115-23. https://doi.org/10.1093/emboj/17.21.6115.

302. Idro R, Marsh K, John CC, Newton CRJ. Cerebral malaria: mechanisms of brain injury and strategies for improved neurocognitive outcome. Pediatr Res. 2010;68(4):267-74. https://doi.org/10.1203/PDR.0b013e3181eee738.

303. Kordelas L, Rebmann V, Ludwig A-K, et al. MSC-derived exosomes: a novel tool to treat therapy-refractory graft-versus-host disease. Leukemia. 2014;28(4):970-3. https://doi. org/10.1038/leu.2014.41.

304. Sisquella X, Ofir-Birin Y, Pimentel MA, et al. Malaria parasite DNA-harbouring vesicles activate cytosolic immune sensors. Nat Commun. 2017;8(1):1985. https://doi.org/10.1038/ s41467-017-02083-1.

305. Sampaio NG, Cheng L, Eriksson EM. The role of extracellular vesicles in malaria biology and pathogenesis. Malar J. 2017;16(1):245. https://doi.org/10.1186/ s12936-017-1891-z.

306. Teixeira ARL, Hecht MM, Guimaro MC, Sousa AO, Nitz N. Pathogenesis of chagas' disease: parasite persistence and autoimmunity. Clin Microbiol Rev. 2011;24(3):592-630. https://doi.org/10.1128/CMR.00063-10.

307. de Pablos Torró LM, Retana Moreira L, Osuna A. Extracellular vesicles in Chagas disease: a new passenger for an old disease. Front Microbiol. 2018;9:1190. https://doi.org/10. 3389/fmicb.2018.01190.

308. Urbanelli L, Buratta S, Tancini B, et al. The role of extracellular vesicles in viral infection and transmission. Vaccines. 2019;7(3):102. https://doi.org/10.3390/vaccines7030102.

309. Checkley MA, Luttge BG, Freed EO. HIV-1 envelope glycoprotein biosynthesis, trafficking, and incorporation. J Mol Biol. 2011;410(4):582-608. https://doi.org/10.1016/j.jmb. 2011.04.042.

310. Nolte-'t Hoen E, Cremer T, Gallo RC, Margolis LB. Extracellular vesicles and viruses: are they close relatives? Proc Natl Acad Sci U S A. 2016;113(33):9155-61. https://doi.org/10. 1073/pnas.1605146113.

311. Ostrowski LE, Blackburn K, Radde KM, et al. A proteomic analysis of human cilia: identification of novel components. Mol Cell Proteomics. 2002;1(6):451-65. https://doi.org/10. 1074/mcp.m200037-mcp200.

312. Bleackley MR, Dawson CS, Anderson MA. Fungal extracellular vesicles with a focus on proteomic analysis. Proteomics. 2019;19(8):1800232. https://doi.org/10.1002/pmic.20180 0232.

313. Pathirana RD, Kaparakis-Liaskos M. Bacterial membrane vesicles: biogenesis, immune regulation and pathogenesis. Cell Microbiol. 2016;18(11):1518-24. https://doi.org/10. $1111 / \mathrm{cmi} .12658$.

314. Kuipers ME, Hokke CH, Smits HH, Nolte-'t Hoen ENM. Pathogen-Derived Extracellular Vesicle-Associated Molecules That Affect the Host Immune System: An Overview . Front Microbiol . 2018;9:2182. https://www.frontiersin.org/ article/10.3389/fmicb.2018.02182.

315. Herrera J, Henke CA, Bitterman PB. Extracellular matrix as a driver of progressive fibrosis. J Clin Invest. 2018;128(1):4553. https://doi.org/10.1172/JCI93557.

316. He S, Chen D, Hu M, et al. Bronchial epithelial cell extracellular vesicles ameliorate epithelial-mesenchymal transition in COPD pathogenesis by alleviating M2 macrophage polarization. Nanomedicine. 2019;18:259-71. https://doi. org/10.1016/j.nano.2019.03.010.

317. Nagano T, Katsurada M, Dokuni R, et al. Crucial role of extracellular vesicles in bronchial asthma. Int J Mol Sci. 2019;20(10):2589. https://doi.org/10.3390/ijms20102589. 
318. Bourdonnay E, Zasłona Z, Penke LRK, et al. Transcellular delivery of vesicular SOCS proteins from macrophages to epithelial cells blunts inflammatory signaling. J Exp Med. 2015;212(5):729-42. https://doi.org/10.1084/jem.20141 675 .

319. Kadota T, Fujita Y, Yoshioka Y, Araya J, Kuwano K, Ochiya T. Extracellular vesicles in chronic obstructive pulmonary disease. Int J Mol Sci. 2016;17(11):1801. https://doi.org/ 10.3390/ijms17111801.

320. Kesimer M, Scull M, Brighton B, et al. Characterization of exosome-like vesicles released from human tracheobronchial ciliated epithelium: a possible role in innate defense. FASEB J Off Publ Fed Am Soc Exp Biol. 2009;23(6):185868. https://doi.org/10.1096/fj.08-119131.

321. Fujita Y, Araya J, Ochiya T. Extracellular vesicles in smokingrelated lung diseases. Oncotarget. 2015;6(41):43144-43145. doi:https://doi.org/10.18632/oncotarget.6556

322. Qiao Q, Liu X, Yang T, et al. Nanomedicine for acute respiratory distress syndrome: the latest application, targeting strategy, and rational design. Acta Pharm Sin B. 2021;11(10):3060-91. https://doi.org/10.1016/j.apsb.2021. 04.023 .

323. Kim HJ, Kim Y-S, Kim K-H, et al. The microbiome of the lung and its extracellular vesicles in nonsmokers, healthy smokers and COPD patients. Exp Mol Med. 2017;49(4):e316-6. https://doi.org/10.1038/emm.2017.7.

324. Tsitoura E, Vasarmidi E, Bibaki E, et al. Accumulation of damaged mitochondria in alveolar macrophages with reduced OXPHOS related gene expression in IPF. Respir Res. 2019;20(1):264. https://doi.org/10.1186/ s12931-019-1196-6.

325. Martin-Medina A, Lehmann M, Burgy O, et al. Increased extracellular vesicles mediate WNT5A signaling in idiopathic pulmonary fibrosis. Am J Respir Crit Care Med. 2018;198(12):1527-38. https://doi.org/10.1164/rccm. 201708-1580OC.

326. Harrell CR, Jovicic N, Djonov V, Arsenijevic N, Volarevic V. Mesenchymal stem cell-derived exosomes and other extracellular vesicles as new remedies in the therapy of inflammatory diseases. Cells. 2019;8(12):1605. https://doi.org/ $10.3390 /$ cells8121605.

327. Li X, Yue S, Luo Z. Mesenchymal stem cells in idiopathic pulmonary fibrosis. Oncotarget. 2017;8(60):102600-102616. https://doi.org/10.18632/oncotarget.18126

328. Shentu T-P, Huang T-S, Cernelc-Kohan M, et al. Thy-1 dependent uptake of mesenchymal stem cell-derived extracellular vesicles blocks myofibroblastic differentiation. Sci Rep. 2017;7(1):18052. https://doi.org/10.1038/ s41598-017-18288-9.

329. Colombo M, Raposo G, Théry C. Biogenesis, secretion, and intercellular interactions of exosomes and other extracellular vesicles. Annu Rev Cell Dev Biol. 2014;30:255-89. https://doi.org/10.1146/annurev-cellbio-101512-122326.

330. Ostrowski M, Carmo NB, Krumeich S, et al. Rab27a and Rab27b control different steps of the exosome secretion pathway. Nat Cell Biol. 2010;12(1):13-9. https://doi.org/ $10.1038 /$ ncb2000.

331. Hsu C, Morohashi Y, Yoshimura S-I, et al. Regulation of exosome secretion by Rab35 and its GTPase-activating proteins TBC1D10A-C. J Cell Biol. 2010;189(2):223-32. https://doi. org/10.1083/jcb.200911018.

332. Yang T, Martin P, Fogarty B, et al. Exosome delivered anticancer drugs across the blood-brain barrier for brain Cancer therapy in danio Rerio. Pharm Res. 2015;32 (6):2003-14. https://doi.org/10.1007/s11095-014-1593-y.
333. Gehrmann U, Näslund TI, Hiltbrunner S, Larssen P, Gabrielsson S. Harnessing the exosome-induced immune response for cancer immunotherapy. Semin Cancer Biol. 2014;28:58-67. https://doi.org/10.1016/j.semcancer.2014. 05.003 .

334. Pitt JM, Charrier M, Viaud S, et al. Dendritic cell-derived exosomes as immunotherapies in the fight against cancer. J Immunol. 2014;193(3):1006 LP - 1011. https://doi.org/ 10.4049/jimmunol.1400703

335. Colino J, Snapper CM. Exosomes from bone marrow dendritic cells pulsed with diphtheria toxoid preferentially induce type 1 antigen-specific $\operatorname{IgG}$ responses in naive recipients in the absence of free antigen. J Immunol. 2006;177(6):3757-62. https://doi.org/10.4049/jimmu nol.177.6.3757.

336. Näslund TI, Gehrmann U, Qazi KR, Karlsson MCI, Gabrielsson S. Dendritic cell-derived exosomes need to activate both $\mathrm{T}$ and $\mathrm{B}$ cells to induce antitumor immunity. J Immunol. 2013;190(6):2712-9. https://doi.org/10.4049/jimmu nol.1203082.

337. Zitvogel L, Regnault A, Lozier A, et al. Eradication of established murine tumors using a novel cell-free vaccine: dendritic cell derived exosomes. Nat Med. 1998;4(5):594600. https://doi.org/10.1038/nm0598-594.

338. Nolte-'t Hoen ENM, van der Vlist EJ, de Boer-Brouwer M, Arkesteijn GJA, Stoorvogel W, Wauben MHM. Dynamics of dendritic cell-derived vesicles: high-resolution flow cytometric analysis of extracellular vesicle quantity and quality. J Leukoc Biol. 2013;93(3):395-402. https://doi. org/10.1189/jlb.0911480.

339. Escudier B, Dorval T, Chaput N, et al. Vaccination of metastatic melanoma patients with autologous dendritic cell (DC) derived-exosomes: results of thefirst phase I clinical trial. J Transl Med. 2005;3(1):10. https://doi.org/10. 1186/1479-5876-3-10.

340. Morse MA, Garst J, Osada T, et al. A phase I study of dexosome immunotherapy in patients with advanced non-small cell lung cancer. J Transl Med. 2005;3(1):9. https://doi. org/10.1186/1479-5876-3-9.

341. Ma Y, Adjemian S, Mattarollo SR, et al. Anticancer chemotherapy-induced intratumoral recruitment and differentiation of antigen-presenting cells. Immunity. 2013;38(4):72941. https://doi.org/10.1016/j.immuni.2013.03.003.

342. Fucikova J, Kralikova P, Fialova A, et al. Human tumor cells killed by anthracyclines induce a tumor-specific immune response. Cancer Res. 2011;71(14):4821-33. https://doi. org/10.1158/0008-5472.CAN-11-0950.

343. Kitai Y, Kawasaki T, Sueyoshi T, et al. DNA-containing exosomes derived from Cancer cells treated with Topotecan activate a STING-dependent pathway and reinforce antitumor immunity. J Immunol. 2017;198(4):1649-59. https:// doi.org/10.4049/jimmunol.1601694.

344. Tesniere A, Schlemmer F, Boige V, et al. Immunogenic death of colon cancer cells treated with oxaliplatin. Oncogene. 2010;29(4):482-91. https://doi.org/10.1038/onc. 2009.356 .

345. Garg AD, Krysko DV, Vandenabeele P, Agostinis P. DAMPs and PDT-mediated photo-oxidative stress: exploring the unknown. Photochem Photobiol Sci Off J Eur Photochem Assoc Eur Soc Photobiol. 2011;10(5):670-80. https://doi. org/10.1039/c0pp00294a.

346. Ahn J, Barber GN. Self-DNA, STING-dependent signaling and the origins of autoinflammatory disease. Curr Opin Immunol. 2014;31:121-6. https://doi.org/10.1016/j.coi. 2014.10.009. 
347. Ahn J, Xia T, Konno H, Konno K, Ruiz P, Barber GN. Inflammation-driven carcinogenesis is mediated through STING. Nat Commun. 2014;5:5166. https://doi.org/10. 1038/ncomms6166.

348. Lian Q, Xu J, Yan S, et al. Chemotherapy-induced intestinal inflammatory responses are mediated by exosome secretion of double-strand DNA via AIM2 inflammasome activation. Cell Res. 2017;27(6):784-800. https://doi.org/10.1038/cr. 2017.54.

349. Finn OJ. Cancer immunology. N Engl J Med. 2008;358(25):2704-15. https://doi.org/10.1056/NEJMr a072739.

350. Steer HJ, Lake RA, Nowak AK, Robinson BWS. Harnessing the immune response to treat cancer. Oncogene. 2010;29(48):6301-13. https://doi.org/10.1038/onc.2010. 437.

351. Pejawar-Gaddy S, Finn OJ. Cancer vaccines: accomplishments and challenges. Crit Rev Oncol Hematol. 2008;67 (2):93-102. https://doi.org/10.1016/j.critrevonc. 2008.02.010.

352. Zeelenberg IS, Ostrowski M, Krumeich S, et al. Targeting tumor antigens to secreted membrane vesicles in vivo induces efficient antitumor immune responses. Cancer Res. 2008;68(4):1228-35. https://doi.org/10.1158/0008-5472. CAN-07-3163.

353. Smyth LA, Afzali B, Tsang J, Lombardi G, Lechler RI. Intercellular transfer of MHC and immunological molecules: molecular mechanisms and biological significance. Am J Transplant. 2007;7(6):1442-9. https://doi.org/10.1111/j. 1600-6143.2007.01816.x.

354. Hartman ZC, Wei J, Glass OK, et al. Increasing vaccine potency through exosome antigen targeting. Vaccine. 2011;29(50):9361-7. https://doi.org/10.1016/j.vaccine. 2011.09.133.

355. Lu Z, Zuo B, Jing R, et al. Dendritic cell-derived exosomes elicit tumor regression in autochthonous hepatocellular carcinoma mouse models. J Hepatol. 2017;67 (4):739-48. https://doi.org/10.1016/j.jhep.2017.05.019.

356. Geis-Asteggiante L, Belew AT, Clements VK, et al. Differential content of proteins, mRNAs, and miRNAs suggests that MDSC and their exosomes may mediate distinct immune suppressive functions. J Proteome Res. 2018;17(1):486-98. https://doi.org/10.1021/acs.jproteome.7b00646.

357. Ezernitchi AV, Vaknin I, Cohen-Daniel L, et al. TCR zeta down-regulation under chronic inflammation is mediated by myeloid suppressor cells differentially distributed between various lymphatic organs. J Immunol. 2006;177(7):4763-72. https://doi.org/10.4049/jimmunol. 177.7.4763.

358. Roier S, Blume T, Klug L, et al. A basis for vaccine development: comparative characterization of Haemophilus influenzae outer membrane vesicles. Int J Med Microbiol. 2015;305(3):298-309. https://doi.org/10.1016/j.ijmm. 2014.12.005.

359. Plotkin SA. Six revolutions in vaccinology. Pediatr Infect Dis J. 2005;24(1):1-9. https://doi.org/10.1097/01.inf.00001 48933.08301.02.

360. Zurita ME, Wilk MM, Carriquiriborde $\mathrm{F}$, et al. A pertussis outer membrane vesicle-based vaccine induces lung-resident memory CD4 T cells and protection against Bordetella pertussis. Including Pertactin Deficient Strains Front Cell Infect Microbiol. 2019;9:125. https://doi.org/10.3389/ fcimb.2019.00125.

361. Di Bonito P, Accardi L, Galati L, Ferrantelli F, Federico M. Anti-cancer vaccine for HPV-associated neoplasms: focus on a therapeutic HPV vaccine based on a novel tumor antigen delivery method using endogenously engineered exosomes. Cancers (Basel). 2019;11(2). https://doi.org/10.3390/ cancers 11020138

362. McElroy AK, Akondy RS, Davis CW, et al. Human Ebola virus infection results in substantial immune activation. Proc Natl Acad Sci U S A. 2015;112(15):4719-24. https://doi.org/10. 1073/pnas. 1502619112 .

363. Anticoli S, Manfredi F, Chiozzini C, et al. An exosome-based vaccine platform imparts cytotoxic T lymphocyte immunity against viral antigens. Biotechnol J. 2018;13(4):e1700443. https://doi.org/10.1002/biot.201700443.

364. Rosenberg SA, Restifo NP. Adoptive cell transfer as personalized immunotherapy for human cancer. Science. 2015;348(6230):62-8. https://doi.org/10.1126/science. aaa4967.

365. Peters PJ, Geuze HJ, Van der Donk HA, et al. Molecules relevant for $\mathrm{T}$ cell-target cell interaction are present in cytolytic granules of human T lymphocytes. Eur J Immunol. 1989;19(8):1469-75. https://doi.org/10.1002/eji. 1830190819.

366. Peters PJ, Borst J, Oorschot V, et al. Cytotoxic T lymphocyte granules are secretory lysosomes, containing both perforin and granzymes. J Exp Med. 1991;173(5):1099109. https://doi.org/10.1084/jem.173.5.1099.

367. Fu W, Lei C, Liu S, et al. CAR exosomes derived from effector CAR-T cells have potent antitumour effects and low toxicity. Nat Commun. 2019;10(1):4355. https://doi. org/10.1038/s41467-019-12321-3.

368. Li Y, Liu Y, Xiu F, et al. Characterization of exosomes derived from toxoplasma gondii and their functions in modulating immune responses. Int J Nanomedicine. 2018;13:467-77. https://doi.org/10.2147/IJN.S151110.

369. Song J, Huang J, Chen X, et al. Donor-derived exosomes induce specific regulatory $\mathrm{T}$ cells to suppress immune inflammation in the allograft heart. Sci Rep. 2016;6(1):20077. https://doi.org/10.1038/srep20077.

370. Alraies MC, Eckman P. Adult heart transplant: indications and outcomes. J Thorac Dis. 2014;6(8):1120-8. https:// doi.org/10.3978/j.issn.2072-1439.2014.06.44.

371. Costello JP, Mohanakumar T, Nath DS. Mechanisms of chronic cardiac allograft rejection. Texas Hear Inst J. 2013;40(4):395-9.

372. Baran DA, Galin ID, Gass AL. Calcineurin inhibitor-associated early renal insufficiency in cardiac transplant recipients: risk factors and strategies for prevention and treatment. Am J Cardiovasc Drugs. 2004;4(1):21-9. https:// doi.org/10.2165/00129784-200404010-00003.

373. Gratz IK, Campbell DJ. Organ-specific and memory treg cells: specificity, development, function, and maintenance. Front Immunol. 2014;5:333. https://doi.org/10. 3389/fimmu.2014.00333.

374. Powell JD, Pollizzi KN, Heikamp EB, Horton MR. Regulation of immune responses by mTOR. Annu Rev Immunol. 2012;30:39-68. https://doi.org/10.1146/annurev-immun ol-020711-075024.

375. Wu X-M, Liao Y-W, Wang H-Y, Ji K-Q, Li G-F, Zang B. Integrin alphavbeta6 is involved in measles protein-induced airway immune suppression. Cytokine. 2012;59(1):59-64. https://doi.org/10.1016/j.cyto.2012.04.005.

376. Li X, Li J-J, Yang J-Y, et al. Tolerance induction by exosomes from immature dendritic cells and rapamycin in a mouse cardiac allograft model. PLoS One. 2012;7(8):e44045 https://doi.org/10.1371/journal.pone.0044045.

377. Blazquez R, Sanchez-Margallo FM, de la Rosa O, et al. Immunomodulatory potential of human adipose mesenchymal stem cells derived exosomes on in vitro stimulated $\mathrm{T}$ cells. 
Front Immunol. 2014;5:556 https:/ /www.frontiersin.org/ article/10.3389/fimmu.2014.00556.

378. Andrews DW, Resnicoff M, Flanders AE, et al. Results of a pilot study involving the use of an antisense oligodeoxynucleotide directed against the insulin-like growth factor type I receptor in malignant astrocytomas. J Clin Oncol Off J Am Soc Clin Oncol. 2001;19(8):2189-200. https://doi.org/10. 1200/JCO.2001.19.8.2189.

379. Carpentier A, Laigle-Donadey F, Zohar S, et al. Phase 1 trial of a CpG oligodeoxynucleotide for patients with recurrent glioblastoma. Neuro-Oncology. 2006;8(1):60-6. https://doi. org/10.1215/S1522851705000475.

380. Chaput N, Schartz NEC, André F, et al. Exosomes as potent cell-free peptide-based vaccine. II. Exosomes in CpG adjuvants efficiently prime naive Tc1 lymphocytes leading to tumor rejection. J Immunol. 2004;172(4):2137-46. https:/ / doi.org/10.4049/jimmunol.172.4.2137.

381. Tang J, Flomenberg P, Harshyne L, Kenyon L, Andrews DW. Glioblastoma patients exhibit circulating tumor-specific CD8+ T cells. Clin cancer Res an Off J Am Assoc Cancer Res. 2005;11(14):5292-9. https://doi.org/10.1158/10780432.CCR-05-0545.

382. Zimmerman RA. Imaging of adult central nervous system primary malignant gliomas. Staging and follow-up Cancer. 1991;67(4 Suppl):1278-83. https://doi.org/10. 1002/1097-0142(19910215)67:4+<1278::aid-cncr282067 $1526>3.0$. co; $2-u$.

383. Lonza Pharma and Biotech. Exosomes development and manufacturing. https://pharma.lonza.com/technologiesproducts/exosomes.

384. Zhang Y, Liu Y, Liu H, Tang WH. Exosomes: biogenesis biologic function and clinical potential. Cell \& Bioscience 2019;9(1). https://doi.org/10.1186/s13578-019-0282-2
385. Hessvik NP, Llorente A. Current knowledge on exosome biogenesis and release. Cell Mol Life Sci. 2018;75(2):193208. https://doi.org/10.1007/s00018-017-2595-9.

386. Gurung S, Perocheau D, Touramanidou L, Baruteau J. The exosome journey: from biogenesis to uptake and intracellular signaling. Cell Communication and Signaling. 2021;19(1). https://doi.org/10.1186/s12964-021-00730-1

387. Jafari D, Malih S, Eini M, Jafari R, Gholipourmalekabadi M, Sadeghizadeh M, Samadikuchaksaraei A. Improvement scaling-up and downstream analysis of exosome production. Crit Rev Biotechnol. 2020;40(8):1098-112. https:/ /doi.org/ 10.1080/07388551.2020.1805406

388. Jafari D, Malih S, Eini M, et al. Improvement, scaling-up, and downstream analysis of exosome production. Crit Rev Biotechnol. 2020;40(8):1098-112. https://doi.org/10.1080/ 07388551.2020 .1805406 .

389. Adlerz K, Patel D, Rowley J, Ng K, Ahsan T. Strategies for scalable manufacturing and translation of MSC-derived extracellular vesicles. Stem Cell Res. 2020;48101978. https://doi.org/10.1016/j.scr.2020.101978

390. Doyle L, Wang M. Overview of extracellular vesicles their origin composition purpose and methods for exosome isolation and analysis. Cells. 2019;8(7):727. hhttps://doi.org/ $10.3390 /$ cells 8070727

Publisher's Note Springer Nature remains neutral with regard to jurisdictional claims in published maps and institutional affiliations. 